\title{
Metabolic and genetic aspects of thiopurine metabolism
}

Citation for published version (APA):

Bakker, J. A. (2010). Metabolic and genetic aspects of thiopurine metabolism. [Doctoral Thesis, Maastricht University]. Datawyse / Universitaire Pers Maastricht. https://doi.org/10.26481/dis.20101027jb

Document status and date:

Published: 01/01/2010

DOI:

10.26481/dis.20101027jb

Document Version:

Publisher's PDF, also known as Version of record

\section{Please check the document version of this publication:}

- A submitted manuscript is the version of the article upon submission and before peer-review. There can be important differences between the submitted version and the official published version of record.

People interested in the research are advised to contact the author for the final version of the publication, or visit the DOI to the publisher's website.

- The final author version and the galley proof are versions of the publication after peer review.

- The final published version features the final layout of the paper including the volume, issue and page numbers.

Link to publication

\footnotetext{
General rights rights.

- You may freely distribute the URL identifying the publication in the public portal. please follow below link for the End User Agreement:

www.umlib.nl/taverne-license

Take down policy

If you believe that this document breaches copyright please contact us at:

repository@maastrichtuniversity.nl

providing details and we will investigate your claim.
}

Copyright and moral rights for the publications made accessible in the public portal are retained by the authors and/or other copyright owners and it is a condition of accessing publications that users recognise and abide by the legal requirements associated with these

- Users may download and print one copy of any publication from the public portal for the purpose of private study or research.

- You may not further distribute the material or use it for any profit-making activity or commercial gain

If the publication is distributed under the terms of Article $25 \mathrm{fa}$ of the Dutch Copyright Act, indicated by the "Taverne" license above, 
Metabolic and genetic aspects of thiopurine metabolism 
(C) Jacob Adriaan Bakker, Maastricht 2010

Cover: Jules Verschaeren, Afdeling Visuele Communicatie, Open Universiteit Layout: Tiny Wouters

Production: Datawyse | Universitaire Pers Maastricht

ISBN: 978-90-5278-975-0

The printing of this thesis was financially supported by the Department of Clinical Genetics, $\mathrm{MUMC}^{+}$, the ild care foundation (www.ildcare.nl), Shire Human Genetic Therapies and Waters Chromatography.

\section{ild care}

Shire 


\title{
Metabolic and genetic aspects of thiopurine metabolism
}

\author{
PROEFSCHRIFT
}

ter verkrijging van de graad van doctor aan de Universiteit Maastricht, op gezag van de Rector Magnificus, Prof. mr. G.P.M.F. Mols, volgens het besluit van het College van Decanen, in het openbaar te verdedigen

op woensdag 27 oktober 2010 om 14.00 uur

door

Jacob Adriaan Bakker

geboren op 2 juni 1956 te Middelburg

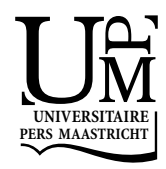




\section{Promotores:}

Prof. dr. J.P.M. Geraedts

Prof. dr. M. Drent

\section{Copromotor:}

Dr. J. Bierau

\section{Beoordelingscommissie:}

Prof. dr. M.P. van Dieijen-Visser (voorzitter)

Prof. dr. J.M.R. Balzarini (Rega Institute for Medical Research, KU Leuven)

Prof. dr. A. Bast

Dr. A.B.P. van Kuilenburg (Laboratorium Genetisch Metabole Ziekten, UvA-AMC)

Prof. dr. V.C.G. Tjan-Heijnen 
'er komt geen einde aan het aantal boeken dat geschreven wordt'

Prediker $12: 12$ 



\section{Contents}

Chapter 1 Introduction 9

Chapter 2 Selectivity of TPMT towards thiopurine nucleosides and 27 nucleotides

Chapter 3 Quantitative measurement of thiopurine metabolites in biological fluids using ultra-performance liquid chromatographytandem mass spectometry

Chapter 4 Azathioprine induced pneumonitis in a patient with ulcerative colitis

Chapter 5 A comparative study of inosine triphosphatase activity in fresh erythrocytes and dried blood spots

Chapter 6 The effect of ITPA polymorphisms on the enzyme kinetic properties of human erythrocyte inosine triphosphatase towards its substrates ITP and 6-thio-ITP.

Chapter 7 Role for ITPA variants in the clinical course of pulmonary Langerhans'cell histiocytosis?

Chapter 8 General discussion

Summary

Samenvatting

List of publications

Dankwoord

Curriculum Vitae 



\section{Chapter 1}

\section{Introduction}

Parts of this chapter were published as:

Bakker JA, Bierau J, Drent M. Therapeutic regimens in interstitial lung disease guided by genetic screening: fact or fiction? Eur Respir J 2007;30:821-822.

Bakker JA, Drent M, Bierau J. Relevance of pharmacogenetic aspects of mercaptopurine metabolism in the treatment of interstitial lung disease. Curr Opin Pulm Med 2007;13:458463.

Bierau J, Lindhout M, Bakker JA. Pharmacogenetic significance of inosine triphosphatase. Pharmacogenomics 2007; 8:1221-1228. 


\section{Introduction}

Purines and pyrimidines belong to a class of heterocyclic compounds, containing both carbon and nitrogen atoms in its ring structures. Purines are nine-atom heterocyclic molecules, pyrimidines contain six atom rings (Figure 1.1).<smiles>C1=Nc2[nH]cnc2CN1</smiles>

purine<smiles>c1cncnc1</smiles>

pyrimidine

Figure 1.1 Basic chemical structures of purines and pyrimidines.

The nature of the atoms and side groups attached to the ring structures define the known purine and pyrimidine bases, nucleosides and nucleotides as is shown in Figure 1.2 for purines.

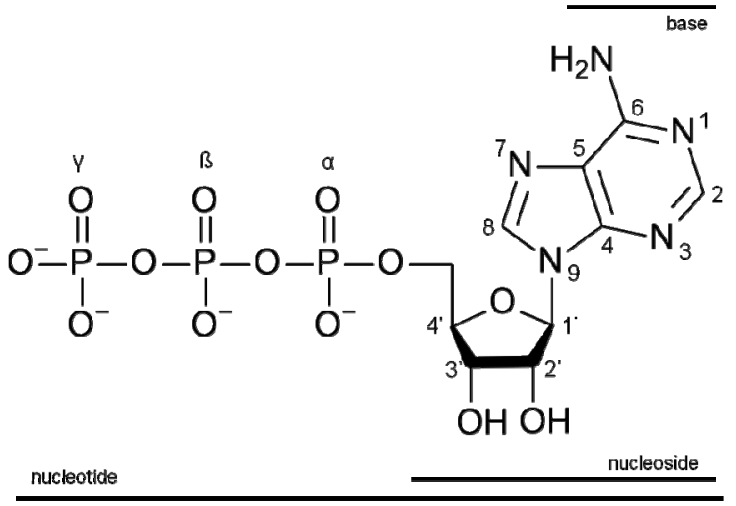

Figure 1.2 Molecular composition of purine base, nucleoside and nucleotide.

Purines and pyrimidines are of utmost importance for the maintenance of (human) life: purine and pyrimidine derivatives, nucleosides and nucleotides serve as building blocks for the nucleic acids RNA and DNA and play a major role in the cellular metabolism ${ }^{1}$. Table 1.1 shows the purine and pyrimidine constituents of DNA and RNA. 
Purine and pyrimidine derived nuclosides present in RNA and DNA.

\begin{tabular}{lll}
\hline Base & Nucleoside (RNA) & Deoxynucleoside (DNA) \\
\hline Purine & & \\
Adenine & Adenosine & Deoxyadenosine \\
Guanine & Guanosine & Deoxyguanosine \\
Cytosine & Cytidine & Deoxycytidine \\
Pyrimidine & & \\
Uracil & Uridine & \\
Thymine & & (deoxy)Thymidine \\
\hline
\end{tabular}

One of the most prominent cellular functions is the supply of high-energy phosphate esters (e.g. adenosine triphosphate, ATP) in phosphate transfer reactions, which are essential for the regulation of metabolism. Adenosine diphosphate (ADP) has a regulatory function in several enzymatic processes, e.g. oxidative phosphorylation ${ }^{2}$. Cyclic purine nucleotides, cyclic adenosine monophosphate (c-AMP) and cyclic guanosine monophosphate (c-GMP), are involved in signal transduction: an example hereof is the regulation of platelet aggregation by $\mathrm{c}-\mathrm{AMP}^{3}$. Furthermore purine and pyrimidine mono-and diphosphate carbohydrates, like CMP-acetylneuraminic acid and UDP-galactose are required for the synthesis of macromolecules like glycoproteins and glycolipids ${ }^{4}$. Nucleotides are also part of several (co)enzymes like coenzyme $A$ and flavin adenine dinucleotide (FAD).

It is clear that metabolism of purine and pyrimidine compounds needs to be tightly regulated to keep a balance between synthesis and demand of these compounds. Disturbances in the balance of these compounds will lead to disregulation of many cellular processes. Examples are inherited metabolic disorders of purine and pyrimidine metabolism and (acquired) derailed nucleotide metabolism in cancer cells ${ }^{5}$. The eminent role of purines and pyrimidines in cellular processes made them an interesting target for drug development, resulting in several classes of synthetic purine and pyrimidine analogues. These synthetic analogues are activated and metabolised along the same pathways as naturally occurring purines and pyrimidines and interfere with normal metabolism. This is the main reason that these compounds are used as therapeutics in a broad spectrum of diseases, in Table 1.2 an arbitrary selection of synthetic purine and pyrimidine analogues used as therapeutics is shown ${ }^{6}$.

It is apparent that a genetic defect in one of the enzymes involved in the metabolism of purine or pyrimidine compounds may result in an altered response to purine or pyrimidine derived medication. The study of alterations in the metabolism of therapeutic drugs is known as pharmacogenetics. This topic will be discussed underneath in general and in more detail in the section on thiopurines and their metabolism. 
Table 1.2 Selection of synthetic purine and pyrimidine analogues and their therapeutic application.

\begin{tabular}{ll}
\hline & Disease \\
\hline Purine analogue & \\
& Inflammatory bowel disease \\
6-mercaptopurine, azathioprine, & Interstitial lung disease \\
6-thioguanine & Organ transplantation \\
& Leukemia \\
& Atopic dermatitis \\
Cladribine (2'-Chloro-2' -deoxyadenosine) & Haematological malignancies \\
Didanosine (2', $3^{\prime}$-dideoxyinosine) & Acquired immune deficiency (HIV) \\
Abacavir & Acquired immune deficiency (HIV) \\
Pyrimidine analogue & \\
5-Fluorouracil & Colon and breast cancer \\
Gemcitabine (2', $2^{\prime}$-difluorodeoxycytidine) & Lung and pancreatic cancer \\
Cytarabine (arabinosyl cytosine) & Solid tumours \\
Azidothymidine & Haematological malignancies \\
Lamivudine (3TC) & Acquired immune deficiency (HIV) \\
Emtricitabine (FTC) & Acquired immune deficiency (HIV) \\
\hline
\end{tabular}

\section{Purine and pyrimidine metabolism}

Metabolism of purine and pyrimidines is an intricate network of biosynthesis, interconversion and degradation, which is tightly regulated by positive and negative feedback mechanisms. The aim of this regulation is to fulfill the demand of the organism for nucleotides, indispensable for replication and metabolic activity.

The central metabolite in purine metabolism is inosine-5'- monophosphate (IMP); this nucleotide is synthesised de novo in a sequence of 11 reactions, starting with the pyrophosphorylation of $\alpha$-D-ribose-5-phosphate, catalysed by phosphoribosyl pyrophosphate synthase (PRPPS). The purine de novo synthesis (PDNS) reaction sequence is outlined in Figure 1.3.

PDNS is highly dependent on high energy phosphates: 4 reactions are ATP driven. In addition 2 reactions in this sequel are dependent on the folic acid cycle. The enzyme adenylosuccinate lyase (ADSL), responsible for the release of fumarate from aminoimidazole succinylcarboxamide ribonucleotide (AICAR), is a bifunctional enzyme and also active in the purine interconversion route where it is involved in the synthesis of adenosine-5'-monophosphate (AMP) from succinyl-AMP.

PNDS is controlled by feedback regulation of the first two steps by the products of the PDNS, AMP, guanosine-5'-monophosphate (GMP) and IMP. In addition pyrimidine nucleotides also inhibit PNDS, in order to maintain the balance between purine and pyrimidine nucleotides. 


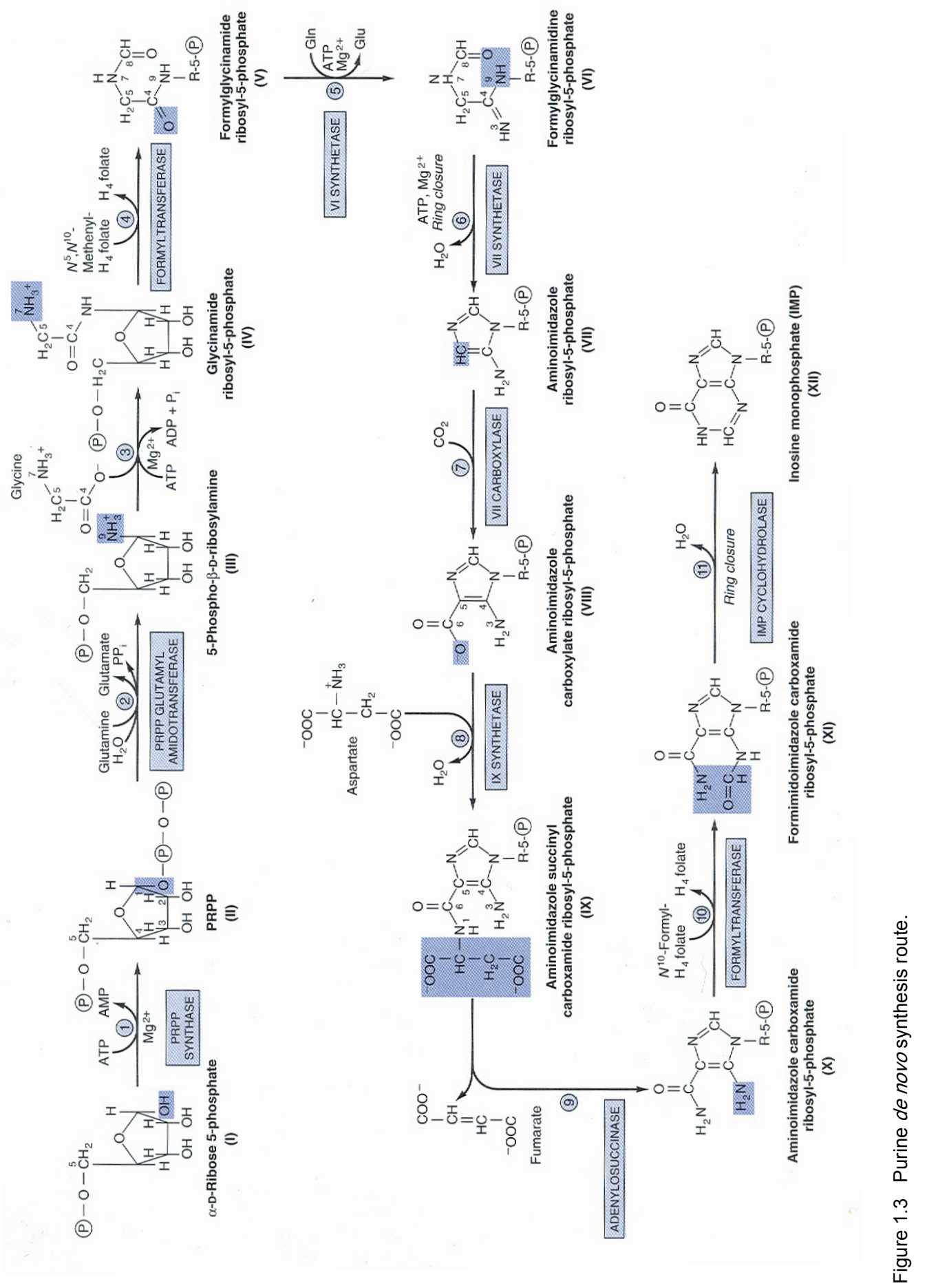


Purine interconversion is the conversion of IMP, to either AMP or GMP (Figure 1.4). From these compounds the purine (deoxy)trinucleotides are synthesised, the building blocks for DNA and RNA, respectively.

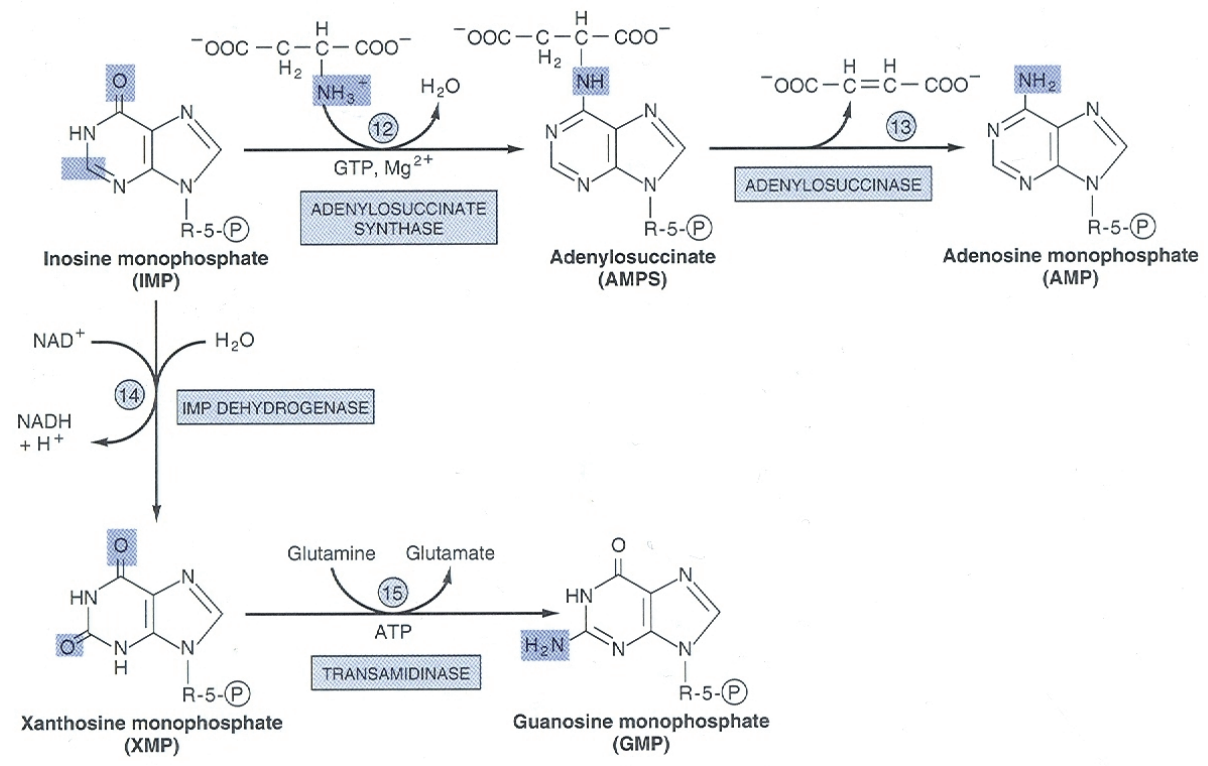

Figure 1.4 Purine interconversion route.

AMP is synthesised in two steps: IMP is converted to succinyl-AMP by adenylosuccinate synthase (ASS). Subsequently the succinyl moiety is spliced off by ADSL and AMP is generated. GMP is synthesised by conversion of IMP by inosinemonophosphate dehydrogenase (IMPDH) to xanthosine-5'-monophosphate (XMP), from which GMP is synthesised by guanosinemonophosphate synthase (GMPS). The majority of IMP is converted to AMP, which is reflected in the higher concentrations of the adenine nucleotides compared to the guanine nucleotides in cells. The balance between adenine and guanine nucleotides is achieved by feedback inhibition through AMP and GMP on the first enzymes in the interconversion route, AAS and IMPDH respectively. Furthermore ATP is essential for GMP synthesis and GTP is necessary for AMP synthesis, this so called 'reciprocal substrate relation' is a second regulator in the balance between adenine and guanine nucleotide synthesis.

The precise physiological role of ITPase in purine metabolism is unclear. In theory ITPase maintains homeostasis of IMP, the key compound in purine metabolism, by catalyzing the pyrophosphohydrolysis of ITP. However, no metabolic or clinical consequences of the accumulation of intracellular ITP are known. About $1 \%$ of the 
general (western) population is deficient for ITPase, and because of the lack of a clinical phenotype it is assumed to be a benign condition ${ }^{7-9}$.

A third mechanism to maintain purine nucleotide balance is the salvage pathway. As is shown in Figure 1.5 purines are degraded to hypoxanthine, guanine and adenine respectively by the action of different enzymes. These end-products can be recycled by hypoxanthine-guanine phosphoribosyl transferase (HGPRT) and adenine phosphoribosyl transferase (APRT) into IMP, GMP and AMP respectively using phosphoribosyl pyrophosphate (PRPP) as the phosphoribosyl donor.

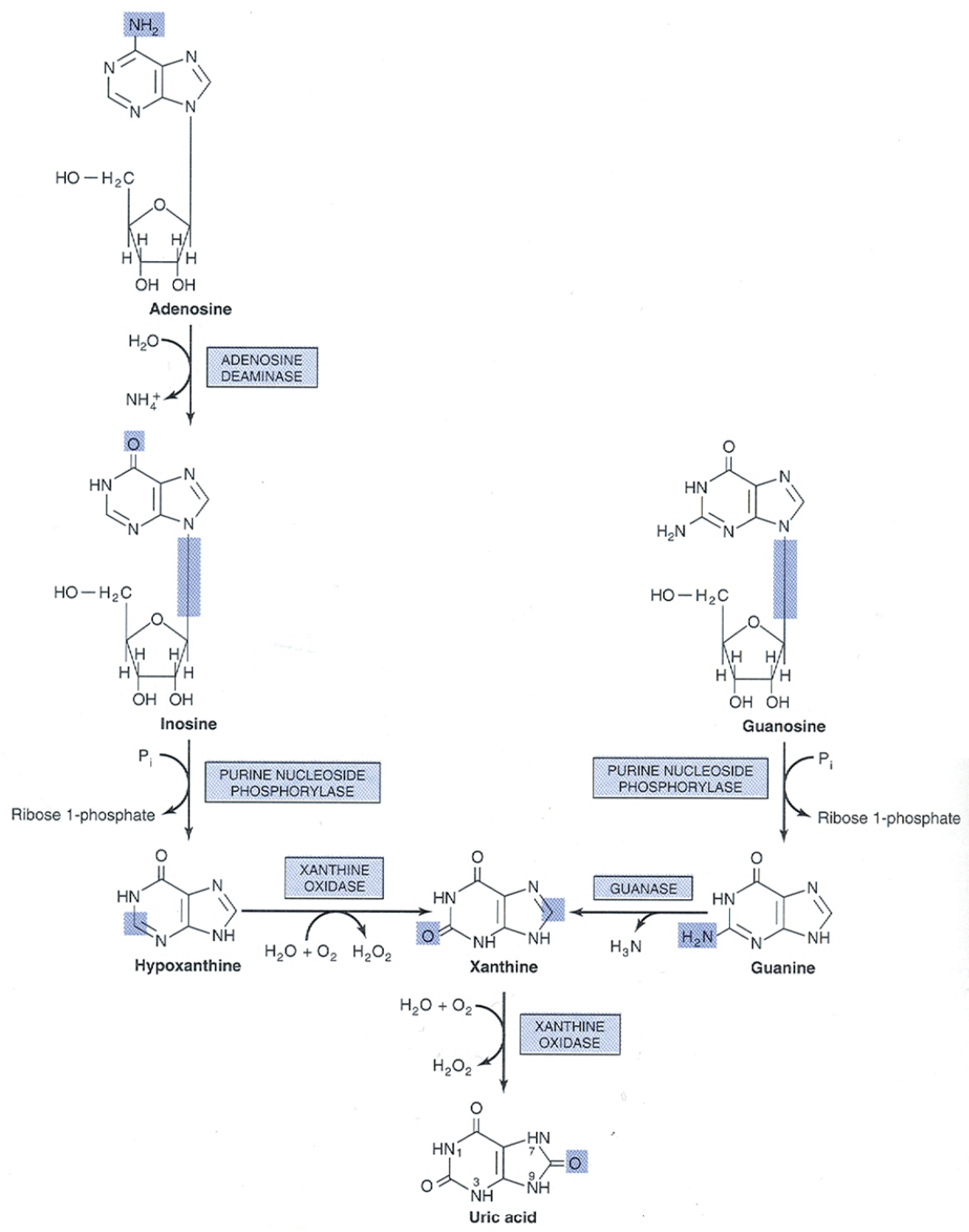

Figure $1.5 \quad$ Purine degradation route. 
The purine nucleotide pool in proliferating cells is maintained by the PNDS, in resting and non-nucleated cells the balance in the purine nucleotide pool is fully dependent on the salvage route.

Pyrimidine synthesis and metabolism differs greatly from purine nucleotide formation: first the pyrimidine ring is synthesised and subsequently attached to the ribose group. Because the focus is on purine metabolism, pyrimidine metabolism will not be further discussed. In the context of this thesis it is noteworthy to mention that the balance of purine and pyrimidine metabolism and synthesis is achieved by PRPP and purine nucleotides.

\section{Pharmacogenetics}

The way an organism, a person or an organ responds to medication depends on a complex of factors, including uptake, bioavailability, activation, deactivation, metabolism and clearance of the drug and its (deactivated) metabolites (Figure 1.6).

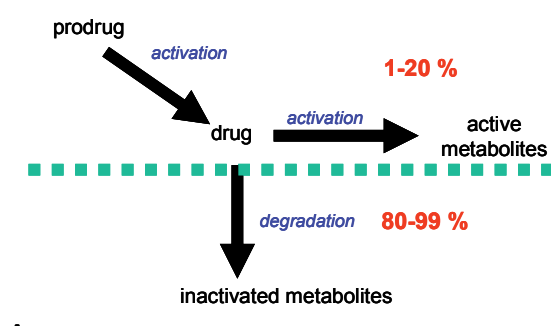

A

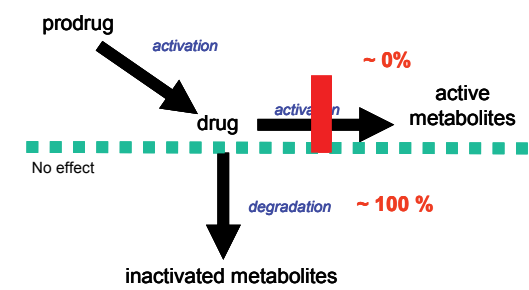

C

Figure 1.6 Interplay between activation, degradation (deactivation) and therapeutic effect of drugs: panel A: normal situation; panel B: impaired degradation, resulting in overreaction on therapy; panel C: defective activation, resulting in non responsiveness; panel D: impaired activation of prodrug, non responsiveness.
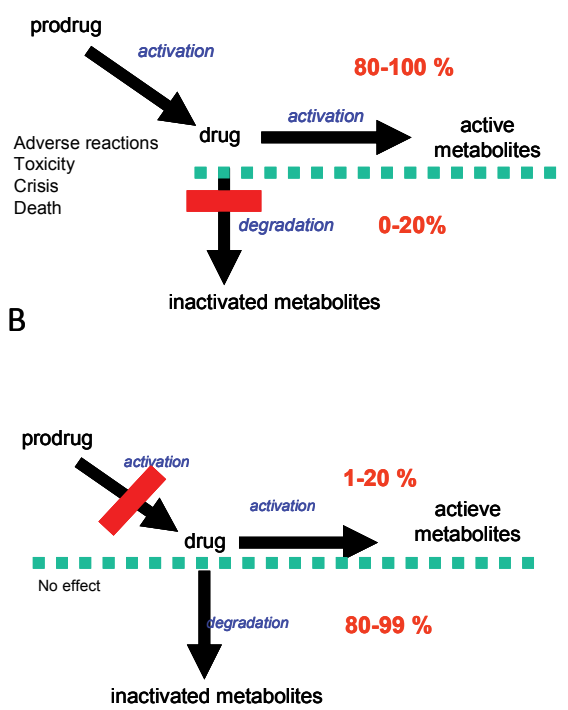

D 
It is apparent that a disturbance of these factors will give an altered reaction to the medication, resulting in unwanted, uncomfortable or dangerous effects related to the use of the drug. These adverse drug reactions (ADR) are defined by the World Health Organisation (WHO) as: 'any noxious, unintended, and undesired effect of a drug that occurs in humans for prophylaxis, diagnosis, or therapy' ${ }^{10}$. Apart from non-genetic reasons, like (acquired) anatomical problems or un-controlled bacterial intestinal environment and drug-drug interactions, a significant number of ADRs is caused by genetic factors. Today inadequate response to a number of drugs is known to be caused by genetic polymorphisms. This concept is neatly outlined in a number of reviews $^{11-15}$. As a result of the sequencing of the human genome, more information has become available about the way genes are organised and what their function is assumed to be. This new knowledge boosted pharmacogenetic research and resulted in a better understanding of the way drugs are handled by the human organism.

Besides monogenic traits with pharmacogenetic consequences, like dihydropyrimidine dehydrogenase deficiency (DPD), pharmacogenetics revealed the role of multiple genes and their corresponding proteins, in the metabolism of medication ${ }^{15}$. Although there are still many unanswered questions, several authors predict a prominent role for pharmacogenetics as the way towards personalised medicine. In their opinion, the response to medication can be predicted from the genetic make-up of a person ${ }^{16-18}$.

Nowadays, the first steps in this regard are set: DPD pheno- and/or genotype of a patient is determined before the start of 5-Fluorouracil (5-FU) therapy in cancer to avoid fatal $A D R^{19}$; CYP subclass genotyping is used to predict the response on often prescribed medications ${ }^{12,20}$. Pre-treatment screening for TPMT pheno- and genotype before commencing thiopurine is introduced as common clinical practice in several countries $^{21-23}$. Although at present screening for TPMT 'only' accounts for $40 \%$ of the expected ADR in thiopurine therapy, the benefits for the patient and the health care system are already outreaching the costs for screening ${ }^{24,25}$.

It may be imminent that in the near future more and more patients will be treated on guidance of their genetic makeup, thereby avoiding eventual life threatening ADR.

\section{Thiopurines}

Thiopurines are synthetic purines where the hydrogen atom at the 6 position in the ring is substituted by a sulphur group. Soon after their development in the 1950s by Gertrude Elion and George Hitchings, thiopurines found their application in clinical medicine. Three of these compounds are used as drugs for the treatment of a number of diseases : 6-mercaptopurine (6-MP, Purinethol ${ }^{\circledR}$ ), the prodrug of 6-MP, azathioprine $\left(\mathrm{AZA}\right.$, Imuran $\left.^{\circledR}\right)$, and 6-thioguanine (6-TG, Lanvis $\left.{ }^{\circledR}\right)$; the structures of these compounds are shown in Figure 1.7. 

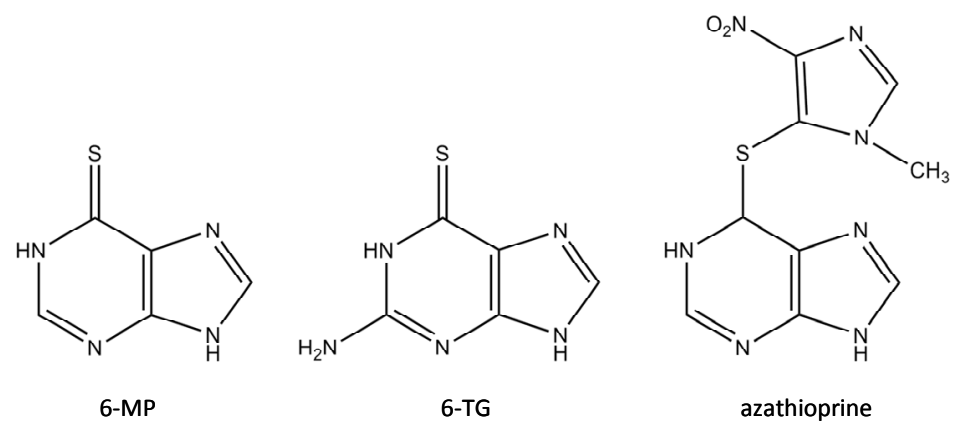

Figure 1.7 Commercially available thiopurine drugs.

AZA is widely used in the treatment of (auto)immune diseases, like inflammatory bowel disease (IBD), rheumatoid arthritis (RA), sarcoidosis, systemic lupus erythematosis (SLE), dermatological diseases and, before the introduction of more efficient drugs, in organ transplantation. 6-MP is routinely used in childhood acute lymphoblastic leukemia (ALL) and in case patients show allergic reactions due to the protective imidazole group in AZA. 6-TG is used in acute myeloid leukemia (AML) and $\mathrm{ALL}^{6}$. After activation 6-TG directly enters the guanine nucleotide pathway, therefore its immediate myelotoxicity is much greater than 6-MP and careful dosing of 6-TG is recommended.

\section{Metabolism of thiopurines}

The metabolism of thiopurines follows the same pathways as the natural occurring purines, with one addition: deactivation of thiopurines by thiopurine-Smethyltransferase (TPMT). In Figure 1.8 the current knowledge of thiopurine metabolism is outlined ${ }^{26}$.

Not all enzymes are ubiquitously expressed throughout the organism, which means that the extent of thiopurine metabolism depends on the cell type. Erythrocytes exhibit TPMT, inosine triphosphatase (inosine triphosphate pyrophosphohydrolase, ITPase), adenosine deaminase (ADA), purine nucleoside phosphorylase (PNP) and HGPRT activities, whereas nucleated cells also have purine-5'-nucleotidase (5'-NT), IMPDH, GMPS, xanthine oxidase (XO) and nucleotide kinase activities. The highest expression of $\mathrm{XO}$ is found in endothelial cells and liver. It is reported that systemic XO activity is highly dependent on external stimuli like metabolic stress ${ }^{27}$.

As with natural purines, thiopurine handling depends on activation, deactivation, metabolism and intracellular thiopurine nucleotide equilibrium. To activate AZA, the prodrug of 6-MP, the imidazole group is removed, either by non-enzymatic degradation or, most probably, through glutathione-S-transferase (GST) activity. 
A study with cultured HUVEC cells showed a decrease in glutathione concentrations after incubation with AZA, incubation with 6-MP did not alter the glutathione concentration $^{28}$.

The next step in thiopurine metabolism is the activation of 6-MP or 6-TG by HGPRT to the corresponding nucleotide monophosphates, thioinosine- $5^{\prime}$-monophosphate (TIMP) and thioguanosine-5'-monophosphate (TGMP) respectively .

TGMP is further activated by mono- and diphosphate kinases and ribonucleotide reductase to thioguanosine-5'-triphosphate (TGTP) and thiodeoxyguanosine-5'triphosphate (TdGTP) respectively, which are incorporated in RNA and DNA. TIMP needs further (inter)conversion through IMPDH and GMPS to generate TGMP.

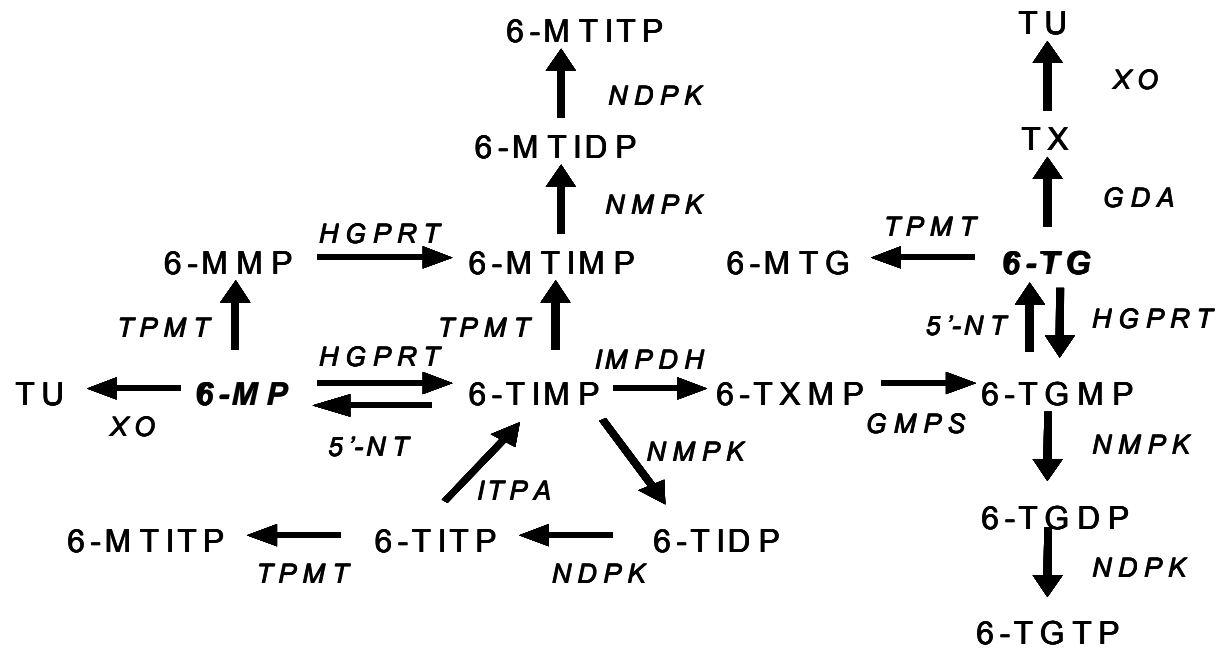

Figure $1.8 \quad$ Generally accepted metabolism of thiopurines ${ }^{26}$.

IMPDH is the rate-limiting enzyme of the interconversion of IMP to GMP, thereby regulating the necessary balance of adenine and guanine nucleotides inside the cell. The knowledge of the role of IMPDH in thiopurine metabolism is merely based on the inhibition of IMPDH by the immunosuppressant mycophenolic acid (MPA). This results in accumulation of TIMP, and, as is assumed, methyl-TIMP (MTIMP), a potent inhibitor of PDNS $^{29}$. Recently a study was reported where a mutation in the promoter of IMPDH1 resulted in resistance to thiopurine therapy, thereby illustrating the importance of IMPDH in thiopurine therapy ${ }^{30}$.

The way GMPS plays a role in thiopurine metabolism is unknown. It can be predicted that a diminished activity of this enzyme will results in less efficacy of 6-MP and AZA. 
If the response on 6-MP or AZA is less than expected, and the patient is committed to the therapy, 6-TG can be used instead. Although studies show that the way 6-MP and 6-TG exert their therapeutic action is somewhat different (see section on therapeutic action of thiopurines).

Deactivation is an important tool for an organism to control the concentrations of active and potentially toxic metabolites. In thiopurine metabolism several enzymes are involved in deactivation: 5'-NT, TPMT, PNP, XO and guanosine deaminase (GAD) ${ }^{26}$.

Purine 5'-NT is active in nucleated cells like leucocytes, and therefore is an important regulator of thiopurine nucleotide concentrations in replicating cells ${ }^{31}$. Compared to pyrimidine 5'-NT the activity of purine 5'-NT in erythrocytes is negligible and will not be of importance for erythrocyte thiopurine metabolism.

Since the introduction of thiopurines in medicine, the role of the enzyme TPMT is the most extensively studied in thiopurine metabolism ${ }^{32}$. TPMT catalyses the transfer of a methyl group from a methyl donor (S-adenosyl methionine, SAM) to the sulphur atom of the thiopurine compound, 6-MP or 6-TG. Introduction of the methyl group at this position will deactivate the thiopurine molecule, most probably due to an alteration of the tautomeric configuration of the molecule. About $10-15 \%$ of thiopurines entering the circulation are deactivated by TPMT, so it is obvious that a deficiency, or even a lowered activity, of TPMT will have major consequences. The flux towards TGMP, catalysed by IMPDH and GMPS, will increase and results in enhanced intracellular concentrations of thioguanine nucleotides ${ }^{33}$.

There is general agreement on the methylation of 6-MP and 6-TG by TPMT, but there is less consensus on the methylation of thiopurine nucleotides. In particular TIMP is thought to be methylated by TPMT because of the presence of MTIMP in extracts of cells that have been incubated with thiopurines. This was presented in earlier work on the characterisation of human TPMT ${ }^{34,35}$, although later publications from other groups provided an alternative explanation for the presence of MTIMP. In an experiment published by Tay et al. MTIMP was detected in Ehrlich tumour cells after incubation with methylthioinosine $(M M P R)^{36,37}$. This suggests that MTIMP originates from thioinosine (TI), rather than form TIMP. TI is formed through 5'-NT mediated phosphohydrolysis of TIMP. TPMT will methylate $\mathrm{TI}$, which is phosphorylated by adenosine kinase (AK), resulting in MTIMP ${ }^{28,38}$.

As is shown in Figure 1.8 PNP and XO are essential for the degradation of thiopurine nucleosides and bases to the metabolic end product 6-TU. It is estimated that degradation by $\mathrm{XO}$ accounts for over $80 \%$ of thiopurine metabolism of 6-MP administered. The role of polymorphisms XO was recently described by Hawwa et al., but unfortunately they performed no functional studies ${ }^{39}$. Most functional information of the role of XO until now is derived from reports on the use of allopurinol as comedication with thiopurines. Allopurinol is a suicide inhibitor of $\mathrm{XO}$, forcing all the 6MP to be handled by TPMT and IMPDH. This will result in high intracellular concentrations of thioguanine nucleotides and methylated thiopurines ${ }^{40}$. 
The exact role of ITPase in thiopurine metabolism is still unclear, it is evident that thioinosine-5'-triphosphate (TITP) is hydrolyzed by ITPase ${ }^{41}$. Whether TITP accumulates in patients with partial ITPase deficiency is unknown. ITPase activity lowering polymorphisms in the ITPA gene are reported to be associated with ADR, although other reports cannot confirm these findings $s^{39,42-45}$.

Although little is known on PNP involvement in thiopurine metabolism it is considered to be of importance. A lowered activity will result in high concentrations of thiopurine nucleosides and nucleotides, which are substrates for TPMT, resulting in abnormal concentrations of methylated compounds.

The function of guanine deaminase is thought to be minor, it is important when 6-TG is used as medication.

\section{Therapeutic action of thiopurines}

As is outlined above thiopurines need to be metabolised in several steps before they can exert their cytotoxic effect. 6-MP and 6-TG both are converted to thioguanine (deoxy)nucleotides (TGNs) and incorporated into RNA and DNA. Once incorporated into DNA these aberrant TGNs are responsible for the delayed cytotoxic action of thiopurines, causing DNA-protein interactions, due to the active sulphur group, interstrand cross-links and chromatide breaks ${ }^{46}$.

The therapeutic efficacy of 6-MP is augmented further through its metabolite 6-MTIMP, this methylated nucleotide is a strong inhibitor of phosphoribosyl pyrophosphate amidotransferase, the first enzyme of the PNDS. This has several metabolic consequences. First there is depletion of the endogenous purine pool, e.g. ATP and GTP, having its effect on cellular processes depending on purine nucleotides. It will result in inhibition of cell growth: tumour cells treated with 6-MP were arrested in the late $G_{1}+S$ phase of the cell cycle ${ }^{47}$. A second effect, related to the PDNS inhibition, is the increased availability of phosphoribosyl pyrophosphate (PRPP). Increased PRPP concentrations will favour the conversion of 6-MP to 6-TIMP by HGPRT, and the subsequent toxic thionucleotides ${ }^{48}$. Furthermore the excess of PRPP will give an increase in pyrimidine synthesis, thereby altering the purine-pyrimidine nucleotide balance inside the cell. This will result in unbalanced growth and inhibition of cell growth. 


\section{Drug interactions in thiopurine metabolism}

Like all drug metabolising pathways thiopurine metabolism can be altered by the products formed or competing drugs.

As already stated in the section on thiopurine metabolism the use of concomitant MPA or allopurinol will result in either the accumulation of TIMP and methylated analogues. In the case of allopurinol there will also be an aberrant increase in thioguanine nucleotides, resulting in myelotoxicity.

The use of combination therapies consisting of 6-MP or AZA and mesalazine (5-Aminosalicylate, 5-ASA) resulted in higher concentrations of TGNs after 4 weeks. Myelotoxicity rates were higher than in patients on thiopurine monotherapy ${ }^{49}$. TPMT is inhibited by 5-ASA and its acetylated metabolite, Ac-5-ASA. In addition there is information on inhibition of TPMT by sulfalazine, aspirin and other benzoic acid derivatives ${ }^{6}$.

\section{Objective of this thesis}

Despite five decades of research there is still a lack in our knowledge of the metabolism of thiopurines and the way thiopurines exert their therapeutic efficacy. Considering the knowledge available we formulated a number of questions we wanted to be answered.

The first question, chapter 2, regarded the deactivation of thiopurines by TPMT, especially how 6-MTIMP is formed. This compound inhibits purine de novo synthesis at the level of the first step and therefore is an important metabolite in thiopurine metabolism. Is MTIMP generated directly by methylation of TIMP or are other mechanisms involved?

The measurement of thiopurine end metabolites is still cumbersome and only methods with limited analytical power are described. Therefore, our second goal was to establish and validate a method for the measurement of thiopurine metabolites using ultra performance liquid chromatography combined with tandem mass spectrometry and is described in chapter 3.

In chapter 4 the clinical consequences in a patient with a TPMT activity lowering polymorphism and thiopurine therapy are highlighted.

Measurement of the enzyme ITPase and its application in thiopurine therapy was the third objective of this study. More specifically the following questions were addressed in chapter 5: can dried blood spots be used as medium for the measurement of ITPase and if applicable, is the stability of the enzyme sufficient for retrospective measurement? 
The influence of polymorphisms in ITPA are well described, on the other hand much less is known about the kinetic properties of the proteins originating from these polymorphisms. The handling of TITP by ITPase has not been described before, either for the wild type protein nor for the polymorphisms. The results of the experiments are described in chapter 6

There are some indications that ITPase, ITPA, or both are involved in the immune response. This assumption was studied in a group of patients with interstitial lung diseases and the results are described in chapter 7 .

Acknowledgement: Figures 1.3-1.5 were used with permission from McGraw-Hill. 


\section{References}

1. Granner DK. Nucleic Acid Structure and Function. In: Murray RK, ed. Harper's Biochemistry. McGrawHill, New York 2000;402-11.

2. Gnaiger E. Capacity of oxidative phosphorylation in human skeletal muscle: New perspectives of mitochondrial physiology. Int J Biochem Cell Biol 2009:41:1837-45.

3. Dousa TP, Chini EN, Beers KW. Adenine nucleotide diphosphates: emerging second messengers acting via intracellular Ca2+ release. Am J Physiol 1996:1007-24.

4. Kornfeld R, Kornfeld S. Assembly of asparagine-linked oligosaccharides. Ann Rev Biochem 1985:54:631-64.

5. Hitchler MJ, Domann FE. Metabolic defects provide a spark for the epigenetic switch in cancer. Free Radic Biol Med 2009;47:115-27.

6. Sahasranaman S, Howard D, Roy S. Clinical pharmacology and pharmacogenetics of thiopurines. Eur J Clin Pharmacol 2008;64:753-67.

7. Shipkova M, Lorenz K, Oellerich M, Wieland E, von Ahsen N. Measurement of erythrocyte inosine triphosphate pyrophosphohydrolase (ITPA) activity by HPLC and correlation of ITPA genotypephenotype in a Caucasian population. Clin Chem 2006;52:240-7.

8. Sumi S, Marinaki AM, Arenas M, Fairbanks L, Shobowale-Bakre M, Rees DC, Thein SL, Ansari A, Sanderson J, De Abreu RA, Simmonds HA, Duley JA. Genetic basis of inosine triphosphate pyrophosphohydrolase deficiency. Hum Genet 2002;111:360-7.

9. Vanderheiden BS. Human erythrocyte "ITPase": an ITP pyrophosphohydrolase. Biochim Biophys Acta 1970;215:555-8.

10. International drug monitoring: the role of national centres. Report of a WHO meeting. World Health Organ Tech Rep Ser 1972:1-25.

11. Becquemont L. Clinical relevance of pharmacogenetics. Drug Metab Rev 2003;35:277-285.

12. Dervieux T, Meshkin B, Neri B. Pharmacogenetic testing: proofs of principle and pharmacoeconomic implications. Mutat Res 2005;573:180-94.

13. Pierik $M$, Rutgeerts $P$, Vlietinck $R$, Vermeire $S$. Pharmacogenetics in inflammatory bowel disease. World J Gastroenterol 2006;12:3657-67.

14. Relling MV, Dervieux T. Pharmacogenetics and cancer therapy. Nat Rev Cancer 2001;1:99-108.

15. Weinshilboum R. Richard Weinshilboum: Pharmacogenetics: The future is here! Mol Interv 2003;3: 118-22.

16. Oscarson M. Pharmacogenetics of drug metabolising enzymes: importance for personalised medicine. Clin Chem Lab Med 2003;41:573-80.

17. Wang L, Weinshilboum RM. Pharmacogenomics: candidate gene identification, functional validation and mechanisms. Hum Mol Genet 2008;17:R174-9.

18. Weinshilboum R, Wang L. Pharmacogenomics: bench to bedside. Nat Rev Drug Discov 2004;3:739-48.

19. van Kuilenburg $A B$. Dihydropyrimidine dehydrogenase and the efficacy and toxicity of 5-fluorouracil. Eur J Cancer 2004;40:939-50.

20. Wijnen PA, Op den Buijsch RA, Drent M, Kuijpers PM, Neef C, Bast A, Bekers O, Koek GH. Review article: The prevalence and clinical relevance of cytochrome $\mathrm{P} 450$ polymorphisms. Aliment Pharmacol Ther 2007;26(S2): 211-9.

21. Ford L, Prout C, Gaffney D, Berg J. Whose TPMT activity is it anyway? Ann Clin Biochem 2004;41: 498-500.

22. Gardiner SJ, Begg EJ. Pharmacogenetic testing for drug metabolizing enzymes: is it happening in practice? Pharmacogenet Genomics 2005;15:365-9.

23. Sheffield $L$, Irving P, Gupta A, Byron K, Macrae FA, Phillimore H, Dronavalli M, Rose R, George P, Walmsley T, Dixon B, Poole S, Dooley M, Sparrow M. Thiopurine methyltransferase and thiopurine metabolite testing in patients with inflammatory bowel disease who are taking thiopurine drugs. Pharmacogenomics 2009;10:1091-9.

24. Sheffield LJ, Phillimore HE. Clinical use of pharmacogenomic tests in 2009. Clin Biochem Rev 2009;30:55-65. 
25. van den Akker-van Marle ME, Gurwitz D, Detmar SB, Enzing CM, Hopkins MM, Gutierrez de Mesa E, Ibarreta D. Cost-effectiveness of pharmacogenomics in clinical practice: a case study of thiopurine methyltransferase genotyping in acute lymphoblastic leukemia in Europe. Pharmacogenomics 2006;7: 783-92.

26. Bakker JA, Drent M, Bierau J. Relevance of pharmacogenetic aspects of mercaptopurine metabolism in the treatment of interstitial lung disease. Curr Opin Pulm Med 2007;13:458-63.

27. Parks DA, Granger DN. Xanthine oxidase: biochemistry, distribution and physiology. Acta Physiol Scand 1986;548:87-99.

28. Weigel G, Griesmacher A, DeAbreu RA, Wolner E, Mueller MM. Azathioprine and 6-mercaptopurine alter the nucleotide balance in endothelial cells. Thromb Res 1999;94:87-94.

29. Stet EH, De Abreu RA, Janssen YP, Bokkerink JP, Trijbels FJ. A biochemical basis for synergism of 6mercaptopurine and mycophenolic acid in Molt F4, a human malignant T-lymphoblastic cell line. Biochim Biophys Acta 1993;1180:277-82.

30. Roberts RL, Gearry RB, Barclay ML, Kennedy MA. IMPDH1 promoter mutations in a patient exhibiting azathioprine resistance. Pharmacogenomics J 2006;7: 312-7.

31. Brouwer C, Vogels-Mentink TM, Keizer-Garritsen JJ, Trijbels FJ, Bokkerink JP, Hoogerbrugge PM, van Wering ER, Veerman AJ, De Abreu RA. Role of 5'-nucleotidase in thiopurine metabolism: enzyme kinetic profile and association with thio-GMP levels in patients with acute lymphoblastic leukemia during 6-mercaptopurine treatment. Clin Chim Acta 2005;361:95-103.

32. Weinshilboum RM. Pharmacogenomics: catechol O-methyltransferase to thiopurine S-methyltransferase. Cell Mol Neurobiol 2006;26:539-61.

33. Krynetski E, Evans WE. Drug methylation in cancer therapy: lessons from the TPMT polymorphism. Oncogene 2003;22:7403-13.

34. Deininger M, Szumlanski CL, Otterness DM, Van Loon J, Ferber W, Weinshilboum RM. Purine substrates for human thiopurine methyltransferase. Biochem Pharmacol 1994;48:2135-8.

35. Krynetski EY, Krynetskaia NF, Yanishevski Y, Evans WE. Methylation of mercaptopurine, thioguanine, and their nucleotide metabolites by heterologously expressed human thiopurine S-methyltransferase. Mol Pharmacol 1995;47:1141-7.

36. Tay BS, Lilley RM, Murray AW, Atkinson MR. Inhibition of phosphoribosyl pyrophosphate amidotransferase from Ehrlich ascites-tumour cells by thiopurine nucleotides. Biochem Pharmacol 1969;18:936-8.

37. Yamanaka H, Kamatani N, Nishida Y, Nishioka K, Mikanagi K. Relationship between phosphorylation and cytotoxicity of 2-chloroadenosine and 6-methylmercaptopurine riboside in human cells. Biochim Biophys Acta 1984;798:291-4.

38. Duley JA, Florin TH. Thiopurine therapies: problems, complexities, and progress with monitoring thioguanine nucleotides. Ther Drug Monit 2005;27:647-54.

39. Hawwa AF, Millership JS, Collier PS, Vandenbroeck K, McCarthy A, Dempsey S, Cairns C, Collins J, Rodgers C, McElnay JC. Pharmacogenomic studies of the anticancer and immunosuppressive thiopurines mercaptopurine and azathioprine. Br J Clin Pharmacol 2008;66:517-28.

40. Ansari A, Aslam Z, de Sica A, Smith M, Gilshenan K, Fairbanks L, Marinaki A, Sanderson J, Duley J. Influence of xanthine oxidase on thiopurine metabolism in Crohn's disease. Aliment Pharmacol Ther 2008;28:749-57.

41. Bierau J, Lindhout M, Bakker JA. Pharmacogenetic significance of inosine triphosphatase. Pharmacogenomics 2007;8:1221-8.

42. Marinaki AM, Ansari A, Duley JA, Arenas M, Sumi S, Lewis CM, Shobowale-Bakre el M, Escuredo E, Fairbanks LD, Sanderson JD. Adverse drug reactions to azathioprine therapy are associated with polymorphism in the gene encoding inosine triphosphate pyrophosphatase (ITPase). Pharmacogenetics 2004;14:181-7.

43. Marinaki AM, Duley JA, Arenas M, Ansari A, Sumi S, Lewis CM, Shobowale-Bakre M, Fairbanks LD, Sanderson J. Mutation in the ITPA gene predicts intolerance to azathioprine. Nucleosides Nucleotides Nucleic Acids 2004;23:1393-7.

44. Van Dieren JM, Hansen BE, Kuipers EJ, Nieuwenhuis EE, Van der Woude CJ. Meta-analysis: Inosine triphosphate pyrophosphatase polymorphisms and thiopurine toxicity in the treatment of inflammatory bowel disease. Aliment Pharmacol Ther 2007;26:643-52. 
45. van Dieren JM, van Vuuren AJ, Kusters JG, Nieuwenhuis EE, Kuipers EJ, van der Woude CJ. ITPA genotyping is not predictive for the development of side effects in AZA treated inflammatory bowel disease patients. Gut 2005;54:1664.

46. Coulthard S, Hogarth L. The thiopurines: an update. Invest New Drugs 2005;23:523-32.

47. Vogt MH, Stet EH, De Abreu RA, Bokkerink JP, Lambooy LH, Trijbels FJ. The importance of methylthioIMP for methylmercaptopurine ribonucleoside (Me-MPR) cytotoxicity in Molt F4 human malignant Tlymphoblasts. Biochim Biophys Acta 1993;1181:189-94.

48. Bokkerink JP, Stet EH, De Abreu RA, Damen FJ, Hulscher TW, Bakker MA, van Baal JA. 6Mercaptopurine: cytotoxicity and biochemical pharmacology in human malignant T-lymphoblasts. Biochem Pharmacol 1993;45:1455-63.

49. de Boer NK, Wong DR, Jharap B, de Graaf P, Hooymans PM, Mulder CJ, Rijmen F, Engels LG, van Bodegraven AA. Dose-dependent influence of 5-aminosalicylates on thiopurine metabolism. Am J Gastroenterol 2007;102:2747-53. 


\section{Chapter 2}

\section{Selectivity of TPMT towards thiopurine nucleosides and nucleotides}




\section{Abstract}

Detoxification of xenobiotic compounds is a common defense mechanism to prevent the accumulation of toxic compounds. Thiopurine-S-methyltransferase (TPMT) is one of the methyltransferases involved in methylation of thiol containing heterocyclic compounds, e.g. the thiopurines. Thiopurines are widely used in the treatment of inflammatory disorders and polymorphism in thiopurine metabolizing enzymes like TPMT cause serious adverse events.

To explore the methylation of the various thiopurinebases, -nucleosides and -nucleotides by TPMT, incubation studies were performed. Enzyme sources were recombinant human TPTMT, erythrocyte lysates and cell cultures of MOLT-3 cells. As methyl donor both unlabeled and tritium labeled S-adenosyl methionine (SAM) were used in these studies.

Results of these studies showed that, as expected, 6-mercaptopurine and 6-thioguanine were methylated by all enzyme sources. 6-thioinosine-5'monophosphate on the other hand was methylated by hrTPMT, but not in erythrocyte lysates. In MOLT-3 cultures we detected MTIMP after incubation with 6-MP. Incubation of MOLT-3 cells with 6-TG clearly showed the formation of the consecutive thioguanine nucleotides. Only a modest amount of MTGMP was present. Incubation with 6-MMP showed no formation of 6-MTIMP, hereby excluding the phosphoribosylation of 6-MMP by HGPRT.

Studies on the methylation of thiopurinenucleotides in cells from patients with different defects in (thio)purine metabolizing enzymes or with specific inhibition of pathways are needed to further elucidate the way thiopurines are metabolized. 


\section{Introduction}

Purines and pyrimidines are heterocyclic compounds essential for mammalian life: precursors of RNA and DNA, involved in signal transduction, essential co-factors in enzyme reactions and other indispensable functions. Purine metabolism is a complex network of enzymes catalyzing de novo synthesis, salvage, degradation and interconversion of purines bases, nucleosides and nucleotides. Defects in enzymes involved in this network result in inborn errors of metabolism with a broad spectrum of clinical symptoms and metabolic disturbances ${ }^{1}$. So far defects in all purine metabolizing pathways are described and are detectable by metabolite analysis, enzyme activity measurement, mutation analysis or combinations of these techniques. Deactivation of exogenous metabolites is an important in vivo defense mechanism to control the concentrations of potentially toxic compounds. Thiopurines, substituted analogs of purines, are widely used as antimetabolites for the treatment of leukemia, organ rejection and inflammatory disorders ${ }^{2}$. Their efficacy and safety depends highly on the routes involved in the activation, degradation and deactivation of these compounds ${ }^{3}$. Thiopurines are activated and metabolized by the enzymes of the degradation, salvage and interconversion routes of purine metabolism. In addition thiopurine bases are deactivated by the enzyme thiopurine S-methyltransferase $(\text { TPMT })^{4,5}$. In replicating cells, a high TPMT activity will result in a reduced availability of the activated metabolite 6-thioinosine-5'-monophosphate (TIMP) for the interconversion to the active compounds, the thioguanine nucleotides, and in higher concentrations of therapeutically inactive, but nevertheless toxic, methylthiopurinenucleotides $^{6}$. Reduced TPMT activity will increase the concentrations of thioguanine nucleotides to toxic limits in replicating cells ${ }^{7}$.

The only recognized role of TPMT in mammalian metabolism is to deactivate thiol containing purine (like) compounds into less active, and supposedly less toxic, metabolites $^{8}$. In aqueous ecosystems TPMT is involved in the detoxification of selenium-containing compounds. Whether TPMT is involved in selenium metabolism in man is unclear, although the high affinity for selenium containing purines suggests an active role of the enzyme in this context ${ }^{9}$.

TPMT is thought to be involved not only in the deactivation of thiopurine bases, but also in the methylation of thiopurine nucleosides and nucleotides. Although this is generally accepted, little is known about the selectivity of TPMT towards the thiopurine-nucleosides and -nucleotides ${ }^{10}$. The limited studies on this subject report the substrate specificity of these compounds for human TPMT (hTPMT), which was either purified from human tissue or obtained by an yeast expression system ${ }^{10,11}$. It is apparent that this presumed selectivity for thiopurinenucleotides will influence the bio-availability of these compounds and hence efficacy of the therapy.

To obtain more insight in the role of TPMT in deactivation of thiopurine metabolites a number of experiments were started. First the substrate specificity of hTPMT towards different thiopurine bases, nucleosides and nucleotides was characterized, using 
recombinant human TPMT (rhTPMT) and hTPMT from lysed erythrocytes as the enzyme source. Experiments were repeated with loading of cultured MOLT-3 cells during a fixed period with thiopurines. (Methyl)Thiopurine nucleotides were measured using HPLC-UV detection, with the aid of the appropriate separation conditions.

\section{Materials and methods}

Recombinant human TPMT from an E. coli expression system, full length protein (245 aa), was obtained from Abcam (Cambridge, United Kingdom). Thiopurine bases, nucleosides and nucleotides were obtained from Sigma (Zwijndrecht, the Netherlands) or from Jena Bioscience (Jena, Germany). Methylated thiopurine-bases, - nucleosides and-nucleotides and ${ }^{14} \mathrm{C}-6$-mercaptopurine were obtained from Jena Bioscience (Jena, Germany). Adenosyl Methionine,S-(methyl $\left.{ }^{3} \mathrm{H}\right)\left({ }^{3} \mathrm{H}\right.$-SAM) was purchased from Perkin Elmer (Waltham, MA, USA). Ultra-pure acetonitril was purchased from Biosolve (Valkenswaard, the Netherlands) All other chemicals were of the highest quality and purchased from Sigma (Zwijndrecht, the Netherlands).

\section{Incubation experiments}

Conditions for incubations of the different substrates with hrTPMT were identical to the conditions used for the measurement of TMPT activity in lysed red blood cells: samples were preincubated with the substrate. After 3 minutes the methyldonor SAM or ${ }^{3} \mathrm{H}$-SAM was added and the incubation prolonged to $1 \mathrm{hr}$. The reaction was stopped with ice-cold $10 \% \mathrm{HClO}_{4}$. After neutralization the sample was ready for $\mathrm{HPLC}$ separation. Molt-3 cells were cultured and incubated with the different substrates and (un)labeled SAM during 4 and 24 hrs. Cells were washed with medium and isolated. Intracellular thionucleotides were measured in perchloric acid extracts.

\section{Separation of (methyl)thiopurine bases, nucleosides and nucleotides}

Separation of 6-TG from 6-MTG (AMMP) was achieved using a reversed-phase Nucleosil 100-5-C18 column, $250 \mathrm{~mm} \times 4.6 \mathrm{~mm}$, particle size $5 \mu \mathrm{m}$ (Bischoff Chromatography, Leonberg, Germany). The HPLC system (Shimadzu, 's-Hertogenbosch, The Netherlands) consisted of a system controller (SCL-10A), a binary pump (LC-10AD), an autosampler (SIL-10AD) and a DAD detector (SPD-M10A). The mobile phase consisted of $0.1 \%$ acetic acid (Solvent A) and $100 \%$ acetonitrile (solvent B). The components were separated using the following gradient: 0 to $15.0 \mathrm{~min}, 88 \% \mathrm{~A} ; 20.0$ to $25.0 \mathrm{~min}, 50 \% \mathrm{~A} ; 29.0$ to $35.0 \mathrm{~min} 88 \%$, flow rate $1.0 \mathrm{ml} / \mathrm{min}$. Column temperature: $21^{\circ} \mathrm{C}$. $50 \mu \mathrm{l}$ sample was injected into the HPLC system and AMMP was detected at 290 $\mathrm{nm}$. For the detection of the radioactive labeled compounds a flow scintillation 
analyzer (FSA) Radiomatic 625 TR (PerkinElmer, Groningen, the Netherlands) was coupled in series to the HPLC system.

6-MP / 6-MMP, 6-TIMP / 6-MTIMP and 6-TGMP / 6-MTGMP were analyzed as described before ${ }^{12}$.

Separation of (methyl)thiopurinenucleotide di- and triphosphates was performed on a PerkinElmer Series 200 HPLC system (PerkinElmer, Groningen, the Netherlands) Separation was achieved using a PartiSphere SAX column $(4.6$ × $125 \mathrm{~mm} 5 \mu \mathrm{m}$, Whatman International Ltd, Maidstone, United Kingdom) protected by the appropriate guard cartridge and maintained at $21^{\circ} \mathrm{C}$. The mobile phase consisted of $9 \mathrm{mM}$ ammonium dihydrogen phosphate, $\mathrm{pH} 3.5$ (solvent $\mathrm{A}$ ) and $325 \mathrm{mM}$ ammonium dihydrogen phosphate and $500 \mathrm{mM}$ potassium chloride, $\mathrm{pH} 4.4$ (solution $\mathrm{B}$ ). Separation was achieved using the following gradient: 0 to $2 \mathrm{~min}, 100 \% \mathrm{~A} ; 2$ to $12 \mathrm{~min}, 20 \% \mathrm{~A} ; 12$ to $17 \mathrm{~min}, 10 \% \mathrm{~A} ; 17$ to $47 \mathrm{~min}, 10 \% \mathrm{~A} ; 47$ to $48 \mathrm{~min}, 100 \% \mathrm{~A} ; 48$ to $58 \mathrm{~min}, 100 \% \mathrm{~A}$. The flow rate was $1.0 \mathrm{ml} / \mathrm{min}$; injection volume $50 \mu \mathrm{l}$. The detector was set at the maximal absorbance wavelength for 6-TITP and 6-MTITP, $322 \mathrm{~nm}$ and $292 \mathrm{~nm}$ respectively. 6-TGTP and 6-MTGTP were detected at $341 \mathrm{~nm}$ and $309 \mathrm{~nm}$ respectively. Data acquisition and handling was performed by using Totalchrom software (PerkinElmer, Groningen, the Netherlands) except for the quantification of 6-TG and 6- AMMP which was performed by using Class-VP software (Shimadzu, 's-Hertogenbosch, the Netherlands). External standards with known concentrations of the components of interest were used to determine the retention times of the different metabolites and to calculate the activity of TPMT by relative peak areas. All experiments were performed in duplicate.

\section{Results}

From the results of the incubation experiments of various thiopurine derivatives with rhTPMT we confirmed that 6-MP and 6-TG were substrates for the enzyme, the calculated kinetic parameters were in line with earlier published values (Table 2.1).

Table 2.1 Kinetic properties of hrTPMT for 6-MP and 6-TG.

\begin{tabular}{|c|c|c|c|c|}
\hline \multicolumn{4}{|c|}{ Substrate } & \multirow[b]{3}{*}{ ref } \\
\hline & \multicolumn{2}{|l|}{ 6-MP } & 6-TG & \\
\hline $\mathrm{Km}(\mu \mathrm{M})$ & $\operatorname{Vmax}(\mathrm{nmol} / \mathrm{mg} / \mathrm{min})$ & $\mathrm{Km}(\mu \mathrm{M})$ & $V \max (\mathrm{nmol} / \mathrm{mg} / \mathrm{min})$ & \\
\hline 323 & 2.32 & 603 & 1.72 & Present study \\
\hline 320 & n.d. & 200 & n.d. & [13] \\
\hline 300 & n.d. & 550 & n.d. & [11] \\
\hline $383 \pm 7$ & $14.95 \pm 0.15$ & $557 \pm 10$ & $18.0 \pm 0.3$ & {$[9]$} \\
\hline \multirow[t]{3}{*}{$10.6 \pm 1.3$} & $48 \pm 3$ & $18.1 \pm 3.4$ & $55 \pm 5$ & [10] \\
\hline & & $34.9 \pm 6.7$ & $122.8 \pm 16.9$ & [14] \\
\hline & & $15.2 \pm 0.3$ & $19.2 \pm 1.0$ & [15] \\
\hline
\end{tabular}


The results of the incubation experiments with the other thiopurine derivatives, e.g. 6-thioinosine and 6-TIMP were not consistent and we repeated the incubations with tritium labeled SAM as the methyl donor. We could confirm transfer of the tritium label to the different substrates (Table 2.2). The compounds were separated with HPLC and the retention times were confirmed by non-labeled standards, detected by UV detection, coupled in series with a flow scintillation analyzer.

Table 2.2 Incorporation of ${ }^{3} \mathrm{H}$-methyl label in thiopurine compounds by RHTPMT.

\begin{tabular}{cccc}
\hline & & \multicolumn{2}{c}{ Label incorporated (\%) } \\
Compound & Product & $6 \mathrm{hr}$ & $24 \mathrm{hr}$ \\
\hline 6-MP & 6-MMP & $10.2 \pm 0.40$ & $15.3 \pm 0.95$ \\
6-TG & 6-MTG & $8.9 \pm 0.25$ & $16.7 \pm 1.55$ \\
TIMP & 6-MTIMP & $11.3 \pm 0.64$ & $16.4 \pm 0.57$ \\
6-TI & 6-MTI & $11.4 \pm 0.64$ & $16.3 \pm 0.62$ \\
\hline
\end{tabular}

We repeated this experiment by incubating MOLT-3 cells over 24 hours with 6-TI, 6-MP and 6-MMP, together with tritium labeled SAM. Incubation with 6-TI showed formation of 6-MP and 6-MTIMP, the latter compound could be detected through the transfer of the ${ }^{3} \mathrm{H}$-methyl group from SAM. Incubation with ${ }^{14} \mathrm{C}-6-\mathrm{MP}$ resulted in the formation of 6-MTIMP, both the ${ }^{3} \mathrm{H}$ and ${ }^{14} \mathrm{C}$ label were detected at the retention time of 6-MTIMP, 6-MMP was not found in the intracellular extracts. From the incubation experiment with 6-MMP we could confirm that 6-MMP enters the cell and stays unchanged. No changes in the pattern of intracellular thiopurine metabolites were detected.

When a full (methyl)thionucleotides profile was analyzed, 4 hours after addition of 6-MP to the cell culture 6-TIMP and 6-MTIMP were detectable. Using 6-TG as a substrate 6-TGMP, 6-TGDP and 6-TGTP (ratio 12:4:1) were detectable after 4 hours of incubation (Figure 2.1). Only a modest amount of 6-MTGMP was detectable after 4 hours.

We also tested human erythrocyte lysates with the different substrates: we could only confirm the S-methylation of 6-MP and 6-TG, 6-TIMP was not methylated. In theory MTIMP can be generated from the phosphoribosylation of 6-MMP by HGPRT. To test this hypothesis we incubated 6-MP and 6-MMP with PRPP in an erythrocyte lysate under conditions used for HGPRT activity measurement. As expected 6-MP was converted to TIMP, but with 6-MMP as substrate no product was generated. 


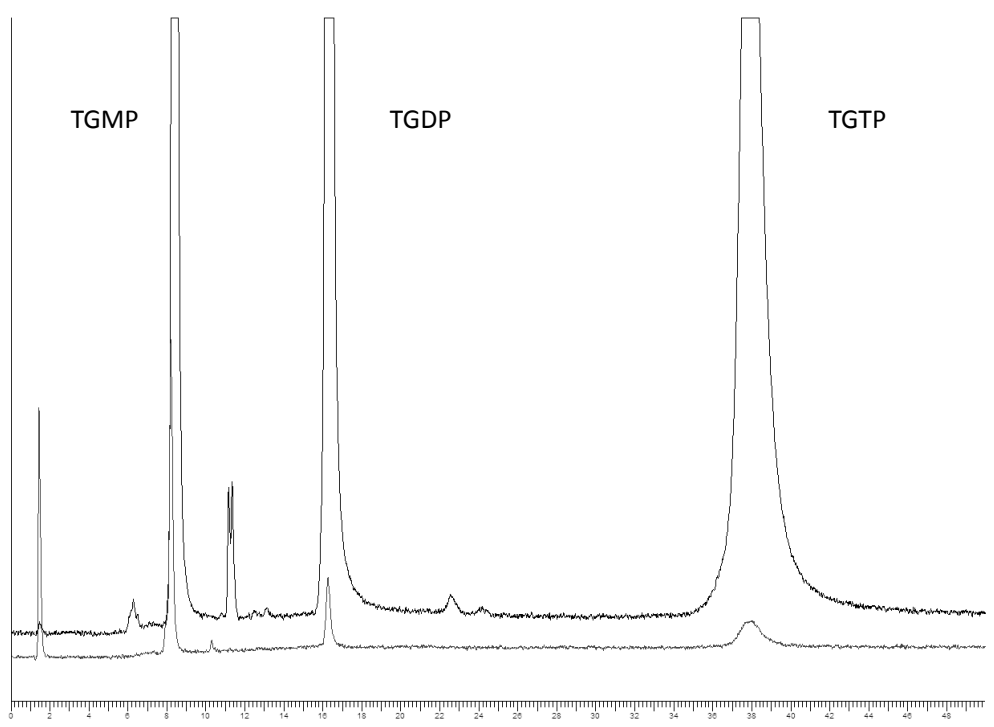

Figure 2.1 Thionucleotide profile in molt-3 extracts after loading with 6-TG (lower trace); upper trace standards TGMP, TGDP, TGTP Rrespectively. Chromatographic conditions are described in the methods section.

\section{Discussion}

The ways thiopurines exert their effect is still not fully understood. The original idea of using thiopurines as drugs in cancer therapy was that these compounds would act as purine antimetabolites through the incorporation of (deoxy)thiopurinenucleotides of guanine into RNA and DNA, thereby inhibiting further replication. A second effect which was observed was the inhibition of the purine de novo synthesis (PNDS) by the methylated thiopurinenucleotides formed in vivo. Methyl-thioinosine-monophosphate (MTIMP) was identified as the inhibitory compound, although earlier reports also named methylthioinosine as the responsible metabolite to inhibit PNDS ${ }^{16,17}$. In general it is assumed that MTIMP is generated by the action of TPMT on TIMP. Our experiments with rhTPMT and labelled ${ }^{3} \mathrm{H}$-SAM show that MTIMP is synthesised in vitro from TIMP. We could also confirm the formation of MTIMP in MOLT-3 cells after incubation with 6-MP. In erythrocyte lysates no methylation of TIMP occurred. The reason why TIMP was not methylated in erythrocyte lysates remains unsolved. From the results from the incubation of rhTPMT with ${ }^{3} \mathrm{H}$-SAM it is clear that the transfer of the methyl group is as efficient to 6-MP as to TIMP (Table 2.2).

In intact cell systems other enzymes will play an additional role in thiopurine metabolism. Nucleated cells have high purine 5'-Nucleotidase (5-NT) activity: this 
enzyme has a high affinity for TIMP, which will be degraded to thioinosine by the action of $5-\mathrm{NT}^{18}$. As reported earlier thioinosine is a substrate for TPMT and methylthioinosine will be formed ${ }^{9}$. Results from experiments in endothelial cells show that methylthioinosine is readily converted to MTIMP. The authors suggest the action of adenosine kinase (AK) responsible for this conversion ${ }^{19}$. Our results also confirm methylation of 6-TI by hrTPMT (Table 2.2). Earlier studies on TPMT suggest the existence of another thiol methyltransferase, 'alkyl thiol methyltransferase'. This microsomal enzyme showed overlapping characteristics with $\mathrm{TPMT}^{8}$.

Currently experiments are planned to further elucidate the methylation of thiopurines. By using inhibitors of enzymes involved in (thio)purine metabolism more insight can be gained regarding the fate of thiopurines in mammalian metabolism. 


\section{References}

1. Bierau J, van Gennip A. Defekte des Purin- und des Pyrimidinstoffwechsels. In: Lentze MJ SJ, Schulte FJ, Spranger J, editor. Pädiatrie Grundlagen und Praxis. Heidelberg: Springer Medizin Verlag, 2007:413-6.

2. Lennard L. The clinical pharmacology of 6-mercaptopurine. Eur J Clin Pharmacol 1992;43:329-39.

3. Hawwa AF, Collier PS, Millership JS, McCarthy A, Dempsey S, Cairns C, McElnay JC. Population pharmacokinetic and pharmacogenetic analysis of 6-mercaptopurine in paediatric patients with acute lymphoblastic leukaemia. Br J Clin Pharmacol 2008;66:826-37.

4. Derijks LJ, Gilissen LP, Hooymans PM, Hommes DW. Review article: thiopurines in inflammatory bowel disease. Aliment Pharmacol Ther 2006;24:715-29.

5. Weinshilboum RM, Otterness DM, Szumlanski CL. Methylation pharmacogenetics: catechol Omethyltransferase, thiopurine methyltransferase, and histamine N-methyltransferase. Annu Rev Pharmacol Toxicol 1999;39:19-52.

6. Nygaard U, Toft N, Schmiegelow K. Methylated metabolites of 6-mercaptopurine are associated with hepatotoxicity. Clin Pharmacol Ther 2004;75:274-81.

7. Krynetski E, Evans WE. Drug methylation in cancer therapy: lessons from the TPMT polymorphism. Oncogene 2003;22:7403-13.

8. Woodson LC, Ames MM, Selassie CD, Hansch C, Weinshilboum RM. Thiopurine methyltransferase. Aromatic thiol substrates and inhibition by benzoic acid derivatives. Mol Pharmacol 1983;24:471-8.

9. Deininger $\mathrm{M}$, Szumlanski CL, Otterness DM, Van Loon J, Ferber W, Weinshilboum RM. Purine substrates for human thiopurine methyltransferase. Biochem Pharmacol 1994;48:2135-8.

10. Krynetski EY, Krynetskaia NF, Yanishevski Y, Evans WE. Methylation of mercaptopurine, thioguanine, and their nucleotide metabolites by heterologously expressed human thiopurine S-methyltransferase. Mol Pharmacol 1995;47:1141-7.

11. Woodson LC, Weinshilboum RM. Human kidney thiopurine methyltransferase. Purification and biochemical properties. Biochem Pharmacol 1983;32:819-26.

12. Bierau J, Bakker JA, Lindhout M, van Gennip AH. Determination of ITPase Activity in Erythrocyte Lysates Obtained for Determination of Tpmt Activity. Nucleosides Nucleotides Nucleic Acids 2006;25:1129-32.

13. Weinshilboum RM, Raymond FA, Pazmino PA. Human erythrocyte thiopurine methyltransferase: radiochemical microassay and biochemical properties. Clin Chim Acta 1978;85:323-33.

14. Hamdan-Khalil R, Allorge D, Lo-Guidice JM, Cauffiez C, Chevalier D, Spire C, et al. In vitro characterization of four novel non-functional variants of the thiopurine S-methyltransferase. Biochem Biophys Res Commun 2003;309:1005-10.

15. Hamdan-Khalil R, Gala JL, Allorge D, Lo-Guidice JM, Horsmans Y, Houdret N, et al. Identification and functional analysis of two rare allelic variants of the thiopurine S-methyltransferase gene, TPMT*16 and TPMT*19. Biochem Pharmacol 2005;69:525-9.

16. Tay BS, Lilley RM, Murray AW, Atkinson MR. Inhibition of phosphoribosyl pyrophosphate amidotransferase from Ehrlich ascites-tumour cells by thiopurine nucleotides. Biochem Pharmacol 1969;18:936-8.

17. Tidd DM, Paterson AR. Distinction between inhibition of purine nucleotide synthesis and the delayed cytotoxic reaction of 6-mercaptopurine. Cancer Res 1974;34:733-7.

18. Brouwer C, Vogels-Mentink TM, Keizer-Garritsen JJ, Trijbels FJ, Bokkerink JP, Hoogerbrugge PM, et al. Role of 5'-nucleotidase in thiopurine metabolism: enzyme kinetic profile and association with thioGMP levels in patients with acute lymphoblastic leukemia during 6-mercaptopurine treatment. Clin Chim Acta 2005;361:95-103.

19. Weigel G, Griesmacher A, DeAbreu RA, Wolner E, Mueller MM. Azathioprine and 6-mercaptopurine alter the nucleotide balance in endothelial cells. Thromb Res 1999;94:87-94. 



\section{Chapter 3}

\section{Quantitative measurement of thiopurine metabolites in biological fluids using ultra- performance liquid chromatography- tandem mass spectometry}




\section{Abstract}

Thiopurines are used as anti-inflammatory drugs in a broad spectrum of diseases, therapy monitoring is of importance because of the clinical consequences of high intracellular concentrations of thiopurine nucleotides. The measurement of thiopurine degradation products is not routinely performed in thiopurine therapy, although this can give important information on drug efficacy.

Sophisticated techniques like UPLC-tandem mass spectrometry are excellent tools to measure metabolites in biological fluids. Using stable isotope dilution techniques a method was developed for the quantitative determination of thiopurine metabolites in urine and plasma of patients treated with thiopurines.

All compounds showed excellent linearity and recovery, both in urine and plasma. Stability of 6-TU, 6-MP and 6-TG in urine was insufficient, concentrations decreased $>50 \%$ over a 3 week period; the methylated compounds 6-MMP and 6-MTG were stable. In plasma all compounds were stable over a period of 3 months. Intra assay variation was within $5 \%$, both in urine and plasma. Inter assay variations for the thiopurines in urine were unsatisfactory for the above mentioned decay over time, for the methylated compounds the inter assay variation varied from $22 \%$ for low concentrations $(0.3 \mu \mathrm{mol} / \mathrm{l})$ to $4 \%$ for the control sample with concentrations of $3 \mu \mathrm{mol} / \mathrm{I}$. Plasma inter assay varied between 4 and $15 \%$.

In control samples thiopurine metabolites were not detectable. In urine and plasma from patients treated with thiopurine medication the method was used to quantify the thiopurine metabolites. 


\section{Introduction}

Thiopurines are a class of drugs used for the treatment of patients suffering from a wide variety of diseases. Today they are the standard steroid sparing therapy in (systemic) inflammatory diseases like Crohn's disease, colitis ulcerosa and sarcoidosis $^{1,2}$. Furthermore they are used as therapeutics in lymphatic proliferative diseases and, although to a lesser extent nowadays, to avoid rejection in organ transplantation ${ }^{3}$.

The metabolism of thiopurines is a complex network of activation and degradation. Genetic factors influence how thiopurines are handled: metabolites accumulate or are converted into less efficient or more toxic compounds ${ }^{4,5}$. It is apparent that measurement of the different (classes of) compounds is important to fully understand the pathway and to detect disturbances in thiopurine handling ${ }^{6}$. In a clinical setting, measurement of thiopurine derivatives has two objectives. The first one is the detection and quantification of the active compounds, the thiopurine nucleotides; the second objective is the quantification of the thiopurine metabolites, either to detect increased degradation or to ascertain therapy compliance.

Measurement of thiopurine nucleotides is mainly part of the therapeutic drug monitoring (TDM) protocol ${ }^{7}$. The goal is to monitor the levels of the active, i.e. toxic, thionucleotides in order to avoid undesired adverse drug reactions (ADR). These reactions can be either the formation of an excess of active metabolites or nonresponsiveness to therapy. The majority of methods used for the measurement of intracellular thionucleotides are HPLC based methods. In these procedures the phosphate groups are removed from the thionucleotides, either by acid hydrolysis or enzymatically, and the remaining thionucleosides and thiobases are separated and quantified by $\mathrm{HPLC}^{8-10}$. The general drawback of these methods is that they measure the 'total' amount of thioguanine or mercaptopurine and their methylated forms. To be able to determine the true intracellular (methyl)thionucleotide content a more sophisticated separation method is needed, using either ion exchange chromatography or ion-pair reversed phase LC separation ${ }^{11}$. The long separation times and the very low concentrations of the individual intracellular (methyl)thionucleotides makes these methods not suitable for routine TDM purposes.

The measurement of the degradation products of thiopurines has not become common practice, although the measurement of these compounds can give important information on the efficacy of therapy and pharmacokinetic properties ${ }^{12,13}$. Recently a revised HPLC method for the determination of 6-mercaptopurine and other thiopurine metabolites in plasma and erythrocytes was published ${ }^{14}$.

We describe the development and validation of a ultra-performance liquid chromatography tandem mass spectrometry method for the determination of thiopurine end-products in biological fluids, requiring minimum amounts of sample and less sample preparation. 


\section{Materials and methods}

\section{Patients}

Urine, plasma and erythrocytes were obtained from patients on thiopurine therapy in the frame of TDM. Samples were used according to the "Code for proper use of human tissue" as formulated by the Dutch Federation of Medical Scientific Societies.

\section{Chemicals}

Thiopurine bases and nucleosides were obtained from Sigma (Zwijndrecht, the Netherlands) or from Jena Bioscience (Jena, Germany). 6-thiouric acid (6-TU), ${ }^{13} C_{1}-6$-thiouric acid $\left({ }^{13} C_{1}-6-T U\right)$ and ${ }^{13} C_{1}-6$-mercaptopurine $\left({ }^{13} C_{1}-6-M P\right)$ were synthesised by SyMO-Chem (Eindhoven, the Netherlands). 6-Methyl- $\mathrm{D}_{3}$-mercaptopurine (6- $\mathrm{D}_{3}-\mathrm{MMP}$ ) was obtained from $\mathrm{C} / \mathrm{D} / \mathrm{N}$ Isotopes Inc (Pointe-Claire, Quebec, Canada). Tris(2-carboxyethyl)phosphine (TCEP) was obtained from Sigma (Zwijndrecht, The Netherlands). LCMS-grade acetonitril, methanol and water were purchased from VWR (Amsterdam, the Netherlands). All other chemicals were of the highest quality and purchased from Sigma (Zwijndrecht, the Netherlands).

\section{Sample preparation}

To $50 \mu \mathrm{l}$ sample, either urine, plasma or a mixture of standards in water, an equal volume of a mixture of stable isotope labelled internal standards (concentrations $\sim 3 \mu \mathrm{M}$ ) was added. Reduction of protein bound thiopurines was achieved using $100 \mu \mathrm{l}$ $25 \mathrm{mM}$ TCEP in $50 \mathrm{mM}$ ammoniumformiate $(\mathrm{pH} \mathrm{6.3)}$ as the reducing agent. After the addition of $300 \mu \mathrm{l}$ ice cold acetonitrile / 0.1\% Formic acid / 0.025\% TFA (v/v/v) the mixture was vigorously vortexed. After centrifugation $400 \mu \mathrm{l}$ supernatant was evaporated to dryness under nitrogen at room temperature. The residue was dissolved in $150 \mu \mathrm{l} 0.2 \mathrm{M}$ ammoniumformiate $\mathrm{pH} 4.0$ and $2 \mu \mathrm{l}$ was injected into the UPLC using full loop injection.

\section{Ultra performance liquid chromatography}

Separation of the compounds of interest was achieved using an Acquity ULPC system equipped with an Acquity HSS T3 column, $100 * 2.1 \mathrm{~mm}$, particle size $1.8 \mu \mathrm{M}$ (Waters, Milford, MA). Mobile phases were as solvent A $0.01 \mathrm{M}$ Ammoniumformiate $(\mathrm{pH} 4.00)$ and as solvent B methanol / $0.01 \mathrm{M}$ Ammoniumformiate $(\mathrm{pH} 4.0)(60 / 40, \mathrm{v} / \mathrm{v})$. A gradient program (see Table 3.1) was used to achieve sufficient retention of the compounds of interest. Run to run time was 18 minutes. 
Table 3.1 Gradient program used for separation of thiopurine metabolites.

\begin{tabular}{lcrr}
\hline Time $(\mathrm{min})$ & Flow $(\mathrm{ml} / \mathrm{min})$ & $\% \mathrm{~A}$ & $\% \mathrm{~B}$ \\
\hline Initial & 0.45 & 98 & 2 \\
2 & 0.45 & 98 & 2 \\
6 & 0.45 & 60 & 40 \\
7 & 0.45 & 0 & 100 \\
8 & 0.45 & 0 & 100 \\
10 & 0.45 & 98 & 2 \\
\hline
\end{tabular}

\section{Tandem mass spectrometry conditions}

Mass spectrometry experiments were performed using a Micromass Quattro Premier XE Tandem Mass Spectrometer (Waters, Milford, MA). The mass spectrometer was used in the multiple reaction mode (MRM), both in electrospray ionisation (ESI) positive and negative mode. Desolvatation temperature was $450^{\circ} \mathrm{C}$, source temperature $130^{\circ} \mathrm{C}$. Capillary voltage setting was $0.5 \mathrm{kV}$, cone and collision settings for the different compounds are shown in Table 3.2. Nitrogen gas was used both as desolvatation and cone gas, flows were $800 \mathrm{l} / \mathrm{h}$ and $50 \mathrm{l} / \mathrm{h}$, respectively. Argon was used as collision gas for MRM and daughter ion scans (flow $0.15 \mathrm{ml} / \mathrm{min}$, pressure $2.8 * 10^{-3}$ bar). Settings of the mass spectrometer for detection of the compounds of interest and internal standards used are shown in Table 3.2. Resolution parameters for the compounds of interest (LM1HM1) and internal standards (LM2HM2) were set to 12 in both positive and negative mode.

Table 3.2 Mass spectrometer settings for detection and quantification of thiopurine metabolites.

\begin{tabular}{lcccccccc}
\hline Compound & mode & parent & daughter & Cone & collision & CV & DT \\
& & $\mathrm{m} / \mathrm{z}$ & $\mathrm{m} / \mathrm{z}$ & $\mathrm{V}$ & $\mathrm{V}$ & $\mathrm{kV}$ & $\mathrm{sec}$ \\
\hline 6-thio-urinezuur & neg & 182.9 & 140.1 & 35 & 15 & 0.25 & 0.1 \\
${ }^{13} \mathrm{C}_{1}$-6-thiourinezuur & neg & 184.1 & 141 & 35 & 15 & 0.25 & 0.1 \\
6-thioguanine & pos & 167.8 & 150.7 & 40 & 19 & 3.5 & 0.005 \\
6-methyl-thioguanine & pos & 181.8 & 133.8 & 40 & 20 & 3.5 & 0.005 \\
6-mercaptopurine & pos & 152.7 & 118.9 & 40 & 20 & 3.5 & 0.005 \\
${ }^{13} C_{1}$-6-mercaptopurine & pos & 153.7 & 119.9 & 40 & 20 & 3.5 & 0.005 \\
6-methyl-mercaptopurine & pos & 166.8 & 151.8 & 40 & 22 & 3.5 & 0.005 \\
6- $\mathrm{D}_{3}$-methyl-mercaptopurine & pos & 169.8 & 151.6 & 30 & 25 & 3.5 & 0.005 \\
\hline
\end{tabular}

Cone: Cone voltage; collision: Collision cell voltage ; CV : capillary voltage ; DT : dwell time ; mode : detection mode 


\section{Linearity and recovery}

All compounds were added to water and three different urine and plasma samples to establish linearity in the expected range of 0-5 $\mu \mathrm{M}$. For quantification stable isotope labelled internal standards were used, for 6-TG and 6-MTG we used ${ }^{13} \mathrm{C}_{1}-6-\mathrm{MP}$ and $6-D_{3}-M M P$ respectively as internal standards. Recovery of the compounds of interest was deduced from the slope of the calibration curves. The limit of detection (LOD) was determined in water at a signal to noise ratio $(S / N)$ of 3 , for the limit of quantification the lower limits were determined in urine and plasma samples at $\mathrm{S} / \mathrm{N}$ of 10 .

\section{Intra- and inter-assay variability}

The intra-assay variation was determined by 10 consecutive analysis of spiked plasma and urine samples, samples were spiked with low $(0.3 \mu \mathrm{mol} / \mathrm{l})$, medium $(1.2 \mu \mathrm{mol} / \mathrm{l})$ and high $(3.0 \mu \mathrm{mol} / \mathrm{l})$ concentrations of thiopurine metabolites. The inter-assay variation was determined by measuring the spiked urine and plasma samples on 10 consecutive days.

\section{Results}

\section{Chromatography}

Baseline separation for the compounds of interest was achieved within 8 minutes, using the gradient conditions listed in Table 3.1. In Figure 3.1 a chromatogram of a standard solution of thiopurine metabolites is shown.

\section{Linearity}

Concentrations of the thiopurine metabolites were linear up to $10 \mu \mathrm{M}$, either in water, plasma and urine $\left(R^{2}>0.99\right)$. Recoveries were $100 \pm 5 \%$ for the compounds measured using this method. In Figure 3.2 the addition curves for 6-TU in urine and plasma are shown. The curves for the other compounds were comparable (data not shown).

\section{Precision/accuracy}

Intra- and inter-assay variations for the plasma samples at the different concentrations were between 2.8 and $4.8 \%$ for all compounds for the low concentrations and between 1.8 and $3.7 \%$ for the high concentrations. Intra-assay variation in urine was comparable to plasma. In urine only the methylated thiopurines were stable, and showed a reasonable inter-assay variation. Inter-assay variations for thiopurines could not be established. In Table 3.2 the intra- and inter-assay variations for 6-TU, 6-MP and 6-MMP in plasma and urine are shown. 


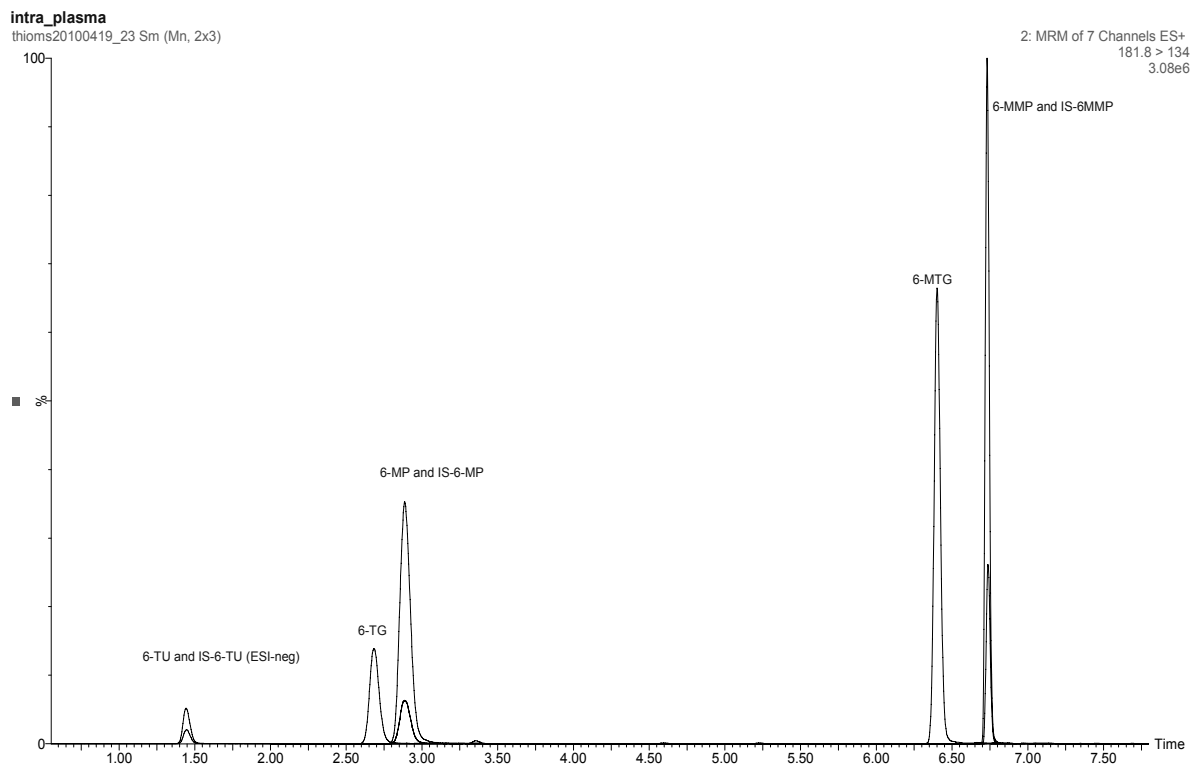

Figure 3.1 LC-MSMS chromatogram of thiourine metabolites. Experimental conditions are described in the methods section.

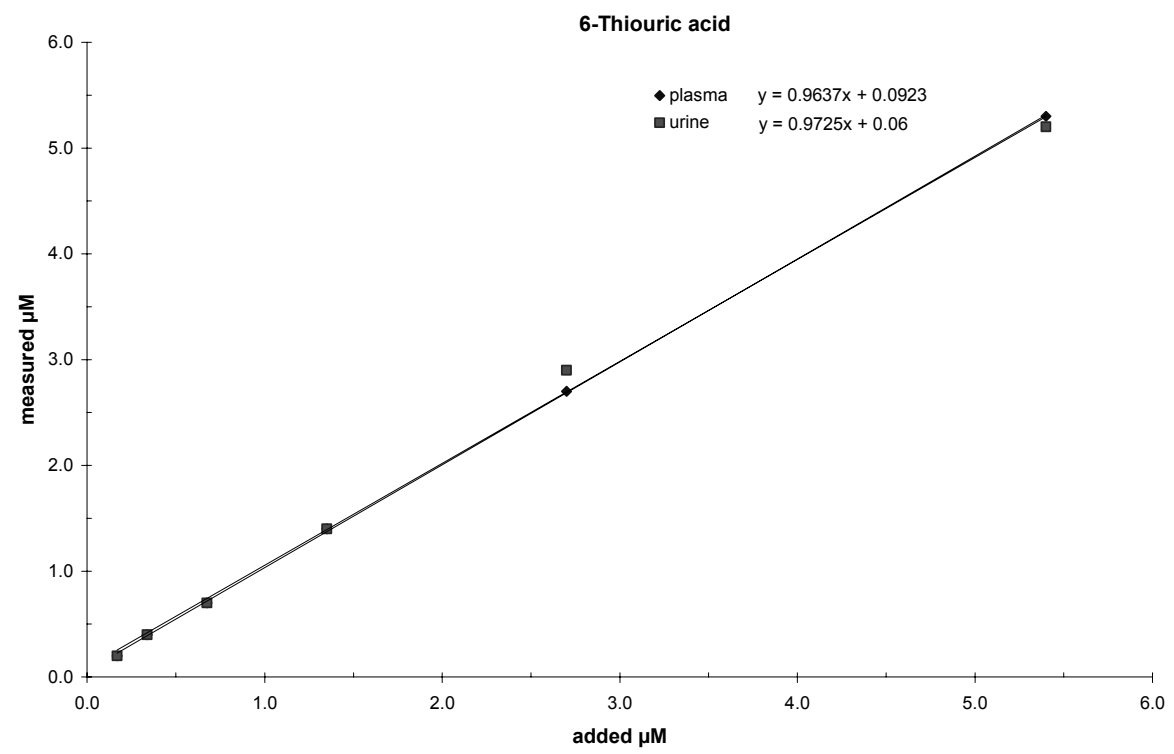

Figure 3.2 Addition curves for 6-TU in urine and plasma. 
Table 3.2 Intra- and inter-assay variation (\%) for 6-TU , 6-MP and 6-MMP in urine and plasma.

\begin{tabular}{lcccccc}
\hline Matrix & \multicolumn{2}{c}{ 6-TU } & \multicolumn{2}{c}{ 6-MP } & \multicolumn{2}{c}{ 6-MMP } \\
& Intra & Inter & Intra assay & Inter & Intra & inter \\
\hline Plasma low & 4.8 & 9.6 & 2.8 & 14.9 & 3.2 & 5.2 \\
Plasma medium & 4.2 & 8.9 & 3.6 & 6.4 & 2.8 & 6.9 \\
Plasma High & 1.8 & 5.6 & 1.9 & 7.3 & 3.7 & 4.7 \\
Urine low & 3.6 & 59 & 3.5 & 48 & 2.9 & 22 \\
Urine medium & 4.1 & 28 & 2.7 & 43 & 3.3 & 6.7 \\
Urine High & 2.3 & 51 & 2.1 & n.d. & 2.8 & 3.7 \\
\hline
\end{tabular}

\section{LOD/LOQ}

The limit of detection (LOD) of the different compounds was established after dissolving the compounds in water and injection of the solutions. As mentioned earlier, a $\mathrm{S} / \mathrm{N}$ ratio of 3 was used for the calculation of the LOD. The limit of quantification (LOQ) was established by adding the compounds of interest it plasma and urine samples. LOQ was set at $\mathrm{S} / \mathrm{N}$ ratio 10 . The LOD and LOQ for the different compounds are shown in Table 3.3.

Table 3.3 Limits of detection and quantification of thiopurine metabolites.

\begin{tabular}{lccc}
\hline Compound & LOD (nmol/I) & \multicolumn{2}{c}{ LOQ (nmol/I) } \\
& & Urine & Plasma \\
\hline 6-thiouric acid & 30 & 200 & 100 \\
6-mercaptopurine & 30 & 200 & 100 \\
6-thioguanine & 30 & 200 & 100 \\
6-methylmercaptopurine & 10 & 75 & 50 \\
6-methylthioguanine & 10 & 75 & 50 \\
\hline
\end{tabular}

\section{Sample stability}

Plasma and urine samples were spiked with 6-TU, 6-MP, 6-TG, 6-MMP and 6-MTG and used as control samples for metabolite sample stability, samples were divided into 500 $\mu \mathrm{l}$ aliquots and stored at $-20^{\circ} \mathrm{C}$. In plasma all metabolites were stable over a period of 2 months when the samples were stored at $-20^{\circ} \mathrm{C}$. In urine methylated thiopurines, 6-MMP and 6-MTG were stable, the thiopurine metabolites with a reactive sulfhydrylgroup, 6-TU, 6-MP and 6-TG were very unstable. Within 3 weeks the concentrations of 6-MP and 6-TG decreased to $10 \%$ of the original concentrations. The decrease of 6-TU was $~ 50 \%$. Addition of EDTA and acidification of the urine before storage did not prevent the degradation of the sulfhydryl metabolites. 


\section{Thiopurine metabolites in patient samples}

Urine and plasma samples from patients treated with thiopurine medication were analysed with the above described method. In urine 6-TUA and 6-MP were present in concentrations ranging from $0.2 \mu \mathrm{M}$ to $30 \mu \mathrm{M}$, depending on dose and co-medication. 6-MMP, 6-TG and 6-MTG were only present in trace amounts. In plasma 6-TUA and 6-MP were detectable, with maximum concentrations of $1 \mu \mathrm{M}$ for 6-TU and $1.5 \mu \mathrm{M}$ for 6-MP. It must be taken into account that the plasma samples were random samples. The other metabolites were below the limit of detection. In control samples, both urine and plasma, we could not detect thiopurine metabolites.

\section{Discussion}

The introduction of liquid chromatography tandem mass spectrometry (LC-MSMS) in clinical laboratory medicine has overcome a lot of the drawbacks of the earlier separation and detection methods ${ }^{15}$. One of the cornerstones of a reliable LC-MSMS method is the availability of stable isotope labelled standards, as was recently shown by our group in a report on the quantitative determination of amino acids in body fluids ${ }^{16}$.

HPLC with UV-detection is currently the standard method for the determination of free and total thiopurine metabolites in urine and plasma ${ }^{14,17}$. These methods have their drawbacks and the results must be interpreted carefully, ${ }^{6,18}$. Because of the relative low specificity of UV detection, we developed a stable isotope dilution based LC-MSMS method for the quantification of thiopurine bases and nucleosides in urine and plasma. From the results obtained with our method it can be concluded that the thiopurine bases and corresponding nucleosides can easily be detected and quantified in urine and plasma. Recoveries, both in urine and plasma, were within acceptable limits. Limits of quantification, using the conditions described above, were set at $200 \mathrm{nmol} / \mathrm{l}$, both in plasma and urine, although limits of determination of $50 \mathrm{nmol} / \mathrm{l}$ for $6-\mathrm{MP}$ were easily attainable. As was expected, thiopurine metabolites were not detectable in samples from patients who did not receive thiopurine therapy. In patients with inflammatory diseases using thiopurines as an anti-inflammatory drug, the metabolites were easily detected. From our results on the stability of the thiopurine bases and nucleosides we concluded that the sulfhydryl compounds were unstable in urine. Sulfhydryl groups are reactive and prone to oxidation and reactions with other reactive groups ${ }^{19}$. A similar phenomenon we have experienced with the measurement of free homocysteine in urine (data not shown). In plasma the sulfhydryl compounds are mainly protein bound to other sulfhydryl compounds in the protein (cysteine-groups) and can be liberated by reduction of the S-S bond by TCEP. Although thiopurines are cleared from the circulation within 3-4 hours after administration, they are detectable in low concentrations in plasma. It is apparent that only a part of the administered 6-MP is 
absorbed in the gastrointestinal tract. $80 \%$ of the circulating 6-MP is metabolised to 6 -TU and only $25 \%$ of the dose is effectively absorbed in the intestine and will enter the activation, deactivation or degradation pathways ${ }^{2}$

In conclusion we have developed a simple and fast method for the determination of thiopurine bases and nucleosides in biological fluids. Furthermore this method can be used for monitoring therapy compliance to thiopurine therapy using urinary 6-TU as a biomarker. 


\section{References}

1. Derijks LJ, Gilissen LP, de Boer NK, Mulder CJ. 6-Thioguanine-related hepatotoxicity in patients with inflammatory bowel disease: dose or level dependent? J Hepatol 2006;44:821-2..

2. Sahasranaman S, Howard D, Roy S. Clinical pharmacology and pharmacogenetics of thiopurines. Eur J Clin Pharmacol 2008;64:753-67.

3. Halloran PF. Immunosuppressive drugs for kidney transplantation. N Engl J Med 2004;351:2715-29.

4. Bakker JA, Drent M, Bierau J. Relevance of pharmacogenetic aspects of mercaptopurine metabolism in the treatment of interstitial lung disease. Curr Opin Pulm Med 2007;13:458-63.

5. Zhou S. Clinical pharmacogenomics of thiopurine S-methyltransferase. Curr Clin Pharmacol 2006;1: 119-28.

6. Duley JA, Florin TH. Thiopurine therapies: problems, complexities, and progress with monitoring thioguanine nucleotides. Ther Drug Monit 2005;27:647-54.

7. de Boer NK, Wong DR, Jharap B, de Graaf P, Hooymans PM, Mulder CJ, Rijmen F, Engels LG, van Bodegraven AA. Dose-dependent influence of 5-aminosalicylates on thiopurine metabolism. Am J Gastroenterol 2007;102:2747-53.

8. Bruunshuus I, Schmiegelow K. Analysis of 6-mercaptopurine, 6-thioguanine nucleotides, and 6-thiouric acid in biological fluids by high-performance liquid chromatography. Scand J Clin Lab Invest 1989; 49:779-84.

9. Dervieux T, Brenner TL, Hon YY, Zhou Y, Hancock ML, Sandlund JT, Rivera GK, Ribeiro RC, Boyett JM, Pui $\mathrm{CH}$, Relling MV, Evans WE. De novo purine synthesis inhibition and antileukemic effects of mercaptopurine alone or in combination with methotrexate in vivo. Blood 2002;100:1240-7.

10. Lennard L. The clinical pharmacology of 6-mercaptopurine. Eur J Clin Pharmacol 1992;43:329-39.

11. Keuzenkamp-Jansen CW, De Abreu RA, Bokkerink JP, Trijbels JM. Determination of extracellular and intracellular thiopurines and methylthiopurines by high-performance liquid chromatography. J Chromatogr B Biomed Appl 1995;672:53-61.

12. Chan GL, Erdmann GR, Gruber SA, Stock P, Chen S, Ascher NL, Canafax DM. Pharmacokinetics of 6thiouric acid and 6-mercaptopurine in renal allograft recipients after oral administration of azathioprine. Eur J Clin Pharmacol 1989;36: 265-71.

13. Jackson PJ. Determination of 6-thiouric acid in human urine. Clin Biochem 1983;16:285-6.

14. Hawwa AF, Millership JS, Collier PS, McElnay JC. Development and validation of an HPLC method for the rapid and simultaneous determination of 6-mercaptopurine and four of its metabolites in plasma and red blood cells. J Pharm Biomed Anal 2009;49:401-9.

15. Pitt JJ. Principles and applications of liquid chromatography-mass spectrometry in clinical biochemistry. Clin Biochem Rev 2009;30:19-34.

16. Waterval WA, Scheijen JL, Ortmans-Ploemen MM, Habets-van der Poel CD, Bierau J. Quantitative UPLC-MS/MS analysis of underivatised amino acids in body fluids is a reliable tool for the diagnosis and follow-up of patients with inborn errors of metabolism. Clin Chim Acta 2009;407:36-42.

17. de Boer NK, Derijks LJ, Keizer-Garritsen JJ, Lambooy LH, Ruitenbeek W, Hooymans PM, van Bodegraven $A A$, de Jong DJ. Extended thiopurine metabolite assessment during 6-thioguanine therapy for immunomodulation in Crohn's disease. J Clinical Pharmacol 2007; 47:187-91.

18. Armstrong VW, Shipkova M, von Ahsen N, Oellerich M. Analytic aspects of monitoring therapy with thiopurine medications. Ther Drug Monit 2004;26:220-6.

19. Hansen RE, Winther JR. An introduction to methods for analyzing thiols and disulfides: Reactions, reagents, and practical considerations. Anal Biochem 2009;394:147-58. 



\section{Chapter 4}

\section{Azathioprine induced pneumonitis in a patient with ulcerative colitis}




\section{Abstract}

Immunomodulator therapy with the thiopurine analogues azathioprine (AZA) or 6-mercaptopurine (6-MP) is commonly prescribed for maintenance of remission in inflammatory bowel disease (IBD).

Ten to twenty-five percent of patients have to withdraw from AZA or 6-MP due to adverse events that are partly explained by the relative activity of the drug metabolizing enzymes. Most of the potential major adverse events (myelosuppression, hepatotoxicity and pancreatitis) are well known. Pulmonary toxicity is rare but severe and may lead to respiratory insufficiency and even death. We describe a case of a young woman with ulcerative colitis (UC) who developed respiratory symptoms and fever combined with nodular densities and ground glass areas in both lungs on CT scan. An infection was ruled out and the diagnosis azathioprine induced pneumonitis was made. The drug was stopped and within one week her fever and respiratory symptoms resolved. Clinicians should be alert to this serious adverse event when treating patients with thiopurines. 


\section{Introduction}

The thiopurines azathioprine (AZA) and 6-mercaptopurine (6-MP) are frequently used as immunomodulating drugs in inflammatory bowel disease (IBD) patients. In both Crohn's disease (CD) and ulcerative colitis (UC) thiopurines have proven to be efficacious as maintenance therapy and are steroid sparing, nevertheless up to $20 \%$ of patients have to discontinue therapy because of adverse events ${ }^{1-3}$. These adverse events can be divided in two categories: dose dependent reactions which are the direct result of altered activity of one of the drug metabolizing enzymes thiopurine-Smethyltransferase (TPMT), xanthine oxidase (XO) or inosine triphosphate pyrophosphatase (ITPase) and subsequently formation of an excess of potentially toxic metabolites and secondly dose independent allergic or hypersensitivity reactions ${ }^{4}$. The first category side effects are well known and include myelosuppression, hepatotoxicity and general symptoms like malaise and nausea. The dose independent idiosyncratic reactions are less frequent and include symptoms like fever, rash, arthralgias and pancreatitis ${ }^{5}$. Severe pulmonary toxicity is rare. We describe a case of a young woman with ulcerative colitis and an allergic pneumonitis on AZA and review the current literature.

\section{Case report}

Our patient is a 40-year-old female known with left-sided ulcerative colitis since 2007. Her other medical history is unremarkable. She was initially treated with mesalazine/beclomethason diproprionate enemas and oral mesalazine $3 \mathrm{~g}$ daily. Because of a refractory disease with frequent stools and rectal blood loss, sigmoidoscopy was performed and showed a distal $(0-25 \mathrm{~cm})$ ulcerative colitis Mayo score 3. Biopsies showed no CMV and infectious colitis was ruled out with a stool culture. A course of oral corticosteroids (starting dose $40 \mathrm{mg}$, gradually tapered) was started combined with azathioprine (AZA) $(2 \mathrm{mg} / \mathrm{kg})$ and mesalazine was discontinued at that point. Monitoring of complete blood count, liver enzymes and lipase was performed according to protocol one week, two weeks and one month after the start of thiopurine therapy and no abnormal values were found. Five weeks after starting prednisone (current dose $10 \mathrm{mg}$ ) and AZA she developed fever, dry cough and shortness of breath. At that time she had no abdominal complaints. An initial course of antibiotics did not improve her symptoms. Physical examination revealed a tachycardia but lung sounds were clear, no skin rash was present. Laboratory results showed a decreased white blood cell count $\left(2.4 \times 10^{9} / \mathrm{l}\right)$ and hemoglobin concentration $(5.4 \mathrm{mmol} / \mathrm{l})$. Platelets were normal. C-reactive protein was $103 \mathrm{mg} / \mathrm{l}$ (normal value $<10 \mathrm{mg} / \mathrm{l}$ ). Liver enzymes including aminotransferases were increased (AST $60 \mathrm{U} / \mathrm{l}$; normal value $<30 \mathrm{U} / \mathrm{I}$, ALT $64 \mathrm{U} / \mathrm{l}$; normal value <35 U/I). TPMT activity in erythrocytes was decreased: $0.28 \mu \mathrm{mol} / \mathrm{mmol} \mathrm{Hb} / \mathrm{h}$ (reference $0.43 \pm 0.07$ ). DNA-analysis revealed $* 1 /{ }^{*} 3$ C TPMT genotype compatible with intermediate TMPT enzyme activity. 
Chest X-ray was normal, but an additional CT-scan revealed multiple nodular densities surrounded by ground glass areas in the apical part of both lungs (Figures 4.1 and 4.2). Subsequently a bronchoscopy with bronchoalveolar lavage was performed. The lavage fluid mainly contained lymphocytes and macrophages and all cultures were negative. Specific tests for viruses, fungi, mycobacteria, Pneumocystis jiroveci, Legionella pneumophilia and ricketsiae were also negative and the diagnosis azathioprineinduced pneumonitis was made. AZA was discontinued three days after onset of fever, prednisone was continued in the current dose of $10 \mathrm{mg}$ and tempered and stopped two weeks later. Within four days after admission to the hospital her fever resolved and respiratory symptoms decreased. Leukocyte count returned to normal within two weeks after discontinuation of AZA. She was not treated with intensified prednisone dosage because no hypoxemia was present. One month later she had recovered completely. Mesalazine was restarted as maintenance therapy for the ulcerative colitis. So far no flares have occurred.

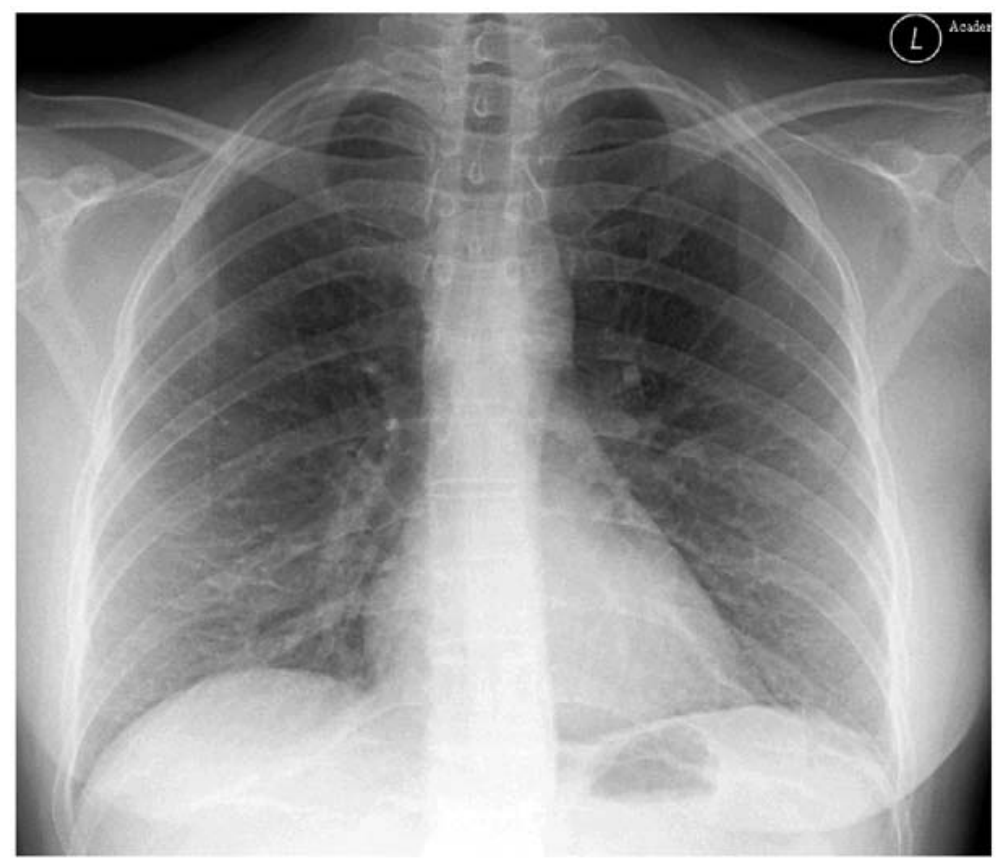

Figure 4.1 Normal chest radiogram. 


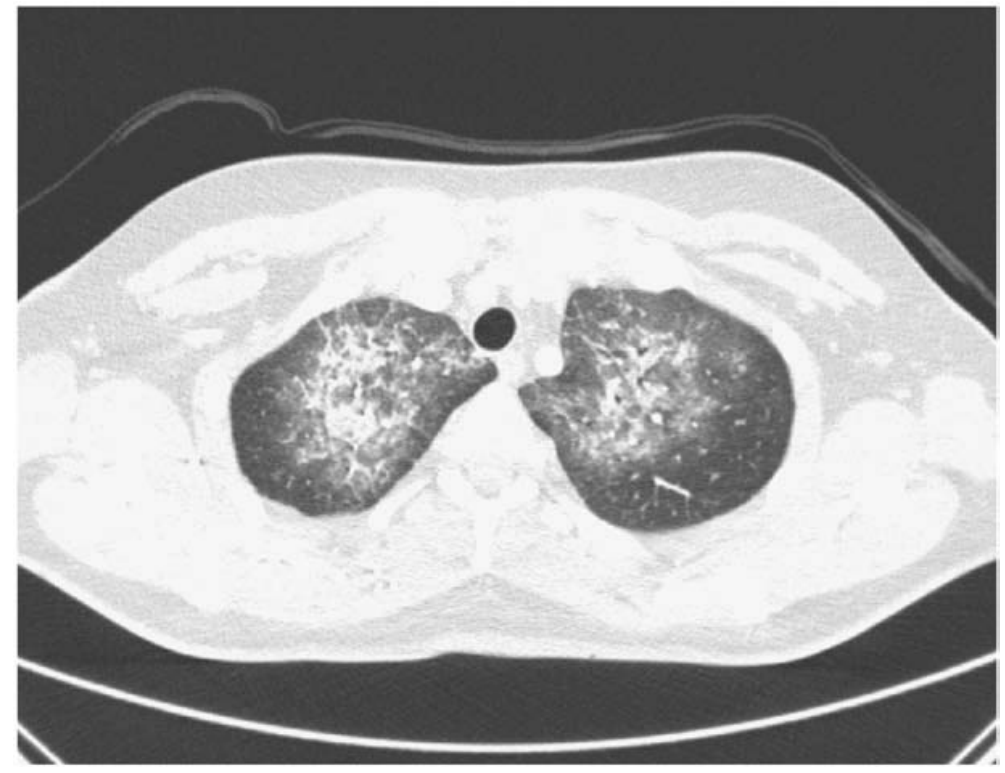

Figure 4.2 High resolution CT scan of chest shows confluencing.

\section{Discussion}

We report a case of lung toxicity of AZA in a young patient with UC. This side effect is only incidentally reported in literature but can be severe and even lethal. Our patient developed pulmonary symptoms five weeks after the initiation of AZA. Cessation of the thiopurine resulted in rapid improvement of symptoms. Most cases of pulmonary toxicity attributed to AZA were reported in patients after renal allograft transplantation. The largest series was published in 1984 by Bedrossian et al. regarding seven patients with diffuse alveolar damage and usual interstitial pneumonitis taking AZA after kidney transplantation. Four of the seven patients died of adult respiratory distress syndrome ${ }^{6,7}$. Diffuse alveolar hemorrhage due to severe AZA induced myelosuppression was also described ${ }^{8}$. During the last 35 years seven cases of pulmonary toxicity in IBD patients on immunosuppressive therapy with thiopurines have been described (Table 4.1).

The majority of the patients were treated with AZA, only one paper reports the use of 6-MP. Most of the IBD patients with reported lung toxicity were men (86\%; $6 \mathrm{M} / 1 \mathrm{~F}$ ). Four patients had CD and three patients were diagnosed with UC. Median age was 41 years (range 18-71). Interestingly the white blood cell count was normal or increased in most cases in contrast to our patient who had a leucopenia due to decreased activity of the TPMT enzyme. 
Patients with * $1 /{ }^{*} 3 C$ TPMT genotype inherit one wild type allele and one mutant allele and have intermediate TPMT enzyme activity. The risk of acute or delayed myelosuppression (mainly leucopenia) is increased in these patients and warrant strict blood monitoring and possibly dose adjustment of AZA or 6MP.

Table 4.1 Cases pulmonary toxicity thiopurines in IBD patients.

\begin{tabular}{|c|c|c|c|c|c|c|c|}
\hline Author ${ }^{\text {(ref) }}$ & $\begin{array}{l}\mathrm{UC} / \\
\mathrm{CD}\end{array}$ & $\begin{array}{l}\text { Age / } \\
\text { sex }\end{array}$ & $\begin{array}{l}\text { AZA / } \\
6 \mathrm{MP}\end{array}$ & Dosage & $\begin{array}{l}\text { Interval between } \\
\text { start therapy and } \\
\text { symptoms }\end{array}$ & $\begin{array}{l}\text { Concommitant } \\
\text { medication }\end{array}$ & $\begin{array}{l}\text { WBC } \\
\left(\times 10^{9} / I\right)\end{array}$ \\
\hline Rubin $^{13}$ & $C D$ & $20 / M$ & AZA & & 4 months & Prednisone & \\
\hline Krowka $^{14}$ & $C D$ & $35 / \mathrm{M}$ & AZA & $125 \mathrm{mg}$ & 4 months & Prednisone & 15,5 \\
\hline $\mathrm{Nagy}^{9}$ & UC & $41 / \mathrm{M}$ & AZA & $\begin{array}{l}150 \mathrm{mg} \\
(1,8 \mathrm{mg} / \mathrm{kg})\end{array}$ & 10 year & $\begin{array}{l}\text { Olsalazine, } \\
\text { methylprednisolone }\end{array}$ & 4,4 \\
\hline Ananthakrishnan ${ }^{10}$ & $C D$ & $66 / \mathrm{M}$ & $\begin{array}{l}\text { First AZA, } \\
\text { later } 6 \mathrm{MP}\end{array}$ & $50 \mathrm{mg}$ & 4 weeks & $\begin{array}{l}\text { Prednisone, } \\
\text { Infliximab } 3 \text { months } \\
\text { before }\end{array}$ & 8,4 \\
\hline & $C D$ & $71 / \mathrm{M}$ & AZA & $100 \mathrm{mg}$ & 4 weeks & \multicolumn{2}{|c|}{$\begin{array}{l}\text { Prednisone, infliximab, >20 } \\
\text { cyclosporine }\end{array}$} \\
\hline & UC & $43 / F$ & AZA & $100 \mathrm{mg}$ & 3 weeks & Prednisone & \\
\hline Katsenos $^{12}$ & UC & $18 / \mathrm{M}$ & AZA & $100 \mathrm{mg}$ & & Mesalazine & \\
\hline
\end{tabular}

The time interval between initiation of thiopurine therapy and the beginning of pulmonary symptoms and fever is in most cases one to four months but can even be years. Nagy et al. published in 2007 a case of a 41-year old man with UC who developed severe pulmonary disease related to AZA ten years after starting treatment. Despite discontinuation of AZA the interstitial inflammation was progressive and resulted in acute respiratory distress syndrome (ARDS) ${ }^{9}$. The largest case series of pulmonary toxicity during AZA/6-MP treatment in IBD patients was published in 2007. Three patients with IBD, two with CD and one with UC were described. They all had a longstanding history of IBD (4-12 years). In all patients AZA was started because of a flare under mesalamine maintenance or inability to taper corticosteroids. The starting dose was $50 \mathrm{mg}$ in one patient and $100 \mathrm{mg}$ in the two other patients. Pulmonary side effects started within four weeks after initiation of thiopurine therapy and symptoms were similar to the symptoms in our patient. Two patients required mechanical ventilation because of progressive hypoxemia despite additional treatment with intravenous corticosteroids. Rechallenge with 6-MP after initial allergic reaction to AZA led to severe pulmonary and systemic disease requiring mechanical ventilation in a 66 -year old man with CD. In two patients open lung biopsy was performed revealing usual interstitial pneumonitis with diffuse alveolar damage and bronchiolitis obliterans organizing pneumonia $(B O O P)^{10}$. Our patient was using mesalazine before starting treatment with AZA. The possibility of mesalazine hypersensitivity in our patient is 
unlikely since the drug was discontinued more than one month before the onset of the respiratory complaints and reintroduced without any problems after discontinuation of AZA. A wide variety of pulmonary manifestations besides (opportunistic) infections and drug-induced reactions is described in IBD patients. Pulmonary vasculitis, chronic bronchitis and bronchiolitis, fibrosing alveolitis or eosinophilic pneumonia should be considered as differential diagnosis in IBD patients presenting with dyspnea, cough or fever $^{11}$. The acute onset of complaints, quick recovery after discontinuation of AZA and no infectious etiology found, clearly favours AZA-induced pneumonitis in our patient. Our case highlights a potentially life-threatening side effect of thiopurine therapy. Interestingly a dose dependent drug reaction (myelosuppression) and an idiosyncratic reaction (pneumonitis) occurred simultaneously in this same patient. This has not been reported before. Clinicians should be aware of the possibility of a severe pulmonary adverse reaction besides opportunistic infections when patients present with pulmonary symptoms, fever and abnormalities on chest X-ray or CT-scan. A careful evaluation for potential infectious etiologies including bronchoscopy and bronchoalveloar lavage should first be performed. AZA or 6-MP should be discontinued immediately when lung toxicity is suspected. Clinical improvement is observed in most cases after cessation of thiopurine therapy. Corticosteroids should be considered as additional treatment in severe cases especially if hypoxemia is present. 


\section{References}

1. Adler DJ, Korelitz BI. The therapeutic efficacy of 6-mercaptopurine in refractory ulcerative colitis. Am J Gastroenterol 1990;85:717-22.

2. Sandborn WJ. A review of immune modifier therapy for inflammatory bowel disease: azathioprine, 6mercaptopurine, cyclosporine, and methotrexate. Am J Gastroenterol 1996;91:423-33.

3. Pearson DC, May GR, Fick GH, Sutherland LR. Azathioprine and 6-mercaptopurine in Crohn's disease. A meta-analysis. Ann Inter med 1995;123:132-42.

4. Derijks LJ, Gilissen LP, Hooymans PM, Hommes DW. Review article: thiopurines in inflammatory bowel disease. Aliment Pharmacol Ther 2006;24:715-29.

5. de Jong DJ, Derijks $\amalg$, Naber AH, Hooymans PM, Mulder CJ. Safety of thiopurines in the treatment of inflammatory bowel disease. Scand J Gastroenterol Suppl 2003;239:69-72.

6. Bedrossian CW, Sussman J, Conklin RH, Kahan B. Azathioprineassociated interstitial pneumonitis. Am J Clin Pathol 1984;82:148-54.

7. Carmichael DJ, Hamilton DV, Evans DB, Stovini PG, Calne RY. Interstitial pneumonitis secondary to azathioprine in a renal transplant patient. Thorax 1983;38:951-2.

8. Perri D, Cole DE, Friedman O, Piliotis E, Mintz S, Adhikari NK. Azathioprine and diffuse alveolar haemorrhage: the pharmacogenetics of thiopurine methyltransferase. Eur Respir J 2007;30:1014-7.

9. Nagy F, Molnar T, Makula E, Kiss I, Milassin P, Zollei E, Tiszlavicz L, Lonovics J. A case of interstitial pneumonitis in a patient with ulcerative colitis treated with azathioprine. World J Gastroenterol 2007;13:316-9.

10. Ananthakrishnan A, Atilla T, Otterson M, Lipchik R, Massey B, Komorowski R, Binion D. Severe pulmonary toxicity after azathioprine/ 6-mercaptopurine initiation for the treatment of inflammatory bowel disease. J Clin Gastroenterol 2007;41:682-8.

11. Storch I, Sachar D, Katz S. Pulmonary manifestations of inflammatory bowel disease. Inflamm Bowel Dis 2003;9:104-15.

12. Katsenos S, Psathakis K, Kokkonouzis I, Panagou P, Tsintiris K, Bouros D. Drug- induced pulmonary toxicity in a patient treated with mesalazine and azathioprine for ulcerative colitis. Acta Gastroenterol Belg 2007;70:290-2.

13. RubinG, Baume $P$, Vandenberg R. Azathioprine and acute restrictive lung disease. Aust N Z Med $1972 ; 2: 272-4$

14. Krowka MJ, Breuer RI, Kehoe TJ. Azathioprine-associated pulmonary dysfunction. Chest 1983;83:696-8. 


\section{Chapter 5}

\section{A comparative study of inosine triphosphatase activity in fresh erythrocytes and dried blood spots}

Parts of this chapter were published as

Bierau J, Bakker JA, Lindhout M, van Gennip AH

Determination of ITPase Activity in Erythrocyte Lysates Obtained for Determination of TPMT Activity. Nucleosides Nucleotides Nucleic Acids 2006; 25:1129-1132.

Bakker JA, Lindhout M, Dorland L, Bierau J. A comparative study of inosine triphosphatase activity in fresh erythrocytes and dried blood spots. Clinica chimica acta; international journal of clinical chemistry 2009; 405:155. 


\section{Abstract}

Inosine triphosphatase (ITPase) is one of the enzymes involved in thiopurine metabolism. Polymorphisms in the ITPA gene, resulting in a decreased activity of ITPase, are associated with adverse drug reactions during thiopurine therapy. Measuring ITPase activity is therefore of utmost importance. We compared measurement of ITPase activity in fresh erythrocyte lysates and eluates of dried blood spots (DBS). Upon storage up to 2 years at room temperature a fast decrease of ITPase activity in DBS was observed. The residual activity declined from $70 \%$ of the activity measured in fresh erythrocyte lysate 3 days after spotting to $~ 5 \%$ of after 2 years. Patients with an activity lowering polymorphism in the ITPA gene could still be detected in DBS after longer periods of storage at room temperature, using DBS of patients with a normal wild type activity, which were stored over the same period as reference. However, routine determination of ITPase activity in fresh erythrocyte lysates is preferred. 


\section{Introduction}

Thiopurines are used as cytotoxic drugs in the treatment of a variety of autoimmune mediated and lymphoproliferative diseases, e.g. inflammatory bowel disease (IBD), rheumatic diseases, dermatological conditions, sarcoidosis and childhood acute lymphatic leukemia $(A L L)^{1}$. The metabolism of thiopurines is a complex network of activation and deactivation, a tight balance being essential for therapeutic efficacy and avoidance of adverse drug reactions $(A D R)^{2-4}$.

One of the enzymes involved in thiopurine metabolism is inosine triphosphatase (ITPase). ITPase catalyses the conversion of inosine-5'-triphosphate (ITP) and deoxyinosine-5'-triphosphate (dITP) into the respective monophosphate esters. A concise outline of this pathway is shown in Figure 5.1A. The ITPA gene is a polymorphic gene $^{5}$. The effects of these polymorphisms on ITPase activity varies, as some have no influence, others result in a very low enzyme activity in the homozygous state. Deficiency of ITPase results in accumulation of intracellular ITP. Under normal physiological conditions ITPase deficiency does not lead to a clinical phenotype, so far it is considered a benign condition ${ }^{6,7}$.

In the last decade more insight has become available on the significance of ITPase in thiopurine metabolism. There is an increasing number of reports on the occurrence of ADR in combination with polymorphisms in the ITPA gene ${ }^{8,9}$. Recently we demonstrated that ITPase can hydrolyze 6-thioITP (TITP), the triphosphate which is formed through the phosphorylation of 6-thioinosine monophosphate (TIMP) by the intracellular mono- and diphosphate kinases ${ }^{10}$. This implies that ITPase is involved in thiopurine homeostasis (Figure 5.1B). In addition, it is generally assumed that thiopurine-S-methyltransferase (TPMT) is capable of methylating 6-thiolTP, resulting in the formation of methyl-6-thiolTP (MTITP). The clinical symptoms associated with accumulation of TITP and MTITP to cytotoxic levels are flu-like symptoms, rash and pancreatitis $^{9,11}$.

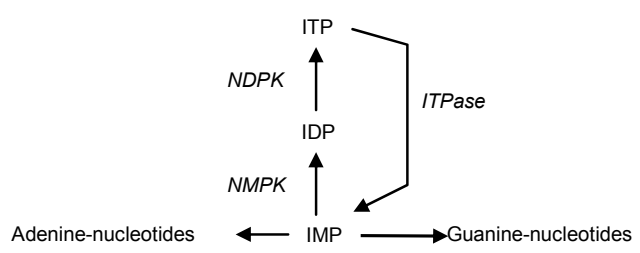

A

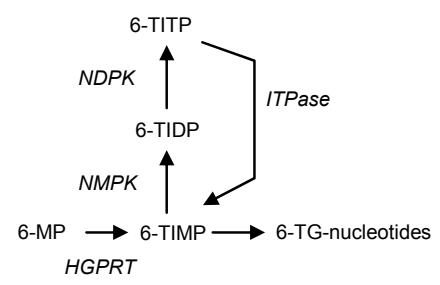

B

Figure 5.1 Role of ITPase in purine metabolism (simplified scheme), panel A physiological metabolism, panel B thiopurine metabolism. Abbreviations used: HGPRT: hypoxanthine-guanine phosphoribosyl transferase, IM/D/TP: inosinemono/di/triphosphate, ITPase: inosine triphosphatase, 6-MP: 6-mercaptopurine, NM/DPK: nucleotide mono/diphosphate kinase, 6-TG: 6-thioguanosine, 6-TIM/D/TP:6-thioinosinemono/di/triphosphate. 
In erythrocytes a relatively high activity of ITPase is present and therefore it is easily measured in erythrocyte lysates ${ }^{5}$. However, shipment of blood samples, both national and international, is subject to tight regulations and sometimes very cumbersome. For ease of transportation the use of dried blood spots (DBS) can be advocated. This urged us to study the feasibility of dried blood spots as a possible material for ITPase measurement.

In neonatal screening programs DBS are in use since the early 70's, phenylalanine being the first analyte measured in $\mathrm{DBS}^{12}$. In the following years the application of DBS was extended by measuring other metabolites and more complex molecules like steroids and thyroid hormones. In addition DBS proved to be suitable for enzyme diagnostics, particularly for lysosomal storage disorders ${ }^{13}$. Jacomelli et al. reported the use of DBS to measure enzymes involved in purine metabolism ${ }^{14}$. Recently Tomkova et al. described a capillary electrophoresis method for the determination of ITPase activity in DBS, proposing the use of DBS for routine measurement of ITPase activity ${ }^{15}$. We compared the ITPase activity in fresh erythrocyte lysates with the ITPase activity in DBS stored over longer periods, using samples from patients having a normal genotype and patients carrying activity lowering polymorphisms in the ITPA gene.

\section{Materials and methods}

IMP, ITP, hypoxanthine, hemoglobin and DTT were purchased from Sigma (Zwijndrecht, The Netherlands). Perchloric acid was purchased from J.T. Baker (Deventer, The Netherlands). $\mathrm{MgCl}_{2}, \mathrm{~K}_{2} \mathrm{CO}_{3}$ and $\left(\mathrm{NH}_{4}\right) \mathrm{H}_{2} \mathrm{PO}_{4}$ and $\left(\mathrm{NH}_{4}\right)_{2} \mathrm{HPO}_{4}$ were purchased from Merck (Amsterdam, The Netherlands). Tetrabutylammonium bi-sulphate (TBS) and Trizma base (Tris) were purchased from Fluka (Zwijndrecht, The Netherlands). Methanol (HPLC-grade) was purchased from Biosolve (Valkenswaard, The Netherlands). Ultrapure water was prepared in house (Advantage system, Millipore, Etten-Leur, The Netherlands) and used for the preparation of all solutions.

\section{Samples}

DBS were made from EDTA anticoagulated blood samples obtained for routine diagnostic purposes shortly after receipt of the sample. Blood was spotted onto newborn screening (NBS) cards and stored at room temperature. Erythrocyte lysates were made as previously described ${ }^{16,17}$. Lysates were stored at $-80^{\circ} \mathrm{C}$ prior to analysis.

\section{ITPase assay}

The ITPase assay was performed as previously described with minor modifications for the measurement in $\mathrm{DBS}^{16,17}$. DBS were incubated with $700 \mu \mathrm{l} 100 \mathrm{mM}$ Tris solution 
$\mathrm{pH} 8.5$ during $30 \mathrm{~min}$ at room temperature. The DBS eluate was transferred to a reaction vial and centrifuged for $10 \mathrm{~min}$ at $11.000 \times \mathrm{g} .165 \mu \mathrm{l}$ of the eluate was used to measure ITPase activity. All measurements were performed in duplicate. Reaction conditions were as described previously for fresh erythrocyte lysates ${ }^{16,17}$. Chromatographic separations were performed using an ion-pair reversed phase protocol (phosphate buffer $0.5 \mathrm{mM} \mathrm{pH} 7.0$ with TBS) on an Alliance binary HPLC system (Waters, Etten-Leur, The Netherlands) coupled with a Jasco 2077 multiwavelength UV/Vis detector (De Meern, The Netherlands) ${ }^{16}$. Data were sampled and analyzed using Totalchrom data acquisition and handling software (Perkin Elmer, Groningen, The Netherlands).

\section{Determination of DBS haemoglobin concentration}

Hemoglobin $(\mathrm{Hb})$ in fresh erythrocyte lysates was measured using a Coulter LH 750 hematology analyzer (Beckman Coulter, Woerden, The Netherlands). Hemoglobin in DBS lysates was measured using a Cary 50 Bio UV-Vis spectrophotometer, equipped with a Cary 50 MPR plate reader unit (Varian Scientific Instruments, Middelburg, The Netherlands). $110 \mu$ I DBS eluate was diluted with $220 \mu \mathrm{l} 100 \mathrm{mM}$ Tris buffer pH 8.5 and the $\mathrm{Hb}$ concentration in the DBS lysate was measured in triplicate and the absorbance at 416 and $640 \mathrm{~nm}$ was recorded. Corrected readings were used to calculate the $\mathrm{Hb}$ concentration against a calibration curve of hemoglobin in $100 \mathrm{mM}$ Tris $\mathrm{pH} 8.5^{18}$.

\section{Results}

The stability of ITPase activity in DBS was studied in the following experiment. Freshly drawn EDTA anticoagulated blood samples were divided in two portions. The first portion was used to isolate erythrocytes. The second portion was spotted onto NBS cards. The ITPase activity measured in erythrocyte lysates was set at $100 \%$. For a period of 45 days the ITPase activity in DBS was measured at regular intervals. Immediately after spotting and drying the ITPase activity in DBS was $70 \%$ of the activity measured in erythrocyte lysates. The ITPase activity declined to $10-20 \%$ within 2 months after spotting (Figure 5.2).

ITPA is a polymorphic gene, and hence there is a great diversity in ITPase activity in the general population ${ }^{5,17}$. Carriers of polymorphisms are easily identified by measuring ITPase activity in fresh erythrocyte lysates ${ }^{16}$. To test the possibility to discriminate between Wt ITPase activity and carriers of known polymorphisms using DBS, we measured the ITPase activity in DBS in patients with known genotypes. DBS between 165 and 910 days old were tested, using DBS of Wt patients spotted at the same time as reference (Figure 5.3). Table 5.1 shows that the relative activity in both the polymorphic DBS and the wild type DBS is comparable, and that carriers of enzyme activity lowering polymorphisms could be detected. 


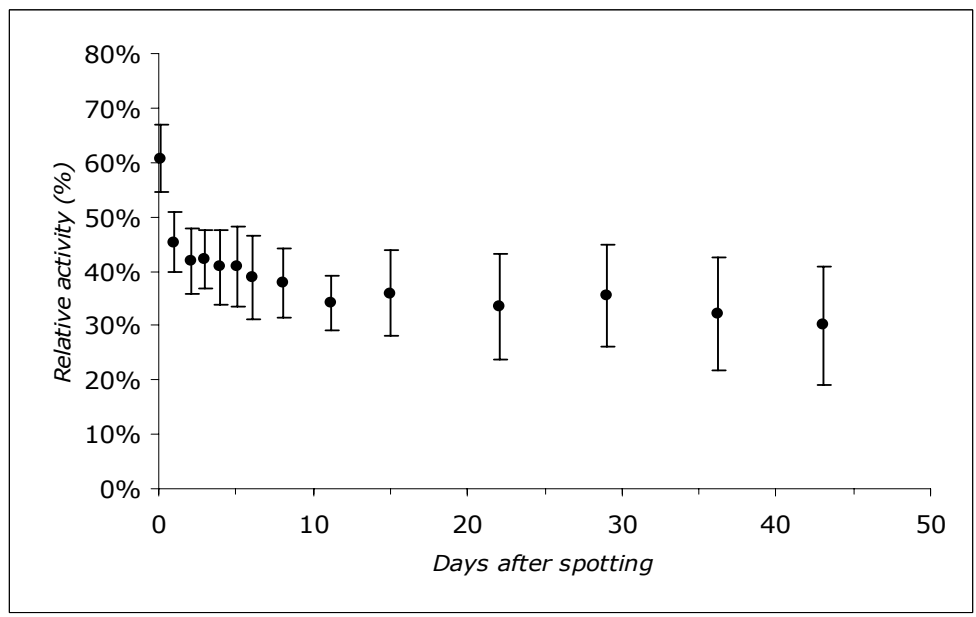

Figure 5.2 ITPase activity in DBS of healthy controls during time, expressed as percentage of the activity in fresh erythrocyte lysate.

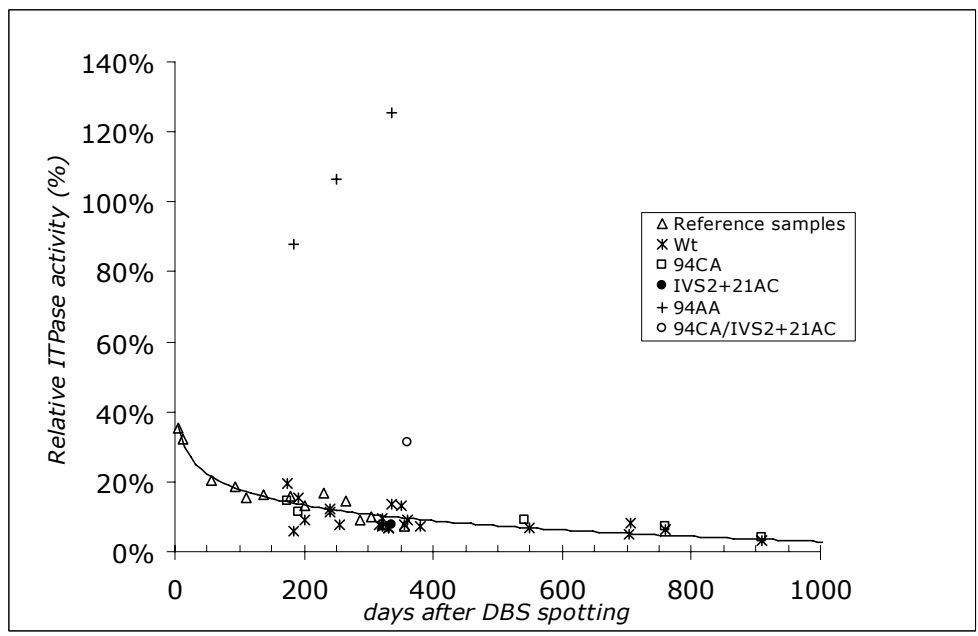

Figure 5.3 Evaluation of influence of storage time at room temperature on ITPase activity in DBS of randomly selected patients with normal ITPase activity and genotyped patients. Relative ITPase activity is calculated as a percentage of the ITPase activity in fresh erythrocyte lysates. 
Table 5.1 ITPase activity in DBS correlated to DNA polymorphism and time after spotting.

\begin{tabular}{|c|c|c|c|c|}
\hline DNA polymorphism & $\begin{array}{c}\text { Lysate activity } \\
\text { (mmol/mmol } \mathrm{Hb} / \mathrm{hr} \text { ) }\end{array}$ & Days after spotting & $\begin{array}{c}\text { DBS activity } \\
\text { (mmol/mmol } \mathrm{Hb} / \mathrm{hr} \text { ) }\end{array}$ & $\begin{array}{c}\text { Rel. activity } \\
(\%) \\
\end{array}$ \\
\hline $\mathrm{Wt}$ & 4.46 & 165 & 0.87 & 19.5 \\
\hline c. $94 \mathrm{C} \rightarrow \mathrm{A}$ & 2.36 & 165 & 0.34 & 14.5 \\
\hline Wt & 4.18 & 180 & 0.65 & 15.5 \\
\hline c. $94 \mathrm{C} \rightarrow \mathrm{A}$ & 1.44 & 180 & 0.16 & 11.2 \\
\hline Wt & 3.71 & 185 & 0.22 & 5.8 \\
\hline c. $94 \mathrm{C} \rightarrow \mathrm{A} /$ c. $94 \mathrm{C} \rightarrow \mathrm{A}$ & 0.03 & 185 & 0.03 & 88.1 \\
\hline Wt & 4.96 & 250 & 0.38 & 7.6 \\
\hline c. $94 \mathrm{C} \rightarrow \mathrm{A} /$ c. $94 \mathrm{C} \rightarrow \mathrm{A}$ & 0.04 & 250 & 0.04 & 106.5 \\
\hline Wt & 7.80 & 335 & 1.05 & 13.1 \\
\hline IVS $2+21 \mathrm{~A} \rightarrow \mathrm{C}$ & 2.00 & 335 & 0.15 & 7.6 \\
\hline c. $94 \mathrm{C} \rightarrow \mathrm{A} / \mathrm{c} .94 \mathrm{C} \rightarrow \mathrm{A}$ & 0.03 & 335 & 0.04 & 125.4 \\
\hline Wt & 4.38 & 360 & 0.9 & 9.0 \\
\hline c. $94 \mathrm{C} \rightarrow \mathrm{A} / \mathrm{IVS} 2+21 \mathrm{~A} \rightarrow \mathrm{C}$ & 0.26 & 360 & 0.08 & 31.1 \\
\hline Wt & 5.21 & 550 & 0.36 & 6.8 \\
\hline c. $94 \mathrm{C} \rightarrow \mathrm{A}$ & 2.44 & 550 & 0.22 & 9.0 \\
\hline Wt & 4.79 & 760 & 0.31 & 6.5 \\
\hline c. $94 \mathrm{C} \rightarrow \mathrm{A}$ & 1.90 & 760 & 0.14 & 7.2 \\
\hline Wt & 4.61 & 910 & 0.14 & 3.1 \\
\hline c. $94 \mathrm{C} \rightarrow \mathrm{A}$ & 1.19 & 910 & 0.05 & 4.1 \\
\hline Reference range & $3.0-11.0$ & & & \\
\hline
\end{tabular}

\section{Discussion}

From the results of our experiments it is obvious that measurement of ITPase activity in DBS is not as straightforward as supposed by Tomkova et al. ${ }^{15}$. The activity of ITPase in freshly prepared DBS is less than $70 \%$ of the lysate activity. Furthermore the decrease of activity in DBS is fast. Within 3 days after spotting the relative activity has declined to $30 \%$. This hampers the use of DBS for the determination of ITPase activity as on the average ordinary mail delivery will take $2-3$ days. In the case of patients with an activity of ITPase in fresh erythrocyte lysate at the lower end of the reference range, which in our laboratory is $3.0-11.0 \mathrm{mmol} \mathrm{IMP} / \mathrm{mmol} \mathrm{Hb} / \mathrm{hr}$ (based on $\mathrm{Wt}$ genotype), the measured activity in the DBS will easily decrease to intermediate values. Given the fact that intermediate values of ITPase are associated with ADR, it is obvious that using DBS may result in erroneous interpretation ${ }^{9,19,20}$. This may lead to suboptimal dosing of thiopurine medication.

Although the difference between normal and low activities still can be made, the older the DBS gets, the more difficult it will be. As can be seen from Table 5.1 patients homozygous for the $\mathrm{c} .94 \mathrm{C} \rightarrow \mathrm{A}$ polymorphism are still easily detected, because of the very low ITPase activity, both in fresh erythrocyte lysate as well as in DBS. However, more specifically the difference between intermediate values, due to heterozygousity for ITPA polymorphisms, and normal activities will not be apparent. An accompanying control DBS might overcome this problem, although one must be aware that $~ 10 \%$ of 
the Caucasian population is heterozygous for an ITPase activity lowering polymorphism ${ }^{5}$.

\section{Conclusion}

The results of our experiments demonstrate that ITPase activity can be measured in DBS without technical difficulties. We have demonstrated that immediately after spotting there was already a $30 \%$ loss of ITPase activity in DBS, which declined further and very rapidly to $30 \%$ residual activity in three days. The idea of DBS is to provide convenient mail order diagnostics. Considering the fact that regular (inter)national mail delivery requires 2-3 days at the minimum, reliable diagnostic measurement in DBS does not seem realistic. Therefore we strongly advocate measurement of ITPase activity in fresh erythrocyte lysates. 


\section{References}

1. Sahasranaman S, Howard D, Roy S. Clinical pharmacology and pharmacogenetics of thiopurines. Eur J Clin Pharmacol 2008;64:753-67.

2. Bakker JA, Drent M, Bierau J. Relevance of pharmacogenetic aspects of mercaptopurine metabolism in the treatment of interstitial lung disease. Curr Opin Pulm Med 2007;13:458-63.

3. Coulthard S, Hogarth L. The thiopurines: an update. Invest New Drugs 2005;23:523-32.

4. Weinshilboum R. Inheritance and drug response. N Engl J Med 2003;348:529-37.

5. Shipkova M, Lorenz K, Oellerich M, Wieland E, von Ahsen N. Measurement of erythrocyte inosine triphosphate pyrophosphohydrolase (ITPA) activity by HPLC and correlation of ITPA genotypephenotype in a Caucasian population. Clin Chem 2006;52:240-7.

6. Duley JA, Simmonds HA, Hopkinson DA, Levinsky RJ. Inosine triphosphate pyrophosphohydrolase deficiency in a kindred with adenosine deaminase deficiency. Clin Chim Acta 1990;188:243-52.

7. Vanderheiden BS. Human erythrocyte "ITPase": an ITP pyrophosphohydrolase. Biochim Biophys Acta 1970;215:555-8.

8. Maeda T, Sumi S, Ueta A, Ohkubo Y, Ito T, Marinaki AM, Kurono Y, Hasegawa S, Togari H. Genetic basis of inosine triphosphate pyrophosphohydrolase deficiency in the Japanese population. Mol Genet Metab 2005;85:271-9.

9. Marinaki AM, Duley JA, Arenas M, Ansari A, Sumi S, Lewis CM, Shobowale-Bakre M, Fairbanks LD, Sanderson J. Mutation in the ITPA gene predicts intolerance to azathioprine. Nucleosides Nucleotides Nucleic Acids 2004;23:1393-7.

10. Bierau J, Lindhout $M$, Bakker JA. Pharmacogenetic significance of inosine triphosphatase. Pharmacogenomics 2007;8:1221-8.

11. Marinaki AM, Ansari A, Duley JA, Arenas M, Sumi S, Lewis CM, Shobowale-Bakre el-M, Escuredo E, Fairbanks LD, Sanderson JD. Adverse drug reactions to azathioprine therapy are associated with polymorphism in the gene encoding inosine triphosphate pyrophosphatase (ITPase). Pharmacogenetics 2004;14:181-7.

12. Guthrie R. Screening for phenylketonuria. Triangle 1969;9:104-9.

13. Chamoles NA, Blanco M, Gaggioli D. Diagnosis of alpha-L-iduronidase deficiency in dried blood spots on filter paper: the possibility of newborn diagnosis. Clin Chem 2001;47:780-1.

14. Jacomelli G, Micheli V, Peruzzi L, Notarantonio L, Cerboni B, Sestini S, Pompucci G. Simple nonradiochemical HPLC-linked method for screening for purine metabolism disorders using dried blood spot. Clin Chim Acta 2002;324:135-9.

15. Tomkova J, Friedecky D, Vyskocilova P, Adam T. ITPase activity in dry blood spots is comparable with that in fresh erythrocytes. Nucleosides Nucleotides Nucleic Acids 2008;27:656-60.

16. Bierau J, Bakker JA, Lindhout M, van Gennip AH. Determination of ITPase Activity in Erythrocyte Lysates Obtained for Determination of Tpmt Activity. Nucleosides Nucleotides Nucleic Acids 2006;25:1129-32.

17. Sumi S, Marinaki AM, Arenas M, Fairbanks L, Shobowale-Bakre M, Rees DC, Thein SL, Ansari A, Sanderson J, De Abreu RA, Simmonds HA, Duley JA. Genetic basis of inosine triphosphate pyrophosphohydrolase deficiency. Hum Genet 2002;111:360-7.

18. Harboe M. A method for determination of hemoglobin in plasma by near-ultraviolet spectrophotometry. Scand J Clin Lab Invest 1959;11:66-70.

19. von Ahsen N, Armstrong VW, Behrens C, von Tirpitz C, Stallmach A, Herfarth H, Stein J, Bias P, Adler G, Shipkova M, Oellerich $M$, Kruis W, Reinshagen M, Schütz E. Association of inosine triphosphatase 94C >A and thiopurine S-methyltransferase deficiency with adverse events and study drop-outs under azathioprine therapy in a prospective Crohn disease study. Clin Chem 2005;51:2282-8.

20. Ansari A, Arenas M, Greenfield SM, Morris D, Lindsay J, Gilshenan K, Smith M, Lewis C, Marinaki A, Duley J, Sanderson J. Prospective evaluation of the pharmacogenetics of azathioprine in the treatment of inflammatory bowel disease. Aliment Pharmacol Ther 2008;28:973-83. 



\section{Chapter 6}

The effect of ITPA polymorphisms on the enzyme kinetic properties of human erythrocyte inosine triphosphatase towards its substrates ITP and 6-thio-ITP

Effects of ITPA polymorphism on ITPase kinetics

Bakker JA, Lindhout M, Habets DDJ, van den Wijngaard A, Paulussen ADC, Bierau J 


\section{Summary}

The role of inosine triphosphatase (ITPase) in adverse drug reactions associated with thiopurine therapy is still under heavy debate. Surprisingly little is known about the way thiopurines are handled by ITPase. We studied the effect of ITPA polymorphisms on handling of inosine triphosphate (ITP) and thioinosine triphosphate (TITP) to gain more insight in this phenomenon.

Human erythrocyte ITPase activity was measured by incubation with ITP, using established protocols and the generated IMP was measured using ion pair RP-HPLC. Molecular analysis of the ITPA gene was performed to establish the genotype. Kinetic parameters were established for the 2 common polymorphisms, both for ITP and TITP as substrates, using the above mentioned protocol.

Both ITP and TITP are substrates for ITPase and enzyme activities are for these substrates comparable. Substrate binding is not altered in the different ITPA polymorphisms. It is shown that the velocity of pyrophosphohydrolysis is compromised when the c.94C>A polymorphism is present, both in the heterozygous or homozygous state.

TITP is handled by ITPase in a similar way as ITP, which implies that TITP will accumulate in cells of patients with an ITPase deficiency, resulting in adverse drug reactions on thiopurine therapy. In carriers of ITPA polymorphisms the matter is more complex and the development of ADR may depend on additional, epigenetic, factors. 


\section{Introduction}

Thiopurines are purine anti-metabolites, widely used as anti-inflammatory agents. These compounds are activated and degraded by the enzymes of the purine pathways for activation, interconversion and degradation. One of the enzymes involved in this metabolism is inosine triphosphatase (ITP pyrophosphohydrolase; ITPase; EC 3.6.1.19). As is shown in Figure 6.1 ITPase is part of the inosine nucleotide cycle. The exact role of ITPase in mammalian metabolism is still unclear. Primarily ITPase plays an important role in the homeostasis of non-canonical purine nucleotides, in addition it is generally considered as a house keeping gene ${ }^{1,2}$. Deficiency of ITPase results in the intracellular accumulation of inosine triphosphate $(\text { ITP })^{3}$. The clinical consequences of this phenomenon are unknown as it is not related to overt pathology ${ }^{4}$.

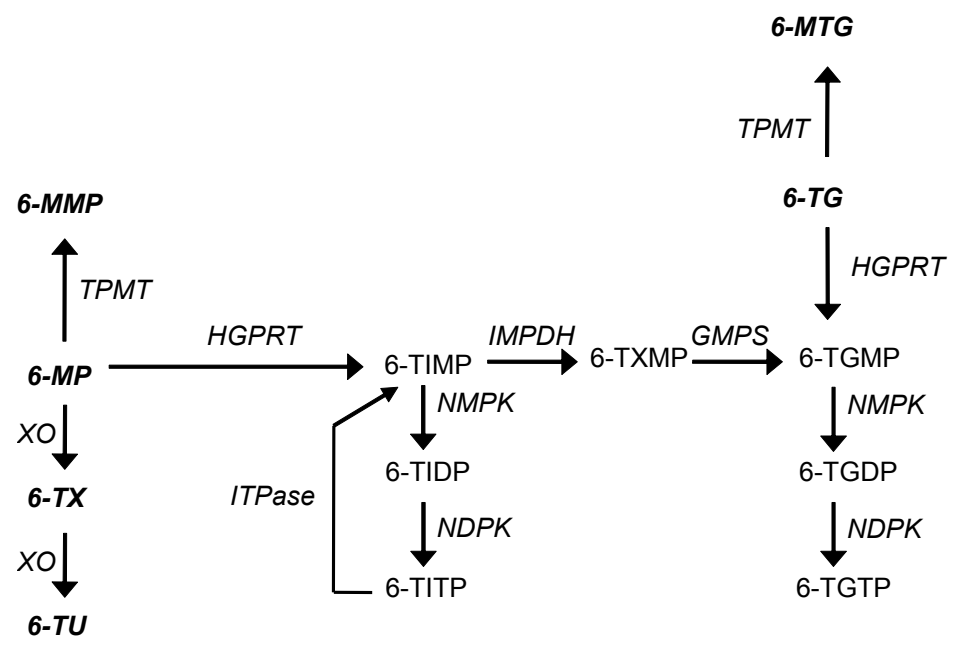

Figure 6.1 Concise scheme of thiopurine metabolism in mammals.

GMPS: Guaninemonophosphate synthase; HGPRT: Hypoxanthine-guanine phosphoribosyl transferase; IMPDH: Inosinemonophosphate dehydrogenase; ITPASE: Inosine triphosphatase; 6-MMP: 6-Methylmercaptopurine; 6-MP: 6-Mercaptopurine; 6-MTG: 6Methylthioguanine; ND/MPK: Nucleotide mono/diphosphatase kinase; 6-TG: 6-Thioguanine; 6-TGM/D/TP: 6-Thioguanine/di/triphosphate; 6-TIM/D/TP: 6-Thioinosinemono/di/ triphosphate; 6-TU: 6-Thiouric acid; 6-TX: 6-Thioxanthine; 6-TXMP: 6-Thioxanthosinemonophosphate.

We recently showed that 6-thio-inosinetriphosphate (TITP) is a substrate for human erythrocyte ITPase ${ }^{1}$. It is assumed that on thiopurine medication a diminished activity of ITPase leads to adverse drug reactions (ADRs), caused by the proposed undesired accumulation of TITP, and consecutively therapy failure ${ }^{5}$. At present the role of ITPA nucleotide polymorphisms in thiopurine induced ADRs is under debate and 
contradicting results have been published. In patients suffering from inflammatory bowel disease (IBD), the reported ADR associated with thiopurine therapy reported are pancreatitis, flu-like symptoms, leucopenia, rash and hepatotoxicity and appear to be associated with the c.94 C>A polymorphism ${ }^{5-7}$. The g.IVS2+21 A>C polymorphism was reported to be associated with thrombopenia ${ }^{8}$. Other studies in (paediatric) IBD and renal transplant populations did not reveal any side effects correlated to ITPA polymorphisms, as was reported in a meta-analysis of studies on ITPA polymorphisms and thiopurine toxicity ${ }^{9-11}$. However, the populations in the above mentioned studies differ greatly and the number of patients included in each study is limited, therefore not allowing definitive conclusions on the association of ITPA polymorphisms and $A D R^{12}$. Moreover, only very little mechanistic data are available on ITPase, providing insight in the binding and handling of its substrates, hereby making interpretation of the conclusions from the different studies even more difficult ${ }^{13,14}$. Recently the crystal structure of the enzyme was elucidated and the implications of the c.94C $>\mathrm{A}$ polymorphism in substrate handling predicted $^{15}$.

One of our major research topics is to elucidate the role of ITPase in thiopurine metabolism. From this perspective we studied the effect of the two common ITPA polymorphisms on the handling of ITP and TITP by human erythrocyte ITPase. In this study we established reference values for the different polymorphisms for the natural substrate ITP. In addition, we compared the pyrophosphohydrolysis of TITP in relation to that of ITP for these polymorphisms. For better understanding of these values the kinetic parameters for the pyrophosphohydrolysis, both for ITP and TITP, were determined for the different ITPA polymorphisms. This study is the first to establish TITP kinetics of human erythrocyte ITPase and the effect of polymorphisms in the ITPA gene on the kinetic properties of ITPase.

\section{Materials and Methods}

\section{Materials}

Recombinant human ITPase from an E. coli expression system, full length protein, 195 amino acids (\#AAH10138), was obtained from Abnova (Bioconnect, Huissen, The Netherlands). Thiopurinenucleotides were obtained from Sigma (Zwijndrecht, the Netherlands) or Jena Bioscience (Jena, Germany). Ultra-pure acetonitril was purchased from Biosolve (Valkenswaard, the Netherlands). All other chemicals were of the highest grade and purchased from Sigma (Zwijndrecht, the Netherlands). HPLC separations were performed on a Supelcosil LC-18 S column (Sigma, Zwijndrecht the Nethterlands), using an Alliance Separation system (Waters, Etten-Leur, the Netherlands) coupled to a Jasco Multi-Wavelength detector (Jasco Benelux, IJsselstein, 
The Netherlands). Data were analysed with the aid of Totalchrom data acquisition and handling software (Perkin-Elmer, Groningen, the Netherlands).

Hemoglobin content of erythrocyte lysates was measured using a Coulter LH-750 hematology analyzer (Beckman Coulter, Mijdrecht, The Netherlands).

\section{Patients}

Samples of patients referred to our laboratory for preventive pharmacogenetic testing of thiopurine-S-methyltransferase (TPMT) and ITPase were used in this study. The study was performed under local ethical standards on the use of patient samples for research.

\section{Measurement of erythrocyte ITPase activity and kinetic parameters}

Assays of ITPase activity in erythrocytes were performed as described earlier ${ }^{16,17}$. Briefly, erythrocytes were isolated after centrifugation. Saline washed erythrocytes were lysed with ice-cold water $(1: 4, \mathrm{v} / \mathrm{v})$ and the lysate was stored at $-80^{\circ} \mathrm{C}$ until ITPase measurement. Lysates were stable for $>3$ years and could withstand 3-4 thaw-freeze cycles before the ITPase activity dropped (data not shown). The erythrocyte lysate was incubated with ITP, $\mathrm{MgCl}_{2}$ and DTT in Tris- $\mathrm{HCl}$ buffer $(\mathrm{pH} 8.5)$ for 30 minutes at $37^{\circ} \mathrm{C}$. The end product, inosine monophosphate (IMP), was measured using ion-pair reversed-phase chromatography with UV-detection at $254 \mathrm{~nm}^{16}$. Activity was calculated using an external standard method and normalised to haemoglobin $(\mathrm{Hb})$ concentration. For the determination of the kinetic parameters for ITP and TITP the same method was used, with the exception of a slight modification of the solvent system and detection wavelength $(320 \mathrm{~nm})$ for the quantification of the thioinosine nucleotides. All kinetic experiments were performed in triplicate on three different samples per genotype.

\section{ITPA genotyping}

Genomic DNA was extracted from buffy coats using the Qiagen FlexiGene DNA kit (Qiagen, Venlo, The Netherlands) and the automated DNA isolation robot Autogenflex 3000 (Westburg, Leusden, The Netherlands).

Exon 2 of the ITPA gene and flanking intronic regions were amplified by PCR using primers ITPA2F-CTTTAGGAGATGGGCAGCAG and ITPA2R-CACAGAAAGTCAGGTCACAGG. PCR mix $(10 \mu \mathrm{l})$ consisted of $1 x$ Amplitaq Gold Mastermix (Applied Biosystems, Nieuwerkerk a/d IJssel, The Netherlands), 8\% glycerol and $200 \mathrm{nM}$ of each primer. PCR conditions were $40 \mathrm{cycli}$ and and $\mathrm{T}_{\text {an }}$ of $60^{\circ} \mathrm{C}$. The resulting $241 \mathrm{bp}$ PCR product was bidirectional sequenced using the $A B I$ Big Dye Terminator Cycle Sequencing Ready Reaction kit and the ABI3730 Genetic Analyzer (Applied Biosystems, Foster City, CA). Functional polymorphisms c.94 C>A (p.P32T) (NCBI rs1127354) and g.IVS2+21 A>C (NCBI rs7270101) were determined using DNA variant analysis software Mutation 
Surveyor with genomic NCBI reference sequence NC_000020. All sequences were evaluated by two independent laboratory experts.

\section{Results}

In total, 160 patients were fully characterized for ITPase activity and ITPA gene polymorphisms. The distribution of the ITPase activity in erythrocyte lysate for the different genotypes is shown in Figure 6.2. From this distribution it is apparent that there is a certain overlap in the activities measured in the different polymorphisms. No overlap was observed for the c.94 CA / g.IVS2+21 AC and c.94 AA / g.IVS2+21 AA genotypes, which both had significantly lower enzyme activities $(p<0.001$ with all other genotypes).

In our cohort of patients we identified two other, so far unknown, mutations. One point mutation, c.97 T>C, is located near the frequently occurring and activity lowering c.94 C>A polymorphism. In the individual heterozygous for this new mutation, the ITPase activity is decreased to values as detected in c.94 C>A heterozygotes: 1.20 and $1.43 \mathrm{mmol} \mathrm{IMP} / \mathrm{mmol} \mathrm{Hb} / \mathrm{hr}$ respectively. A second mutation, c.122 A>G, did not affect ITPase activity. A third patient had a nearly undetectable ITPase activity, but we only detected one polymorphic allele, harbouring the c.94C $>$ A mutation. Investigations are in progress in finding a possible second molecular aberration in the ITPA gene to explain the low ITPase activity in this patient.

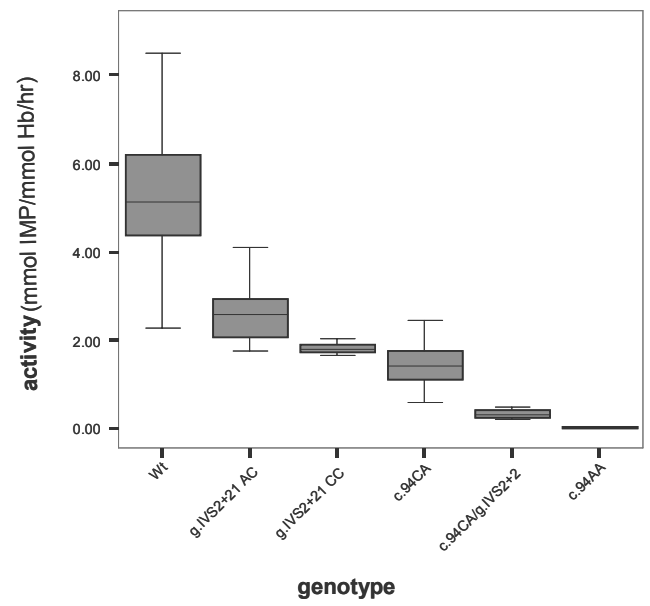

Figure 6.2 ITPase activity ( $\mathrm{mmol} \mathrm{IMP} / \mathrm{mmol} \mathrm{Hb} / \mathrm{hr})$ in different ITPA genotypes.

In Table 6.1 the correlation between ITPase activity and the most common activity lowering polymorphisms is displayed, compared with the relative activities published 
in the literature in the past years. As can be seen, our present results using ITP as the substrate are in line with those of other authors.

To investigate the selectivity of the different ITPA polymorphisms for the substrates ITP and TITP the kinetic properties $V_{\max }$ and apparent $K_{m}$ (further referred to as $K_{m}$ ) for these substrates were determined. The results of these experiments are shown in Table 6.2. The genotypes tested were the wild type, the compound heterozygous c.94 C>A/g.IVS2+21 A $>C$ variant, the homozygous g.IVS2+21 A $>C$ and the heterozygous c.94 C>A and g.IVS2+21 C>A genotypes. Because of the very low residual activity of the c.94 C>A homozygote the experiment was not performed for this genotype.

Table 6.1 Erythrocyte ITPase activity (mmol IMP/mmol $\mathrm{Hb} / \mathrm{hr}$ ) for the different ITPA genotypes, compared with relative activities derived from the literature.

\begin{tabular}{lcccccc}
\hline & \multicolumn{3}{c}{ Present study } & \multicolumn{3}{c}{ Literature } \\
\hline ITPA genotypes & $\mathrm{N}$ & Mean \pm SD & $\% W T$ & {$[17]$} & {$[18]$} & {$[19]$} \\
c.94 CC /g.IVS2+21 AA & 88 & $5.27 \pm 1.56$ & 100 & 100 & 100 & 100 \\
c.94 CC / g.IVS2+21 AC & 19 & $2.61 \pm 0.66$ & 49.5 & 58.6 & 61.0 & \\
c.94 CA /g.IVS2+21 AA & 39 & $1.43 \pm 056$ & 27.1 & 22.5 & 25.5 & 27.3 \\
c.94 CC / g.IVS2+21 CC & 3 & $1.81 \pm 0.19$ & 34.4 & & 29.8 & \\
c.94 CA / g.IVS2+21 AC & 6 & $0.32 \pm 0.10$ & 6.1 & 9.0 & 8.2 & 0.1 \\
c.94 AA / g.IVS2+21 AA & 5 & $0.00 \pm 0.05$ & 0.0 & & 0.0 \\
\hline
\end{tabular}

Table 6.2 Kinetic parameters for ITP and TITP for different ITPA polymorphisms.

\begin{tabular}{|c|c|c|c|c|c|c|}
\hline \multirow[t]{2}{*}{ ITPA genotypes } & \multicolumn{3}{|c|}{ ITP } & \multicolumn{3}{|c|}{ TITP } \\
\hline & $\mathrm{K}_{\mathrm{m}}$ & $\mathrm{V}_{\max }$ & $\mathrm{V}_{\max } / \mathrm{K}_{\mathrm{m}}$ & $\mathrm{K}_{\mathrm{m}}$ & $\mathrm{V}_{\max }$ & $\mathrm{V}_{\max } / \mathrm{K}_{\mathrm{m}}$ \\
\hline c. 94 CC / g.IVS2+21 AA & 201 & 5.44 & 27.1 & 346 & 5.95 & 17.2 \\
\hline c.94 CA / g.IVS2+21 AA & 162 & 0.98 & 6.1 & 313 & 1.43 & 4.5 \\
\hline c.94 CC / g.IVS2+21 AC & 144 & 4.0 & 27.4 & 576 & 2.82 & 4.9 \\
\hline c. 94 CA / g.IVS2+21 AC & 366 & 0.43 & 1.2 & 219 & 0.41 & 1.9 \\
\hline c. 94 CC / g.IVS2+21 CC & 170 & 1.54 & 9.1 & 164 & 1.73 & 10.5 \\
\hline
\end{tabular}

$\mathrm{K}_{\mathrm{m}}: \mu \mathrm{M}$ ITP or TITP; $\mathrm{V}_{\text {max }}: \mathrm{mmol}$ IMP or TIMP/mmol Hb/hr; $\mathrm{V}_{\max } / \mathrm{K}_{\mathrm{m}}: 1000 / \mathrm{mmol} \mathrm{Hb} / \mathrm{hr}$

The results showed that both ITP and TITP are substrates for ITPase. Pyrophosphohydrolysis of ITP and TITP followed Michaelis-Menten kinetics: this is shown in Figure 6.3 for the normal (wild-type) genotype. The other polymorphisms showed similar kinetic behaviour. 


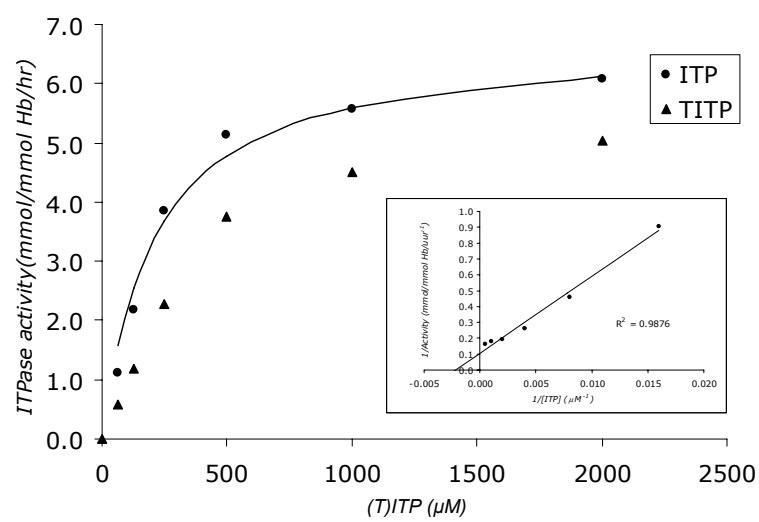

Figure 6.3 Michaelis-Menten kinetics of ITP and TITP in the normal ITPA genotype; insert Lineweaver Burk plot for ITP.

With the exception of the compound heterozygous c.94C $>A / g$.IVS $2+21 \mathrm{~A}>\mathrm{C}$ polymorphism where the binding was less efficient, the substrate binding for ITP was identical in the different genotypes investigated. The velocity of pyrophosphohydrolysis appeared to be genotype dependent: the wild type having the highest $\mathrm{V}_{\max }$, resulting in the most efficient generation of IMP. The heterozygous g.IVS $2+21 \mathrm{~A}>\mathrm{C}$ genotype showed a slightly lower efficiency in the hydrolysis of ITP, the efficiency further decreasing when the second allele is also polymorphic for the g.IVC2+21A>C mutation. The results of this experiment also showed the deleterious effect of the c.94C $>$ A mutation on the capacity of the protein to hydrolyse ITP. The protein resulting from the heterozygous c.94C $>A$ genotype hydrolyzes ITP about 5 times less efficient than the wild type protein. Combined with the g.IVS2+21A $>C$ allele the efficiency decreased to $5 \%$ of the wild type.

Our results for TITP showed that pyrophosphohydrolysis is as efficient as it is for the natural substrate ITP. To confirm this finding we measured human erythrocyte ITPase activity in the different genotypes using ITP and TITP as substrates. As can be seen in Table 6.3 the activities for ITP and TITP were comparable.

Table 6.3 Correlation between erythrocyte ITPase activity towards ITP and TITP in ITPA genotypes.

\begin{tabular}{lccc}
\hline $\begin{array}{l}\text { Substrate } \\
\text { ITPA genotypes }\end{array}$ & $\begin{array}{c}\text { ITP } \\
\text { Activity* }\end{array}$ & $\begin{array}{c}\text { TITP } \\
\text { Activity** }\end{array}$ & ratio \\
\hline c.94 CC /g.IVS2+21 AA & 2.94 & 2.90 & 0.99 \\
c.94 CA / g.IVS2+21 AA & 0.62 & 0.69 & 1.11 \\
c.94 CC /g.IVS2+21 AC & 1.99 & 2.03 & 1.02 \\
c.94 CA / g.IVS2+21 AC & 0.20 & 0.33 & 0.63 \\
c.94 CC /g.IVS2+21 CC & 0.94 & 1.28 & 0.73 \\
\hline
\end{tabular}

* mmol IMP/mmol Hb/hr;** mmol TIMP/mmol Hb/hr 


\section{Discussion}

The ITPA gene is a polymorphic gene, several polymorphisms are described in the literature, some influencing the ITPase activity and others having little or no effect. Since ITPA polymorphisms are associated with thiopurine ADR, it is important to obtain more insight on the effect of ITPA gene polymorphisms on the kinetic behaviour of ITPase, towards both ITP and TITP. We therefore established genotype defined reference values for ITPase in our population (Table 6.1). As is shown in this table, our reference values are in line with earlier published values. A selection of these samples were also used for the mechanistic experiments. To the best of our knowledge, this is the first report on kinetic data for ITPase proteins originating from a variety of genotypes directly obtained from human materials for both ITP and the alternative substrate TITP.

As is shown in Table 6.1 the patients carrying the c.94C>A polymorphism, either in the heterozygous or homozygous state, have significantly decreased erythrocyte ITPase activities. The deleterious effect of the c.94C >A polymorphism is clearly demonstrated by the difference of the activity of the homozygous g.IVS2+21 $\mathrm{A}>\mathrm{C}$ and the compound heterozygous c.94 C>A / g.IVS2+21 A>C variants where the ITPase activity decreases from $\sim 32 \%$ to $8 \%$ of the wild type activity (Table 6.1). In addition we reported two, so far unknown, polymorphisms in the ITPA gene. One polymorphism, c.97T>C, shows the same influence on the ITPase activity as the c.94C>A mutation. It can be speculated that this alteration in the cDNA has the same effect on alternative splicing or affects the catalytic site in a similar mode as the $c .94 \mathrm{C}>\mathrm{A}$ mutation ${ }^{18}$. The other mutation, c.122A $>\mathrm{G}$, did not alter erythrocyte ITPase activity.

From the kinetic data it can be concluded that the binding of the substrate is not altered, as in all investigated polymorphisms the $\mathrm{K}_{\mathrm{m}}$ was comparable. The exception was the compound heterozygous c.94C $>A / g$.IVS2+21A $>C$ genotype, which showed a significant lower affinity for the natural substrate. From our results we conclude that the mutated protein still possesses the normal binding capacity, as was predicted from the study on the ITP crystal structure by Stenmark et al. ${ }^{15}$. They also speculated that most probably the catalytic site of the $\mathrm{P} 32 \mathrm{~T}$ protein, originating from the c.94C $>\mathrm{A}$ polymorphism, is altered. Our data on the catalysis rate support this assumption. The $\mathrm{V}_{\max }$ is significantly lower when the c.94C $>\mathrm{A}$ polymorphism is present alone or in combination with another activity lowering polymorphism. Surprisingly, with respect to the g.IVS2+21A $>C$ variant the efficiency of the enzyme is decreased only in the homozygous state, the heterozygous variant shows the same kinetic properties as the wild type enzyme. This implies that this polymorphism only has a minor influence on the protein activity, only when both monomers originate from a g.IVS $2+21 \mathrm{~A}>\mathrm{C}$ polymorphism the properties of the protein are altered.

In contrast to the results reported by Stepchenkova, we and Shipkova et al. found no substrate inhibition of ITPase by ITP in the wild type genotype ${ }^{14,19}$. We suppose that 
the substrate inhibition in their experiments is possibly caused by the presence of DTT in the reaction solution or another artefact, influencing the pyrophosphate assay, rather than by true substrate inhibition ${ }^{14}$. DTT does not interfere in the HPLC-based methods measuring the formation of IMP, as is the case in the methods quantifying pyrophosphate generated in the assay.

It was proposed that the diminished activity of ITPase in the c.94C $>$ A genetic variant is due to lowered levels of the protein ${ }^{13,14}$. Arenas et al. investigated the occurrence of alternative splice variants and reported less full length mRNA, resulting most probably in diminished amounts of the wild type protein ${ }^{18}$. When comparing our results on the c.94C $>$ A variant with previous published data we propose that the protein, resulting from this polymorphism, has less pyrophosphohydrolysis capacity due to changes in the structure of the protein, affecting the catalytic site in particular.

Our results demonstrate that the pyrophosphohydrolysis of TITP by human erythrocyte ITPase in the normal genotype is as efficient as that of ITP. As a consequence, the accumulation of TITP may reach the same levels as ITP in patients with ITPase deficiency, however this needs further studies. No elevated concentrations of ITP have been demonstrated in individuals heterozygous for ITPA polymorphisms. Therefore we assume that TITP will not accumulate in cells from these individuals during thiopurine therapy, although a dose-dependent effect cannot yet be excluded. The ADR described during thiopurine therapy in patients carrying ITPA polymorphisms in our opinion cannot solely be attributed to intracellular TITP accumulation and it is therefore likely determined by other variables as well. A secondary function/influence of ITPase cannot be excluded. It can be speculated that ITPase is essential in maintaining the intracellular balance of non-canonical nucleotides, as in proliferative disorders it is over-expressed $^{20}$. We propose that the house keeping function of the gene may be compromised under metabolic stress. When thiopurines are given to these patients the residual activity may not be sufficient to cope with this stress and results in ADR. In conclusion, we have shown that polymorphisms in the ITPA gene influence the activity of ITPase in human erythrocytes. The c.94C $>$ A variant had the greatest negative effect on the activity, resulting in a null activity for the homozygous state of this polymorphism. Whether this null activity is due to the decreased availability of mature protein or a true diminished ITPase activity, because of altered binding capacity or changes in catalytic properties, has to be further elucidated. The handling of TITP by ITPase is as efficient as that of ITP, indicating that accumulation of TITP will likely only occur in patients with ITPase deficiency. We speculate that the ADR in thiopurine therapy associated with ITPA polymorphisms is due to epigenetic factors rather than to TITP accumulation related to the decreased ITPase activity. 


\section{References}

1. Bierau J, Lindhout M, Bakker JA. Pharmacogenetic significance of inosine triphosphatase. Pharmacogenomics 2007;8:1221-8.

2. Galperin MY, Moroz OV, Wilson KS, Murzin AG. House cleaning, a part of good housekeeping. Mol Microbiol 2006;59:5-19.

3. Vanderheiden BS. Human erythrocyte "ITPase": an ITP pyrophosphohydrolase. Biochim Biophys Acta 1970;215:555-8.

4. Duley JA, Simmonds HA, Hopkinson DA, Levinsky RJ. Inosine triphosphate pyrophosphohydrolase deficiency in a kindred with adenosine deaminase deficiency. Clin Chim Acta 1990;188:243-52.

5. Marinaki AM, Ansari A, Duley JA, Arenas M, Sumi S, Lewis CM, Shobowale-Bakre el-M, Escuredo E, Fairbanks LD, Sanderson JD. Adverse drug reactions to azathioprine therapy are associated with polymorphism in the gene encoding inosine triphosphate pyrophosphatase (ITPase). Pharmacogenetics 2004;14:181-7.

6. Ansari A, Arenas M, Greenfield SM, Morris D, Lindsay J, Gilshenan K, Smith M, Lewis C, Marinaki A, Duley J, Sanderson J. Prospective evaluation of the pharmacogenetics of azathioprine in the treatment of inflammatory bowel disease. Aliment Pharmacol Ther 2008;28:973-83.

7. Zelinkova Z, Derijks LJ, Stokkers PC, Vogels EW, van Kampen AH, Curvers WL, Cohn D, van Deventer SJ, Hommes DW. Inosine triphosphate pyrophosphatase and thiopurine s-methyltransferase genotypes relationship to azathioprine-induced myelosuppression. Clin Gastroenterol Hepatol 2006;4:44-9.

8. Hawwa AF, Millership JS, Collier PS, Vandenbroeck K, McCarthy A, Dempsey S, Cairns C, Collins J, Rodgers C, McElnay JC. Pharmacogenomic studies of the anticancer and immunosuppressive thiopurines mercaptopurine and azathioprine. Br J Clin Pharmacol 2008;66:517-28.

9. De Ridder L, Van Dieren JM, Van Deventer HJ, Stokkers PC, Van der Woude JC, Van Vuuren AJ, Benninga MA, Escher JC, Hommes DW. Pharmacogenetics of thiopurine therapy in paediatric IBD patients. Aliment Pharmacol Ther 2006;23:1137-41.

10. Kurzawski M, Dziewanowski K, Lener A, Drozdzik M. TPMT but not ITPA gene polymorphism influences the risk of azathioprine intolerance in renal transplant recipients. Eur J Clin Pharmacol 2009;65:533-40.

11. van Dieren JM, van Vuuren AJ, Kusters JG, Nieuwenhuis EE, Kuipers EJ, van der Woude CJ. ITPA genotyping is not predictive for the development of side effects in AZA treated inflammatory bowel disease patients. Gut 2005;54:1664.

12. Van Dieren JM, Hansen BE, Kuipers EJ, Nieuwenhuis EE, Van der Woude CJ. Meta-analysis: Inosine triphosphate pyrophosphatase polymorphisms and thiopurine toxicity in the treatment of inflammatory bowel disease. Aliment Pharmacol Ther 2007;26:643-52.

13. Herting G, Barber K, Zappala MR, Cunningham RP, Burgis NE. Quantitative in vitro and in vivo characterization of the human P32T mutant ITPase. Biochim Biophys Acta 2009.

14. Stepchenkova El, Tarakhovskaya ER, Spitler K, Frahm C, Menezes MR, Simone PD, Kolar C, Marky LA, Borgstahl GE, Pavlov YI. Functional study of the P32T ITPA variant associated with drug sensitivity in humans. J Mol Biol 2009;392:602-13.

15. Stenmark P, Kursula P, Flodin S, Graslund S, Landry R, Nordlund P, Schüler H. Crystal structure of human inosine triphosphatase. Substrate binding and implication of the inosine triphosphatase deficiency mutation P32T. J Biol Chem 2007;282:3182-7.

16. Bierau J, Bakker JA, Lindhout M, van Gennip AH. Determination of ITPase Activity in Erythrocyte Lysates Obtained for Determination of Tpmt Activity. Nucleosides Nucleotides Nucleic Acids 2006;25:1129-32.

17. Sumi S, Marinaki AM, Arenas M, Fairbanks L, Shobowale-Bakre M, Rees DC, Thein SL, Ansari A, Sanderson J, De Abreu RA, Simmonds HA, Duley JA. Genetic basis of inosine triphosphate pyrophosphohydrolase deficiency. Hum Genet 2002;111:360-7.

18. Arenas M, Duley J, Sumi S, Sanderson J, Marinaki A. The ITPA c.94C $>$ A and g.IVS2+21A $>C$ sequence variants contribute to missplicing of the ITPA gene. Biochim Biophys Acta 2007;1772:96-102.

19. Shipkova M, Lorenz K, Oellerich M, Wieland E, von Ahsen N. Measurement of erythrocyte inosine triphosphate pyrophosphohydrolase (ITPA) activity by HPLC and correlation of ITPA genotypephenotype in a Caucasian population. Clin Chem 2006;52:240-7. 
20. Poppe B, Vandesompele J, Schoch C, Lindvall C, Mrozek K, Bloomfield CD, Beverloo HB, Michaux L, Dastugue N, Herens C, Yigit N, De Paepe A, Hagemeijer A, Speleman F. Expression analyses identify MLL as a prominent target of 11q23 amplification and support an etiologic role for MLL gain of function in myeloid malignancies. Blood 2004;103:229-35. 


\section{Chapter 7}

Role for ITPA variants in the clinical course of pulmonary Langerhans'cell

histiocytosis?

ITPA polymorphisms in PLCH 
80 Chapter 7 
Interstitial lung diseases (ILD) comprise a number of clinical conditions including sarcoidosis, pulmonary fibrosis and pulmonary Langerhans' cell histiocytosis (PLCH, Histiocytosis X). The diagnostic work-up for the classification of ILD is often complicated and tedious. PLCH is characterized by the proliferation and infiltration of Langerhans' cells into pulmonary tissues, in disseminated LCH additional tissues are affected. PLCH is strongly associated with smoking and the clinical outcome depends on cessation of smoking ${ }^{1}$.

Treatment of ILD often requires immunosuppressant drugs: corticosteroids, immunosuppressant drugs, including thiopurines and biologicals. It is mandatory to exclude genetic polymorphisms in genes involved in metabolism of thiopurine metabolism, because of the pharmacogenetic consequences of the use of thiopurines. The prospective measuring of erythrocyte enzyme activity of thiopurine-Smethyltransferase (TPMT) and inosine triphosphatase (ITPase) or molecular analyses of the genes encoding for these enzymes is recommended in clinical practice ${ }^{2}$.

Aberrant enzyme activity of either TPMT or ITPase gives rise to a broad spectrum of adverse drug reactions (ADR) associated with thiopurines, ranging from therapeutic failure to life threatening leucopenia, ${ }^{3,4}$.

In order to avoid these ADR, we have incorporated pre-treatment screening of TPMT and ITPase of patients with ILD, who are candidates for treatment with thiopurines, in our hospital.

An unexpected high number of decreased ITPase activities in patients with PLCH was found, all of which had an unfavourable outcome. We hypothesized about the role of the ITPA gene in relation to immunity, which might play a key role in this phenomenon.

We examined a total of 105 patients with ILD, referred to the ild care team of the Maastricht University Medical Centre, a tertiary referral centre in The Netherlands for ILD (Table 7.1).

Table 7.1 Distribution of ITPA polymorphisms in interstitial lung disease (ILD).

\begin{tabular}{lcccc}
\hline & N & Lowered ITPase activity & ITPA polymorphism & $\begin{array}{c}\text { \% ITPA } \\
\text { polymorphisms }\end{array}$ \\
\hline $\begin{array}{l}\text { Pulmonary sarcoidosis } \\
\text { (chest X-ray stage IV) }\end{array}$ & 41 & 8 & 8 & 19.5 \\
$\begin{array}{l}\text { Idiopathic pulmonary } \\
\text { fibrosis (IPF) }\end{array}$ & 50 & 3 & 3 & 6.0 \\
PLCH & 6 & 3 & 3 & 50 \\
Other causes of ILD & 8 & $4 *$ & 4 & 50 \\
Reference population \# & 100 & 11 & 11 & 11 \\
\hline
\end{tabular}

*The four cases with an ITPA polymorphism were suffering from drug-induced pneumonitis $(n=2)$ due to azathioprine, chronic extrinsic allergic alveolitis (EAA; $n=1$ ), and Lymphangioleiomyomatosis (LAM; $n=1$ ), respectively. \# Definition of reference population see text 
According to the local protocol for the workup of patients with ILD where thiopurine medication is considered, TPMT and ITPase activities in erythrocytes were measured prior to the start of the treatment. When a lowered activity of TPMT or ITPase was detected molecular analysis of the TPMT and ITPA gene were performed. Reference values for ITPase and ITPA polymorphism distribution were established in a group of 100 anonymous patients from a general hospital population.

TPMT and ITPase activities were measured in erythrocyte lysates as described earlier ${ }^{5}$. Molecular analyses of TPMT and ITPA genes were performed using previously published protocols ${ }^{6}$.

The results of the TMPT and ITPase phenotyping and genotyping in the ILD population are displayed in Table 7.1. Erythrocyte TPMT activity was normal in the PLCH patients, confirmed by molecular analysis, revealing the wild type $* 1 / *_{1} 1$ genotypes in all patients. ITPase activity was decreased in 50\% (3/6) PLCH patients. The patients were genotyped and in patients with a decreased ITPase activity this was confirmed by the finding of polymorphic ITPA genotypes, either heterozygous or homozygous (Table 7.2). The distribution of ITPase activity and ITPA polymorphisms in the reference population were according earlier published results ${ }^{6}$.

Table 7.2 ITPase activity, ITPA genotype and clinical outcome in PLCH patients.

\begin{tabular}{|c|c|c|c|c|c|c|}
\hline Sex & $\begin{array}{l}\text { Age at diagnosis } \\
\text { (years) }\end{array}$ & $\begin{array}{l}\text { Follow up } \\
\text { (months) }\end{array}$ & $\begin{array}{l}\text { Smoking } \\
\text { status }\end{array}$ & $\begin{array}{c}\text { ITPase activity } \\
\text { (mmol/mmol } \\
\mathrm{Hb} / \mathrm{hr})^{*}\end{array}$ & ITPA genotype & Clinical outcome \\
\hline $\mathrm{F}$ & 17 & 70 & Stopped & 3.15 & Wt & $\begin{array}{c}\text { Favourable**; } \\
\text { clinically improved }\end{array}$ \\
\hline M & 38 & 19 & Stopped & 4.60 & Wt & $\begin{array}{c}\text { Favourable**; } \\
\text { clinically improved }\end{array}$ \\
\hline M & 52 & 21 & Smoking & 2.89 & Wt & Unchanged \\
\hline $\mathrm{F}$ & 32 & 27 & Stopped & 0.03 & c.94AA & $\begin{array}{l}\text { Unfavourable\#; } \\
\text { awaiting lung } \\
\text { transplantation }\end{array}$ \\
\hline M & 36 & 49 & Stopped & 0.79 & c.94CA & Unfavourable\# \\
\hline M & 54 & 37 & Stopped & 0.28 & c. $94 \mathrm{CA} /$ g.IVS2+21AC & Unfavourable\# \\
\hline
\end{tabular}

*reference values : $4.0-10.0 \mathrm{mmol} / \mathrm{mmol} \mathrm{Hb} / \mathrm{hr}(\mathrm{n}=100) ;{ }^{* *}$ Favourable: substantial improvement of the HRCT and >10\% improvement of the DLCO; \# Unfavourable: worse evaluation of the HRCT and more than $10 \%$ decrease of the DLCO and desaturation during a 6 minute walking test.

Although the number of patients with PLCH in our cohort is limited, we detected an unusual high and intriguing prevalence of low erythrocyte ITPase activities and a concomitant higher number of ITPA polymorphisms, i.e. 50\%, compared to the reference population (11\%). 
It is unclear whether there is a connection between the absolute ITPase activity and the occurrence of the disease. Earlier reports referring to patients with a complete ITPase deficiency reported no clinical abnormalities, classifying it as a benign condition ${ }^{7}$. Interestingly, the PLCH cases carrying an ITPA polymorphism all demonstrated an unfavourable outcome despite that they all stopped smoking. To date, smoking is associated with the clinical course of $\mathrm{PLCH}$. In general, the clinical features improve after the patient stops smoking (Figure 7.1). However, our three patients carrying an ITPA polymorphism all deteriorated and no clinical improvement occurred compared to the PLCH patients with the normal genotype. This finding is also clinically relevant regarding the therapeutic options, as patients who do not improve after they quit smoking are sometimes candidates for azathioprine. Therefore, we strongly recommend to assess erythrocyte ITPase activity, in addition to TPMT activity, prior to initiating treatment with azathioprine in patients with $\mathrm{PLCH}$.
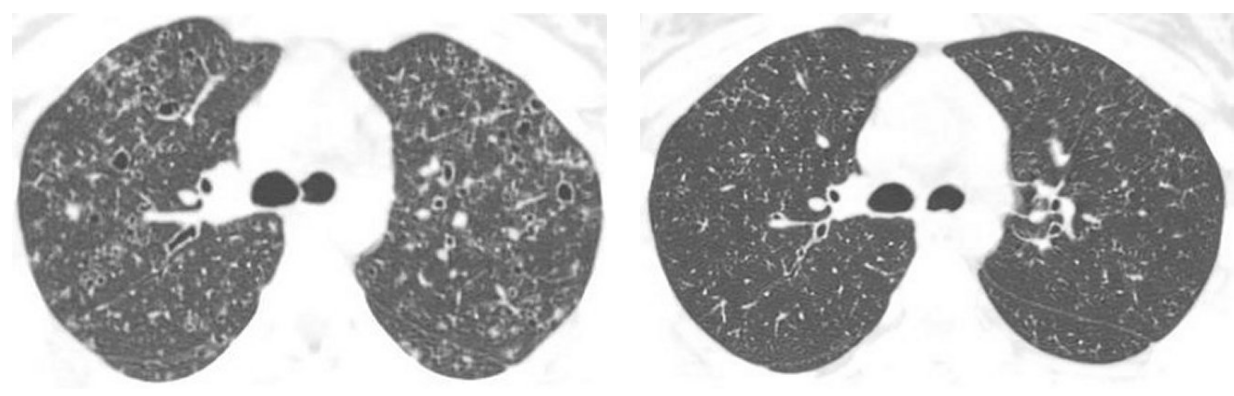

Figure 7.1 HRCT scan of the thorax of a patient (case \#1) with Langerhanscel histiocytosis at presentation showing cyst and micro noduli (left panel) and normalized scan 4 months after stopping with smoking (richt panel)

To the best of our knowledge ITP does not accumulate in patients with a partial ITPase deficiency. Therefore, clinical pathology cannot merely be explained by accumulation of ITP in carriers of ITPA polymorphisms, but is more likely to be associated with housekeeping or moonlighting functions of the gene or its protein(s).

The role of ITPase in mammalian metabolism is still poorly understood ${ }^{8}$. Its primary role is the pyrophosphohydrolysis of ITP (and dITP) to maintain the balance between ITP and IMP, IMP being the key metabolite in the purine interconversion pathway. Tissue distribution of ITPase varies widely, the highest activity is present in tissues with an exocrine function ${ }^{9}$.

The other, less highlighted, function of ITPA is its role as a house keeping gene. ITPase is involved in the maintenance of the degradation of non-canonical purine nucleotide triphosphates, hereby preventing the incorporation of these metabolites into RNA and 
DNA. Under abnormal physiological circumstances, such as metabolic stress or an inflammatory response, proper functioning of housekeeping genes is pivotal for cellular maintenance. In patients carrying one or more polymorphic ITPA alleles, it can be speculated that the house keeping function may be compromised and inflammatory responses cannot be countered properly, resulting in enhanced disease activity. In $\mathrm{PLCH}$ there is excessive eosinophilic granuloma formation, thereby corrupting the immune response. Although little is known about ITPase activity in progenitor cells of eosinophils and macrophages, it can be speculated that a wild type ITPA genotype is crucial to maintain adequate housekeeping in these cells. Comparing ITPase deficiency with two other inherited disorders in purine metabolism, adenosine deaminase (ADA) and purine nucleoside phosphorylase (PNP) deficiency, makes this line of thought even more compelling. Both conditions cause severe immune disease, resulting in SCID and T-cell immunodeficiency respectively. The concept of a potential role of ITPA in immunity is further strengthened by the fact that two proteins, encoded by ITPA, were recognized by cytotoxic T-cells. Whether or not these immunogenic proteins are the products of alternative splicing remains unclear. However, as was shown by Arenas et al., alternative mRNA splice variants are present in significantly higher amounts in patients carrying the ITPA $94 \mathrm{C}>\mathrm{A}$ polymorphism than in wild type individuals ${ }^{10}$. A direct link between ITPase and smoking seems highly unlikely. One may argue, however, that toxic compounds originating from (tobacco) smoke cause oxidative stress in exposed tissues, generating non-canonical nucleotides. ITPase is required to scavenge these toxic compounds. Expression of ITPase in lung tissue is low, which may imply that under metabolic stress the presence of ITPA polymorphisms results in insufficient ITPase activity thus compromising the cellular capability to neutralize toxic, noncanonical, nucleotides.

In conclusion, we hypothesize that ITPA polymorphisms are associated with an unfavourable clinical outcome in PLCH. Future investigations are required to confirm the high prevalence of ITPA polymorphisms in PLCH patients. Moreover, the prognostic value should be evaluated in a larger cohort, focussing especially on the association with smoking. Furthermore, the potential role of ITPase in inflammatory modulating cells needs to be elucidated. These investigations may gain more insight in the real physiological role of ITPase and the clinical effect of polymorphisms in the ITPA gene. 


\section{References}

1. Harari S, Caminati A. Pulmonary Langerhans' cell histiocytosis. Eur Respir Mon 2009;46:155-75.

2. Weinshilboum R, Wang L. Pharmacogenomics: bench to bedside. Nat Rev Drug Discov 2004;3:739-48.

3. Bakker JA, Bierau J, Drent M. Therapeutic regimens in interstitial lung disease guided by genetic screening: fact or fiction? Eur Respir J 2007;30: 821-2.

4. Coulthard S, Hogarth L. The thiopurines: an update. Invest New Drugs 2005;23:523-32.

5. Bierau J, Bakker JA, Lindhout M, van Gennip AH. Determination of ITPase Activity in Erythrocyte Lysates Obtained for Determination of Tpmt Activity. Nucleosides Nucleotides Nucleic Acids 2006;25: 1129-32.

6. Sumi S, Marinaki AM, Arenas M, Fairbanks L, Shobowale-Bakre M, Rees DC, Thein SL, Ansari A, Sanderson J, De Abreu RA, Simmonds HA, Duley JA. Genetic basis of inosine triphosphate pyrophosphohydrolase deficiency. Hum Genet 2002;111:360-7.

7. Vanderheiden BS. Human erythrocyte "ITPase": an ITP pyrophosphohydrolase. Biochim Biophys Acta 1970;215: 555-8.

8. Bierau J, Lindhout $M$, Bakker JA. Pharmacogenetic significance of inosine triphosphatase. Pharmacogenomics 2007;8:1221-8.

9. Lin S, McLennan AG, Ying K, Wang Z, Gu S, Jin H, Wu C, Liu W, Yuan Y, Tang R, Xie Y, Mao Y. Cloning, expression, and characterization of a human inosine triphosphate pyrophosphatase encoded by the ITPA gene. J Biol Chem 2001;276:18695-701.

10. Arenas M, Duley J, Sumi S, Sanderson J, Marinaki A. The ITPA c.94C $>$ A and g.IVS2+21A $>C$ sequence variants contribute to missplicing of the ITPA gene. Biochim Biophys Acta 2007;1772:96-102. 



\section{Chapter 8}

General discussion 
88 Chapter 8 


\section{Introduction}

Since the introduction of thiopurine as an anti-inflammatory drug about 50 years ago, a substantial amount of knowledge has been generated with respect to its activation, metabolization and the way it exerts its action ${ }^{1}$. Polymorphisms in genes involved in thiopurine metabolism result in different responses to thiopurine therapy, ranging from non-responsiveness, disease progression, to an overreaction with clinical consequences $^{2-8}$. The studies described in this thesis have been focused on two enzymes which are involved in the metabolism of thiopurines, thiopurine-Smethyltransferase (TPMT) and inosine triphosphatase (ITPase).

\section{Functional aspects of thiopurine-S-methyltransferase}

One of the defense mechanisms the organism has to reduce the toxicity of xenobiotic compounds is methylation. Therefore a whole class of enzymes, called methyltransferases, exists with a broad spectrum of specificities ${ }^{9,10}$. TPMT is one of the enzymes belonging to this class and its main purpose is the methylation of thiopurine metabolites. Given the fact that thiopurines are man made and not existing in nature, one might wonder how the evolution of the gene encoding for the enzyme TPMT has taken place. It might be that a compound which is rather similar to the thiopurines still exists $^{11}$. Early reports on TPMT tested several aromatic thiol containing compounds as substrates for TPMT and found that TPMT was capable to transfer the methylgroup from S-adenosyl methionine (SAM) to these compounds ${ }^{12}$. Freshwater bacteria use a TPMT-like pathway to methylate selenium-containing compounds, which appears to be a specific selenium methyltransferase ${ }^{13,14}$. Taking into account these findings it can be speculated that TPMT is involved in methylation of endogenous aromatic thiol and/or selenium containing compounds ${ }^{11}$. The methylation of thionucleotides was shown in earlier studies. However, at the start of our study it was still unclear whether thiopurine nucleotides are methylated inside the cell or if thiopurines are first methylated by TPMT and subsequently phosphoribosylated by HGPRT. Studies were initiated by incubating recombinant human TPMT (rhTPMT) with different thiopurine substrates, including thioinosine monophosphate (TIMP), and tritium labeled S-adenosylmethionine (SAM) as methyl donor, showing transfer of the labeled methyl group to the substrates. From the results obtained we were able to conclude that methylation of TIMP is as efficient as the methylation of the thiopurine bases, the incorporation of tritium was the same for all compounds, both after 6 and 24 hours of incubation.

Incubation experiments of MOLT-3 cells with different thiopurine species showed that 6-MTIMP is present intracellularly after 24 hours of incubation with 6-MP but not with 6-MMP. In the case of 6-MMP this means that 6-MMP is not phosphoribosylated by HGPRT in MOLT-3 cells. Studies with labeled precursors confirmed the results obtained 
from the studies with rhTPMT. From our results we conclude that the generally accepted pathway for activation and deactivation of thiopurines is valid. Future experiments with TPMT deficient cell lines and the use of specific inhibitors of activating or deactivating enzymes can provide more insight in the way fluxes of thiopurines are directed through the pathways. The results from earlier studies with the xanthine oxidase (XO) inhibitor allopurinol and the inosine monophosphate dehydrogenase (IMPDH) inhibitor mycophenolic acid are good examples of such studies $^{15,16}$.

\section{Determination of thiopurine metabolites}

Analytical methods for the measurement of thiopurine metabolites are important tools in therapeutic drug monitoring (TDM) ${ }^{17-19}$. The aim of TDM in thiopurine therapy is to monitor the intracellular concentrations of the toxic compounds thioguanine triphosphate (TGTP) and methylthioinosine monophosphate (MTIMP) ${ }^{20}$. Both compounds are responsible for the observed ADR in thiopurine treatment: an intracellular excess of thioguanine nucleotides results in severe myelosuppresion, whereas an increased concentration of MTIMP is associated with liver dysfunction and inhibition of purine de novo synthesis ${ }^{21}$.

For a better understanding of thiopurine metabolism it is of crucial importance to further investigate the distribution of thiopurine metabolites with respect to activation, deactivation and degradation. In the last decade liquid chromatography combined with tandem mass spectrometry was introduced in clinical chemistry and pharmacology. This technique makes it possible to measure metabolites at low concentrations while requiring a minimum of sample pre-treatment ${ }^{22}$. Our goal was to develop and validate a method for the measurement of thiopurine degradation products in biological fluids. This approach allowed us to quantify 6-mercaptopurine (6-MP), 6-thiouric acid (6-TUA), 6-thioguanine (6-TG), 6-methylmercaptopurine (6-MMP) and 6-methylthioguanine (6-MTG) in urine and plasma. The applications of this method go beyond the measurement of these metabolites in body fluids, as it can be used in translational studies like intestinal absorption and transport of thiopurines in vitro. A lot of insight is still lacking on how thiopurines are handled by the intestine, especially during inflammation ( $\mathrm{M}$. Crohn and Colitis ulcerosa). We expect that thiopurine efficacy will decrease further during of inflammation, due to up-regulation of XO expression in the intestinal tract. Future studies with cultured monolayers of intestinal cells and biopsies mounted in Ussing chambers can provide more insight in intestinal thiopurine kinetics ${ }^{23-26}$. 


\section{Pharmacogenetic significance of TPMT}

Although the pharmacogenetic significance of TPMT in thiopurine therapy is widely accepted, it is still not common in clinical practice to test patients for a decreased TPMT activity or polymorphisms in the TPMT gene before installing thiopurine therapy $^{27-29}$. The importance of pre-treatment testing is highlighted by the case described in chapter 4 and other cases ${ }^{2,4,5,7}$. We strongly advocate a more prominent role for pharmacogenetic testing in general, and TPMT and ITPase in particular, to prevent adverse drug reactions, determined by genetic polymorphisms ${ }^{2,45,30-40}$. Pretreatment screening will not only prevent ADR and hence improve the quality of life of the patient to be treated, it has also important socio-economic implications. In a significant number of cases the patient is hospitalized for several days, requiring specialist care. The volume of cost reduction as a consequence of pre-treatment TMPT pheno- or genotyping is substantial ${ }^{41-44}$. Recently the European Commission published a report on the potential socio-economic impact of pharmacogenetics and pharmacogenomics in the European Union $(E U)^{45}$. This report stressed several recommendations which need to be implemented in the near future. Only thereafter patients can successfully benefit from the advantages of pharmacogenetic testing. Education of the medical professionals on the subject is regarded as essential. Not all physicians are aware of the great advantages pharmacogenetics can provide in treating patients. So far in the UK only dermatologists have guidelines for TPMT screening in case of thiopurine treatment ${ }^{27,29}$. Currently TPMT screening is not common clinical practice in the Netherlands, only local initiatives are active in this respect $^{30}$. Moreover, in order to successfully implement pharmacogenetic testing, the services of laboratories offering these test should be easily accessible. To achieve this it is necessary that the costs of pharmacogenetic testing are covered by health insurances, making it more attractive for physicians to use pharmacogenetic tests in patient care and management.

\section{The role of ITPase in thiopurine metabolism}

The role of inosine triphosphatase (ITPase) in human metabolism is still not fully understood. It is apparent that its primary role is the pyrophosphohydrolysis of ITP and dITP, in order to maintain the inosine nucleotide balance. In addition, ITPase is involved in the removal of non-canonical nucleotides, hereby maintaining RNA and DNA integrity ${ }^{32,46}$.

It is this last property of ITPase which makes it an intriguing part of human metabolism. Complete deficiency of ITPase is not associated with a clinical condition in humans. Excessive intracellular concentrations of ITP are the only abnormality reported in ITPase deficient individuals ${ }^{32,46-48}$. However the house keeping function of ITPase, the removal of the non-canonical nucleotides, is thought to be associated with 
the outcome in (auto)inflammatory disorders or, in the case of viral infections, with the absence of adverse drug reactions under anti-viral therapy ${ }^{49,50}$. In a recent study ITPA gene knockout mice were not viable, they died within two weeks after birth. Besides growth retardation, the main clinical feature was cardiac myofiber disarray, most probably due to ATP displacement by ITP in the ATP pool, indispensable for proper sarcomere function ${ }^{51}$. Although the murine ITPA knock-out model, in which the whole gene was deleted, is not comparable to the human ITPA polymorphism with a mutated protein, the finding of this report suggests an yet unknown structural function of ITPase.

In chapter 6 we focused on one aspect of the house keeping function of ITPase, e.g. the handling of thioinosine triphosphate (TITP). This thiopurine metabolite is formed from thioinosine monophosphate (TIMP) and accumulates inside the cell when ITPase is deficient. Whether it will accumulate in individuals bearing activity lowering polymorphisms is still unclear. In the literature conflicting results on the occurrence of adverse drug reactions due to thiopurine therapy have been reported ${ }^{52,53}$. We studied the handling of ITP and TITP by ITPase in individuals with the different ITPA polymorphisms to gain more information on the influence of these polymorphisms on ITPase activity. Surprisingly the binding of the substrate did not differ greatly for the different genotypes. As was shown in our study, the apparent $K_{m}$ for ITP and TITP for the genotypes tested was comparable. However, the pyrophosphohydrolysis of ITP and TITP was clearly diminished when one of the alleles contained the c.94 C>A polymorphism. The c.94C $>\mathrm{A}$ polymorphism results in an amino acid change in the ITPase protein at position 32, a proline is substituted by a threonine. This results in a structural change of the protein which affects most probably the catalytic site ${ }^{54}$. A decrease in catalytic velocity may imply that the catalytic site remains occupied, which can result in higher intracellular concentrations of ITP or other non-canonical nucleotides. In line with this, it can be argued that this may compromise the housekeeping function of ITPase, as defined by removing the intra-cellular noncanonical nucleotides. Non-canonical nucleotides will be incorporated in RNA and DNA and lead to aberrations ${ }^{55}$. The integrity of RNA and DNA is essential for proper cell functioning and proliferation ${ }^{56}$. The importance of a balanced nucleotide pool is emphasized by Arczewska and Kusmierek in their review on the role of the bacterial mutT gene and its human orthologue hMTH1 in the proper functioning of DNA repair ${ }^{57}$. MutT negative bacteria were susceptible to higher mutation rates due to increased concentrations of 8-oxo-deoxyguanosine triphosphate, emphasizing the universal importance of a balanced nucleotide pool ${ }^{56}$. One line of research would be to study the effect of ITPA polymorphisms on intracellular nucleotide pools and chromosomal stability during development, both under physiological an non-physiological conditions. 
Interestingly, the occurrence of an unexpected high number of interstitial deletions and intragenic rearrangements in the DPYD gene in patients with a deficiency of the enzyme Dihydropyrimidine dehydrogenase (DPD) has been described recently ${ }^{58}$. DPD is the rate-limiting enzyme in the pyrimidine degradation pathway. A deficiency of this enzyme causes accumulation of uracil and thymine. It can be speculated that an excess of uracil and thymine will have upstream effects in pyrimidine metabolism and will effect the intracellular pyrimidine nucleotide balance, disturbing proper cell proliferation and regulation. The presence of a fragile site, FRA1E, on chromosome 1 in the vicinity of the DPYD gene can be additive in the effect of the disturbed pyrimidine nucleotide balance in DPD deficient patients. Thymidine phosphorylase (TP), which is also a defect in pyrimidine metabolism, results in depletion of and multiple deletions in mitochondrial DNA (mtDNA). Excess thymidine will result in higher intramitochondrial concentrations of thymidine triphosphate (TTP) and subsequently a disbalance in the deoxynucleotide pool ${ }^{59}$. At present it is unknown if mechanisms analogous to the ones in DPD and TP deficiency are causative in the case of ITPA polymorphisms or ITPase deficiency.

The mechanisms described above affect DNA, either nuclear or mitochondrial. Arenas et al. reported an abnormal distribution of mRNA splice variants in IPTA polymorphisms, which was associated with specific splice enhancing or silencing sequences ${ }^{60}$. Future investigations may focus on ITPase protein expression associated with these abnormal splice variants.

Understanding of the above mentioned mechanisms is important with respect to the possible pharmacogenetic consequences of ITPA polymorphisms in thiopurine based therapy. In relation with thiopurine metabolism cellular experiments have to be repeated with precursors of TIMP, this can provide more insight in the role of thionucleotides in cell cycle regulation. The importance of ITPA polymorphisms in thiopurine therapy is described in a study by Stocco et al. where patients were treated with thiopurines for acute lymphoblastic leukemia (ALL) on basis of their TPMT genotype. The results of this study show that patients with an ITPA polymorphism had more ADR, e.g. severe febrile neutropenia, than patients with a ITPA wild type genotype $^{61}$. The pharmacogenetic relevance of ITPase activity or ITPA polymorphisms was further strengthened by a recent report by Fellay et al. on the outcome of treatment in hepatitis $C^{49}$. Patients with ITPA polymorphisms were protected against ribavirin induced anaemia. So far no in vitro studies on the role of ITPA polymorphisms in pharmacogenetics, and in thiopurine metabolism in particular, have been reported.

It is remarkable that most reports referring to ITPase activity or ITPA polymorphism are somehow related to (auto)inflammatory diseases ${ }^{62-64}$. This raises the question if ITPase or ITPA is involved in the immune response. In one study an overrepresentation of ITPA polymorphisms in a group of patients with inflammatory bowel disease (IBD) has been found ${ }^{65}$. We have observed an association between ITPA polymorphisms and pulmonary Langerhans' cell histiocystosis ${ }^{66}$. Compromised immunity is the key clinical 
feature in two other disorders in purine metabolism: adenosine deaminase (ADA) deficiency which causes severe combined immunodeficiency (SCID) and purine nucleoside phosphorylase (PNP) deficiency which causes T cell immunodeficiency ${ }^{67}$. In both disorders there is intracellular accumulation of purine (deoxy)ribonucleotide triphosphates (dNTPs), analogous to ITPase deficiency. This excess dNTPs has consequences on various cellular processes. These include inhibition of ribonucleotide reductase, leading to inhibition of DNA replication and increased susceptibility for apoptosis due to activation of several aspartate-specific cysteine proteases (caspases) by dATP and dGTP ${ }^{68,69}$. The assumption that an accumulation of (d) ITP would not interfere in cellular processes is compelling, since dITP is demonstrated to be mutagenic $^{70}$.

How the immune system responds to an excess of intracellular (d)ITP can be studied in cell lines of patients with ITPA polymorphisms and control cell lines. Whether this response is different from the response seen in ADA and PNP deficient cell lines will be of special interest. In addition B- and T-cell populations of both wild type and polymorphic individuals need to be investigated to find more evidence for the hypothesis that ITPase and/or ITPA are involved in cellular immunity.

\section{Conclusions}

At the start of this thesis we formulated a number of questions. Results of the studies described in this thesis elucidated some of the questions and, if not conclusive, raised new questions which have to be addressed in the near future. It is apparent that thiopurine metabolism is far more complicated than suggested by the 'simple' metabolic pathway which is generally accepted. This resulted in the initiation of further research in this field, both mechanistic studies and patient related research. In addition there is the challenge to develop validated methods for the determination of thiopurine metabolites, both intra- and extracellular. Nothing is known on the role of other genes as inhibitors or effectors of ITPA so far, in depth molecular analysis of the human genome with new generation sequence techniques can reveal epigenetic factors. Expansion of the knowledge of thiopurine metabolism is the cornerstone for personalized drug regimens. The ultimate goal will be a more personalized medicine, resulting in better treatment, less adverse drug reactions and cost reduction in healthcare. 


\section{References}

1. Coulthard S, Hogarth L. The thiopurines: an update. Invest New Drugs 2005;23:523-32.

2. Bodelier AGL, Masclee AAM, Bakker JA, Hameeteman WH, Pierik MJ. Azathioprine induced pneumonitis in a patient with ulcerative colitis. J Crohn's Colitis 2009;3:309-12.

3. de Boer NK, Derijks LJ, Gilissen LP, Hommes DW, Engels LG, de-Boer SY, et al. On tolerability and safety of a maintenance treatment with 6-thioguanine in azathioprine or 6-mercaptopurine intolerant IBD patients. World J Gastroenterol 2005;11:5540-4.

4. Demirtas-Ertan G, Rowshani AT, ten Berge IJ. Azathioprine-induced shock in a patient suffering from undifferentiated erosive oligoarthritis. Neth J Med 2006;64:124-6.

5. Gardiner SJ, Gearry RB, Barclay ML, Begg EJ. Two cases of thiopurine methyltransferase (TPMT) deficiency--a lucky save and a near miss with azathioprine. Br J Clin Pharmacol 2006;62:473-6.

6. Hawwa AF, Millership JS, Collier PS, Vandenbroeck K, McCarthy A, Dempsey S, et al. Pharmacogenomic studies of the anticancer and immunosuppressive thiopurines mercaptopurine and azathioprine. $\mathrm{Br} \mathrm{J}$ Clin Pharmacol 2008;66:517-28.

7. McLeod HL, Miller DR, Evans WE. Azathioprine-induced myelosuppression in thiopurine methyltransferase deficient heart transplant recipient. Lancet 1993;341:1151.

8. Sahasranaman S, Howard D, Roy S. Clinical pharmacology and pharmacogenetics of thiopurines. Eur J Clin Pharmacol 2008;64:753-67.

9. Weinshilboum RM, Otterness DM, Szumlanski CL. Methylation pharmacogenetics: catechol Omethyltransferase, thiopurine methyltransferase, and histamine N-methyltransferase. Ann Rev Pharmacol Toxicol 1999;39:19-52.

10. Weisiger RA, Jakoby WB. Thiol S-methyltransferase. Methods Enzymol 1981;77:257-62.

11. Deininger $M$, Szumlanski CL, Otterness DM, Van Loon J, Ferber W, Weinshilboum RM. Purine substrates for human thiopurine methyltransferase. Biochem Pharmacol 1994;48:2135-8.

12. Woodson LC, Ames MM, Selassie CD, Hansch C, Weinshilboum RM. Thiopurine methyltransferase. Aromatic thiol substrates and inhibition by benzoic acid derivatives. Mol Pharmacol 1983;24:471-8.

13. Ranjard L, Nazaret S, Cournoyer B. Freshwater bacteria can methylate selenium through the thiopurine methyltransferase pathway. Appl Environ Microbiol 2003;69:3784-90.

14. Ranjard L, Prigent-Combaret C, Favre-Bonte S, Monnez C, Nazaret S, Cournoyer B. Characterization of a novel selenium methyltransferase from freshwater bacteria showing strong similarities with the calicheamicin methyltransferase. Biochim Biophys Acta 2004;1679:80-5.

15. Hedstrom L. IMP dehydrogenase: mechanism of action and inhibition. Curr Med Chem 1999;6:545-60.

16. Sparrow MP, Hande SA, Friedman S, Lim WC, Reddy SI, Cao D, et al. Allopurinol safely and effectively optimizes tioguanine metabolites in inflammatory bowel disease patients not responding to azathioprine and mercaptopurine. Aliment Pharmacol Ther 2005;22:441-6.

17. Dervieux T, Meyer G, Barham R, Matsutani M, Barry M, Boulieu R, Neri B, Seidman E. Liquid chromatography-tandem mass spectrometry analysis of erythrocyte thiopurine nucleotides and effect of thiopurine methyltransferase gene variants on these metabolites in patients receiving azathioprine/6-mercaptopurine therapy. Clin Chem 2005;51:2074-84.

18. Dubinsky MC, Yang H, Hassard PV, Seidman EG, Kam LY, Abreu MT, Targan SR, Vasiliauskas EA. 6-MP metabolite profiles provide a biochemical explanation for 6-MP resistance in patients with inflammatory bowel disease. Gastroenterology 2002;122:904-15.

19. Duley JA, Florin TH. Thiopurine therapies: problems, complexities, and progress with monitoring thioguanine nucleotides. Ther Drug Monit 2005;27:647-54.

20. Derijks LJ, Gilissen LP, Hooymans PM, Hommes DW. Review article: thiopurines in inflammatory bowel disease. Aliment Pharmacol Ther 2006;24:715-29.

21. Dervieux T, Brenner TL, Hon YY, Zhou Y, Hancock ML, Sandlund JT, Rivera GK, Ribeiro RC, Boyett JM, Pui $\mathrm{CH}$, Relling MV, Evans WE. De novo purine synthesis inhibition and antileukemic effects of mercaptopurine alone or in combination with methotrexate in vivo. Blood 2002;100:1240-7.

22. Pitt JJ. Principles and applications of liquid chromatography-mass spectrometry in clinical biochemistry. Clin Biochem Rev 2009;30:19-34. 
23. Gotoh Y, Kamada N, Momose D. The Advantages of the Ussing Chamber in Drug Absorption Studies. J Biomol Screen 2005;10:517-23.

24. Lennard L. The clinical pharmacology of 6-mercaptopurine. Eur J Clin Pharmacol 1992;43:329-39.

25. Schwab M, Klotz U. Pharmacokinetic considerations in the treatment of inflammatory bowel disease. Clin Pharmacokinet 2001;40:723-51.

26. Stockmann M, Engelmann BE, Langrehr JM, Neuhaus P. Influence of immunosuppressive drugs on intestinal epithelial transport function. Transplant Proc 2002;34:1449-50.

27. Anstey AV, Wakelin S, Reynolds NJ. Guidelines for prescribing azathioprine in dermatology. $\mathrm{Br} \mathrm{J}$ Dermatol 2004;151:1123-32.

28. Clunie GP, Lennard L. Relevance of thiopurine methyltransferase status in rheumatology patients receiving azathioprine. Rheumatology (Oxford) 2004;43:13-8.

29. Ford LT, Berg JD. Thiopurine S-methyltransferase (TPMT) assessment prior to starting thiopurine drug treatment; a pharmacogenomic test whose time has come. J Clin Pathol 2010;63:288-95.

30. Bakker JA, Bierau J, Drent M. Therapeutic regimens in interstitial lung disease guided by genetic screening: fact or fiction? Eur Respir J 2007;30:821-2.

31. Becquemont L. Clinical relevance of pharmacogenetics. Drug Metab Rev 2003;35:277-85.

32. Bierau J, Lindhout $M$, Bakker JA. Pharmacogenetic significance of inosine triphosphatase. Pharmacogenomics 2007;8:1221-8.

33. Bosch TM, Meijerman I, Beijnen JH, Schellens JH. Genetic polymorphisms of drug-metabolising enzymes and drug transporters in the chemotherapeutic treatment of cancer. Clin Pharmacokinet 2006;45:253-85.

34. Bugelski PJ. Genetic aspects of immune-mediated adverse drug effects. Nat Rev Drug Discov 2005;4:59-69.

35. Eichelbaum M, Ingelman-Sundberg M, Evans WE. Pharmacogenomics and Individualized Drug Therapy. Annu Rev Med 2006;57:119-37.

36. Evans WE, Relling MV. Pharmacogenomics: translating functional genomics into rational therapeutics. Science 1999;286:487-91.

37. Ferraccioli G, De Santis M, Tolusso B. Pharmacogenetics/pharmacogenomics and antirheumatic drugs in rheumatology. Pharmacogenomics 2004;5:1107-16.

38. Nagasubramanian R, Innocenti F, Ratain MJ. Pharmacogenetics in cancer treatment. Annu Rev Med 2003;54:437-52.

39. O'Kane DJ, Weinshilboum RM, Moyer TP. Pharmacogenomics and reducing the frequency of adverse drug events. Pharmacogenomics 2003;4:1-4

40. Wilkinson GR. Drug metabolism and variability among patients in drug response. N Engl J Med 2005;352:2211-21.

41. Compagni A, Bartoli S, Buehrlen B, Fattore G, Ibarreta D, de Mesa EG. Avoiding adverse drug reactions by pharmacogenetic testing: A systematic review of the economic evidence in the case of TPMT and AZA-induced side effects. Int J Technol Assess Health Care 2008;24:294-302.

42. Dubinsky MC, Reyes E, Ofman J, Chiou CF, Wade S, Sandborn WJ. A cost-effectiveness analysis of alternative disease management strategies in patients with Crohn's disease treated with azathioprine or 6-mercaptopurine. Am J Gastroenterol 2005;100:2239-47.

43. Priest VL, Begg EJ, Gardiner SJ, Frampton CM, Gearry RB, Barclay ML, Clark DW, Hansen P. Pharmacoeconomic analyses of azathioprine, methotrexate and prospective pharmacogenetic testing for the management of inflammatory bowel disease. Pharmacoeconomics 2006;24:767-81.

44. Sayani FA, Prosser C, Bailey RJ, Jacobs P, Fedorak RN. Thiopurine methyltransferase enzyme activity determination before treatment of inflammatory bowel disease with azathioprine: effect on cost and adverse events. Can J Gastroenterol 2005;19:147-51.

45. Zika E GD, Ibarreta D. Pharmacogenetic and Pharmacogenomics: State-of-the-art and potential socioeconomic impact in the EU. European Commision, 2006.

46. Lin S, McLennan AG, Ying K, Wang Z, Gu S, Jin H, Wu C, Liu W, Yuan Y, Tang R, Xie Y, Mao Y. Cloning, expression, and characterization of a human inosine triphosphate pyrophosphatase encoded by the ITPA gene. J Biol Chem 2001;276:18695-701.

47. Duley JA, Simmonds HA, Hopkinson DA, Levinsky RJ. Inosine triphosphate pyrophosphohydrolase deficiency in a kindred with adenosine deaminase deficiency. Clin Chim Acta 1990;188:243-52. 
48. Vanderheiden BS. Human erythrocyte "ITPase": an ITP pyrophosphohydrolase. Biochim Biophys Acta 1970;215:555-8.

49. Fellay J, Thompson AJ, Ge D, Gumbs CE, Urban TJ, Shianna KV, Little LD, Qiu P, Bertelsen AH, Watson M, Warner A, Muir AJ, Brass C, Albrecht J, Sulkowski M, McHutchison JG, Goldstein DB. ITPA gene variants protect against anaemia in patients treated for chronic hepatitis C. Nature 2010;464:405-8.

50. Galperin MY, Moroz OV, Wilson KS, Murzin AG. House cleaning, a part of good housekeeping. Mol Microbiol 2006;59:5-19.

51. Behmanesh M, Sakumi K, Abolhassani N, Toyokuni S, Oka S, Ohnishi YN, Tsuchimoto D, Nakabeppu Y. ITPase-deficient mice show growth retardation and die before weaning. Cell Death Differ 2009;16:1315-22.

52. Stocco G, Crews KR, Evans WE. Genetic polymorphism of inosine-triphosphate-pyrophosphatase influences mercaptopurine metabolism and toxicity during treatment of acute lymphoblastic leukemia individualized for thiopurine-S-methyl-transferase status. Expert Opin Drug Saf 2010;9:23-37.

53. Van Dieren JM, Hansen BE, Kuipers EJ, Nieuwenhuis EE, Van der Woude CJ. Meta-analysis: Inosine triphosphate pyrophosphatase polymorphisms and thiopurine toxicity in the treatment of inflammatory bowel disease. Aliment Pharmacol Ther 2007;26:643-52.

54. Stenmark P, Kursula P, Flodin S, Graslund S, Landry R, Nordlund P, Schüler H. Crystal structure of human inosine triphosphatase. Substrate binding and implication of the inosine triphosphatase deficiency mutation P32T. J Biol Chem 2007;282:3182-7.

55. Abolhassani N, lyama T, Tsuchimoto D, Sakumi K, Ohno M, Behmanesh M, Nakabeppu Y. NUDT16 and ITPA play a dual protective role in maintaining chromosome stability and cell growth by eliminating dIDP/IDP and dITP/ITP from nucleotide pools in mammals. Nucleic Acids Res. 2010;38:2891-903.

56. Mathews CK. DNA precursor metabolism and genomic stability. Faseb J 2006;20:1300-14.

57. Arczewska KD, Kusmierek JT. Bacterial DNA repair genes and their eukaryotic homologues: 2. Role of bacterial mutator gene homologues in human disease. Overview of nucleotide pool sanitization and mismatch repair systems. Acta Biochim Pol 2007;54:435-57.

58. van Kuilenburg AB, Meijer J, Mul AN, Hennekam RC, Hoovers JM, de Die-Smulders CE, Weber P, Mori AC, Bierau J, Fowler B, Macke K, Sass JO, Meinsma R, Hennermann JB, Miny P, Zoetekouw L, Vijzelaar R, Nicolai J, Ylstra B, Rubio-Gozalbo ME. Analysis of severely affected patients with dihydropyrimidine dehydrogenase deficiency reveals large intragenic rearrangements of DPYD and a de novo interstitial deletion del(1)(p13.3p21.3). Hum Genet 2009;125:581-90.

59. Taanman JW, Daras M, Albrecht J, Davie CA, Mallam EA, Muddle JR, Weatherall M, Warner TT, Schapira AH, Ginsberg L. Characterization of a novel TYMP splice site mutation associated with mitochondrial neurogastrointestinal encephalomyopathy (MNGIE). Neuromuscul Disord 2009;19: 151-4.

60. Arenas M, Duley J, Sumi S, Sanderson J, Marinaki A. The ITPA c.94C $>$ A and g.IVS2+21A $>C$ sequence variants contribute to missplicing of the ITPA gene. Biochim Biophys Acta 2007;1772:96-102.

61. Stocco G, Cheok MH, Crews KR, Dervieux T, French D, Pei D, et al. Genetic polymorphism of inosine triphosphate pyrophosphatase is a determinant of mercaptopurine metabolism and toxicity during treatment for acute lymphoblastic leukemia. Clin Pharmacol Ther 2009;85:164-72.

62. Marinaki AM, Ansari A, Duley JA, Arenas M, Sumi S, Lewis CM, Shobowale-Bakre el-M, Escuredo E, Fairbanks LD, Sanderson JD. Adverse drug reactions to azathioprine therapy are associated with polymorphism in the gene encoding inosine triphosphate pyrophosphatase (ITPase). Pharmacogenetics 2004;14:181-7.

63. van Dieren JM, van Vuuren AJ, Kusters JG, Nieuwenhuis EE, Kuipers EJ, van der Woude CJ. ITPA genotyping is not predictive for the development of side effects in AZA treated inflammatory bowel disease patients. Gut 2005;54:1664.

64. Zelinkova Z, Derijks L, Stokkers PC, Vogels EW, van Kampen AH, Curvers WL, Cohn D, van Deventer SJ, Hommes DW. Inosine triphosphate pyrophosphatase and thiopurine s-methyltransferase genotypes relationship to azathioprine-induced myelosuppression. Clin Gastroenterol Hepatol 2006;4:44-9.

65. Cheon JH, Kim JH, Kim BY, Kim SW, Hong SY, Eun CS, Hong SS, Byeon JS, Kim TI, Han DS, Yang SK, Lee $\mathrm{KR}$, Kim WH. Allele frequency of thiopurine methyltransferase and inosine triphosphate pyrophosphatase gene polymorphisms in Korean patients with inflammatory bowel diseases. Hepatogastroenterology 2009;56:421-3. 
66. Bakker JA, Bierau, J, Drent, M. Role for ITPA variants in the clinical course of pulmonary Langerhans' cell histiocytosis? Eur Respir J 2010;36: in press.

67. Hershfield M. Immunodeficiency diseases caused by adenosine deaminase deficiency and purine nucleoside phosphorylase deficiency. In: Scriver CR SW, Valle D, editor. The Metabolic and Molecular Basis of Inherited Disease. New York: McGraw-Hill, 2001.

68. Kashlan OB, Scott CP, Lear JD, Cooperman BS. A Comprehensive Model for the Allosteric Regulation of Mammalian Ribonucleotide Reductase. Functional Consequences of ATP- and dATP-Induced Oligomerization of the Large Subunit Biochemistry 2001;41:462-74.

69. Seetulsingh-Goorah SP. Mechanisms of adenosine-induced cytotoxicity and their clinical and physiological implications. BioFactors (Oxford, England) 2006;27:213-30.

70. Spee JH, de Vos WM, Kuipers OP. Efficient random mutagenesis method with adjustable mutation frequency by use of PCR and dITP. Nucleic Acids Res 1993;21:777-8. 
Summary 


\section{Summary}

Thiopurines are frequently used in the treatment of patients suffering from (auto)immune diseases. Since their introduction in the mid fifties of the $20^{\text {th }}$ century the way these compounds exert their therapeutic action has been the subject of many clinical and laboratory studies. In chapter 1 the reader is introduced into this topic. After a brief introduction on purines and pyrimidines and the importance of synthetic analogues of these compounds, the metabolism of purines is described. As is outlined purine metabolism can be divided into 3 main parts: purine de novo synthesis (PDNS), interconversion and the degradation-salvage pathway. The complexity of these pathways reflects the importance of these compounds in life, by tight regulation mechanisms the intracellular concentrations of purines are kept in balance. Modern molecular genetic methods, generating vast amounts of genetic information, have opened the field of pharmacogenetics and it was shown that several enzymes involved in purine metabolism are essential in the handling of synthetic purine analogues, used as therapeutics in a variety of diseases. Thiopurines are metabolized by the enzymes from the purine pathways and it is apparent that alterations in the activity of these enzymes by genetic polymorphisms may influence the efficacy of thiopurine therapy. This thesis focuses on two enzymes involved: thiopurine-S-methyltransferase (TPMT) and inosine triphosphatase (ITPase). The effects of alterations in the expression of these enzymes are discussed in relation to thiopurine metabolism. The therapeutic targets of thiopurines and drug/drug interactions influencing thiopurine efficacy are briefly mentioned.

The selectivity of TPMT to thiopurine compounds is still puzzling. This topic is addressed in chapter 2. Experiments using human recombinant TPMT (hrTPMT) and (methyl- ${ }^{14} \mathrm{C}$ )-S-adenosylmethionine (SAM) confirmed the transfer of the methyl group from SAM to the different substrates. In human erythrocyte lysates this was seen with 6-MP and 6-TG, but not with 6-TIMP. In contrast, using MOLT-3 cells, we were able to confirm the formation of 6-Methyl-TIMP from 6-MP and 6-thioinosine (6-TI). The thionucleotide profile in MOLT-3 lysates after incubation with 6-methyl-MP showed no formation of 6-Methyl-TIMP. Further investigations are warranted to elucidate the way thiopurine compounds are metabolized in human cells.

Chapter 3 describes the development and application of a method to determine thiopurine metabolites in body fluids, using ultra performance liquid chromatography - tandem mass spectrometry. Using stable isotope labeled internal standards (methylated) thiopurines and metabolites could be detected in urine and plasma in concentrations down to 50 nanomolar. Intra assay variations were within acceptable limits for the compounds measured. Instability of 6-MP and 6-TG, most probably due to oxidation, made it nearly impossible to establish inter assay variation for these compounds. For methylated thiopurines inter assay variations ranged from $4-7 \%$ in plasma. In urine the low concentration range intra assay variations were $>15 \%$. The method was further validated by analyzing samples from patients on thiopurine 
therapy. In urine and plasma 6-MP and 6-thiouric acid (6-TU) were readily detectable. The other compounds were only found in trace amounts, below the limit of quantification (LOQ) of the method.

The relevance of measuring TPMT before starting thiopurine therapy is emphasized by the clinical history of the case presented in chapter 4 . The patient was treated for refractory Ulcerative Colitis (UC). Within 5 weeks after starting Azathioprine (AZA), a prodrug of 6-MP, the patient developed severe leucopenia and anemia. After admission to the hospital an adverse drug reaction caused by AZA was suspected and AZA was stopped immediately. TMPT activity was measured in erythrocytes and was found decreased. Molecular analysis revealed a *1/*3C TPMT genotype, associated with a decreased TMPT activity. After 4 weeks the patient recovered and treatment was continued with mesalazine.

A second enzyme involved in (thio)purine metabolism is inosine triphosphatase (ITPase). In chapter 5 the method for the measurement of ITPase activity in erythrocytes is described, using liquid chromatography with UV-detection. The method was optimized for measuring ITPase activity in dried blood spots (DBS). Although the method was applicable for the measurement in DBS and decreased activities could easily be detected, the stability of the enzyme was poor. It was therefore concluded that ITPase activity measurement in DBS is not reliable. Therefore the use of fresh erythrocyte lysates for the measurement of ITPase activity is required.

The debate on ITPA polymorphisms and ADR during thiopurine therapy is still ongoing. In chapter 6 , the focus is on the enzyme ITPase and its kinetic properties. Genotype associated reference values for ITPase in erythrocytes were established. The specificity of ITPase for the substrates ITP and thio-ITP was determined, both for the wild type genotype as for the activity lowering polymorphisms. Surprisingly the binding of the substrates was comparable for the genotypes tested, however, the velocity of pyrophosphohydrolysis was greatly decreased when the c.94C $>$ A polymorphism was present. The efficiency of ITPase for both substrates was found to be comparable under the assay conditions. From these results it appears that other (epigenetic) factors may be responsible for the occurrence of ADR during thiopurine therapy in the presence of ITPA polymorphisms.

Chapter 7 describes a pilot study in which the association between ITPA polymorphisms and clinical outcome in patients with pulmonary Langerhans' cell histiocytosis is evaluated. Interestingly, patients with a with an ITPase activity lowering polymorphism were found to have a more unfavorable outcome compared to the patients with a wild type genotype. The cause of this phenomenon is unclear: possibly the house keeping function of ITPA is compromised in patients with a decreased ITPase activity.

Finally, the major findings of this thesis are discussed in chapter 8 and the suggestions for future research are given. Although the knowledge on TPMT and ITPase is expanding continually, still many questions have to be answered. To answer some of these questions future research needs to follow two lines: one will be focused on the 
biological function of ITPase in health and disease. The other line will focus on the handling of thiopurines by the organism, especially the way thiopurines are absorbed by the intestinal tract and how inflammation is influencing this process. 

Samenvatting 


\section{Samenvatting}

Thiopurine medicatie wordt frequent voorgeschreven voor de behandeling van (auto)immuun ziekten. Na de introductie van deze verbindingen in het midden van de jaren vijftig van de vorige eeuw zijn ze onderwerp geweest van een groot aantal klinische en laboratorium studies. De algemene introductie in hoofdstuk 1 beschrijft in het kort wat purines en pyrimidines zijn en welke niet natuurlijke analogen als medicijn tegen een scala van (auto)immuun stoornissen worden gebruikt. Het metabolisme van purines wordt daarna op een drietal hoofdlijnen verder uitgewerkt: de purine de novo synthese (PDNS), de interconversie en de route die de afbraak en hergebruik van purines beschrijft. De complexiteit van deze processen weerspiegelt het belang van purines voor het voortbestaan van een organisme. Om deze reden worden de intracellulaire concentraties van purines (en pyrimidines) sterk gereguleerd.

Door de opkomst van het moleculair genetisch onderzoek gedurende de laatste decennia is er een keur aan genetische informatie beschikbaar gekomen, wat ondermeer heeft geleid tot de snelle ontplooiing van de pharmacogenetica. Dit heeft geresulteerd in de kennis dat enzymen betrokken bij het purine metabolisme eveneens verantwoordelijk zijn voor de activering en afbraak van de niet natuurlijk voorkomende purine analogen die gebruikt worden in de medicamenteuze behandeling van verschillende (auto)immuun stoornissen. Daar thiopurines ook door dit metabolisme worden verwerkt, mag het duidelijk zijn dat veranderingen in de activiteit van de betrokken enzymen, veroorzaakt door genetische variaties, consequenties zullen hebben voor de effectiviteit van de behandeling met thiopurines. Een tweetal enzymen die betrokken zijn bij het thiopurine metabolisme worden in dit proefschrift in het bijzonder behandeld: thiopurine-S-methyltransferase (TPMT) en inosine triphosphatase (ITPase). De effecten van veranderingen in de mate van expressie van deze enzymen worden besproken in relatie tot thiopurines. In het laatste deel van de introductie wordt kort ingegaan op de werking van thiopurines en hoe andere medicijnen de effectiviteit van thiopurines beïnvloeden.

In hoofdstuk 2 wordt stil gestaan bij de selectiviteit van TPMT voor verschillende thiopurine componenten. In experimenten met humaan recombinant TPMT (hrTPMT) en radioactief gelabeld SAM als methyldonor kon worden aangetoond dat de methylgroep werd overgedragen op de verschillende substraten. Als daarentegen het lysaat van humane erytrocyten als enzymbron werd gebruikt dan bleek er geen overdracht te zijn de methylgroep op 6-TIMP, terwijl dit wel het geval was bij incubatie met 6-mercaptopurine (6-MP) en 6-thioguanine (6-TG). Incubatie van MOLT-3 cellen met 6-MP en 6-thioinosine (6-TI) toonde aan dat er 6-methyl-thioinosinemonofosfaat (6-MTIMP) werd gevormd. Indien de incubatie werd herhaald met 6-methylmercaptopurine (6-MMP) als substraat dan kon er geen 6-MTIMP worden aangetoond. Deze resultaten geven aanleiding om verder onderzoek te initiëren om het metabolisme van thiopurines op te helderen. 
Hoofdstuk 3 beschrijft de ontwikkeling van een methode voor de bepaling van thiopurine metabolieten in lichaamsvloeistoffen met behulp van zogeheten ultra performance vloeistof chromatografie (UPLC) gecombineerd met tandem massaspectrometrie. Met behulp van stabiele isotoop gelabelde interne standaarden was het mogelijk om (gemethyleerde) thiopurine metabolieten te meten in concentraties tot minimaal $50 \mathrm{nmol} / \mathrm{l}$. De dupliceerbaarheid van de analyse voor de verschillende componenten was zeer acceptabel. Instabiliteit van 6-MP en 6-TG in de monstermatrix, mogelijk als gevolg van oxidatie, maakte het nagenoeg onmogelijk om de reproduceerbaarheid voor deze componenten in urine vast te stellen. Voor de gemethyleerde thiopurine metabolieten bedroeg de reproduceerbaarheid in plasma 4-7\%. Voor het lage concentratiegebied werd in urine een reproduceerbaarheid gevonden van $>15 \%$. De klinische validatie werd verricht door het analyseren van monsters van patiënten die 6-MP of AZA gebruikten: in urine en plasma waren 6-MP en 6-TU duidelijk aantoonbaar. De andere componenten waren wel aantoonbaar, de concentraties lagen echter beneden de limiet voor kwantificering (LOQ) zoals deze bepaald was voor de methode.

De klinische relevantie van de bepaling van TPMT in het kader van de medicamenteuze behandeling met thiopurines wordt geaccentueerd door de casus beschreven in hoofdstuk 4. Het betreft een patiënte die behandeld wordt voor Colitis Ulcerosa (UC). Vijf weken na start van de behandeling met Azathioprine (AZA), een pro-drug van 6-MP, ontwikkelde de patiënte een ernstige leucopenie en bloedarmoede (anemie). Bij opname in het ziekenhuis rees de verdenking van een overgevoeligheidsreactie (ADR) welke toegeschreven kan worden aan het gebruik van AZA. Hierop werd de medicatie gestopt. De activiteitsmeting van TPMT in rode bloedcellen (erytrocyten) werd aangevraagd en deze bleek verlaagd te zijn. Verder moleculair biologisch onderzoek toonde de aanwezigheid aan van een TPMT activiteit verlagend polymorfisme in heterozygote vorm, het zogenoemde ${ }^{*} 1 /{ }^{*} 3 C$ genotype. Na 4 weken was de patiënte hersteld van de ADR en werd de behandeling voortgezet met mesalazine, een niet aan purines verwant medicijn.

Een ander enzym dat betrokken is bij het metabolisme van thiopurines is inosine triphosphatase (ITPase). In hoofdstuk 5 wordt de methode beschreven voor de activiteitsmeting van ITPase in erytrocyten, met behulp van vloeistof chromatografie gekoppeld aan UV-detectie. De methode werd verder geoptimaliseerd voor de meting van de ITPase activiteit in bloed spots (DBS). Alhoewel de methode bruikbaar is voor meting van ITPase activiteit in DBS, kwam naar voren dat de stabiliteit van het enzym onvoldoende was voor een betrouwbare meting. Op basis van deze resultaten wordt de meting van de ITPase activiteit uitgevoerd in een erytrocyten lysaat.

De associatie tussen ITPA polymorfismen en ADR bij thiopurine gebruik is onderwerp van een voortdurende discussie. In hoofdstuk 6 ligt het zwaartepunt op het ITPase en de kinetische eigenschappen van het enzym. Genotype gerelateerde referentie waarden voor ITPase in erytrocyten lysaat werden bepaald. De specificiteit van ITPase voor de substraten ITP en thio-ITP werden vastgesteld, zowel voor het normale 
genotype als voor de 2 meest voorkomende ITPA polymorfismen. De effectiviteit van het enzym was voor beide substraten vergelijkbaar, onder de standaard condities waaronder de meting van het enzym plaatsvindt. De binding van het substraat bleek in de geteste genotypen vergelijkbaar. De snelheid waarmee het enzym de pyrofosfaat groep van het substraat afsplitst bleek in het geval van de aanwezigheid van het c.94C >A polymorfisme echter sterk vertraagd. Uit deze resultaten kan worden geconcludeerd dat voor het ontstaan van ADR onder thiopurine gebruik bij patiënten met een ITPA polymorfisme mogelijk andere (epigenetische) factoren een rol zullen spelen.

Hoofdstuk 7 beschrijft de resultaten van een studie die betrekking heeft op de associatie tussen ITPA polymorfismen en de klinische evolutie van patiënten met de pulmonaire vorm van Langerhans' cel histiocytose (PLCH). Uit deze studie komt naar voren dat patiënten die drager zijn van een ITPase activiteit verlagend polymorfisme een slechtere prognose hebben dan PLCH patiënten met het normale (wild type) genotype. De oorzaak van deze bevinding is momenteel nog onduidelijk. Het is mogelijk dat de 'housekeeping' functie van het ITPA gecompromitteerd is in patiënten met een ITPase activiteit verlagend polymorfisme.

De belangrijkste bevindingen beschreven in dit proefschrift worden bediscussieerd in hoofdstuk 8 en de hieruit voortkomende mogelijkheden voor toekomstig onderzoek worden besproken. Ondanks het continue voortschrijdende inzicht aangaande het metabolisme van TPMT en ITPase blijven er nog veel vragen open. Door continuering van het onderzoek langs twee hoofdlijnen kunnen mogelijk in de toekomst verdere antwoorden verkregen worden. Een eerste onderzoekslijn dient zich te richten op de biologische functie van ITPase, zowel onder normale omstandigheden als in relatie tot ziekte. Het verwerven van verder inzicht in het metabolisme van thiopurines is het thema van de tweede onderzoekslijn. Met name dient te worden onderzocht hoe thiopurines worden opgenomen in de darm en hoe ontstekingen van het darmweefsel dit proces beïnvloeden. 



\section{List of publications}


112 


\section{Publications}

Dumoulin JC, Evers JL, Bakker JA, Bras M, Pieters MH, Geraedts JP. Temporal effects of taurine on mouse preimplantation development in vitro. Hum Reprod 1992;7:403-7.

van Pelt J, Bakker JA, Velmans MH, Spaapen LJ. Carbohydrate-deficient transferrin values in neonatal and umbilical cord blood. J Inherit Metab Dis 1996;19:253-6.

Claeys M, Van der Hoeven M, de Die-Smulders C, Bakker JA, Offermans JP, Forget PP, et al. Early-infantile type of galactosialidosis as a cause of heart failure and neonatal ascites. J Inherit Metab Dis 1999;22:666-7.

Forget PP, van Oosterhout M, Bakker JA, Wermuth B, Vles JS, Spaapen LJ. Partial Nacetyl-glutamate synthetase deficiency masquerading as a valproic acid-induced Reyelike syndrome. Acta Paediatr 1999;88:1409-11.

Spaapen LJ, Bakker JA, Velter C, Loots W, Rubio-Gozalbo ME, Forget PP, et al. Tetrahydrobiopterin-responsive phenylalanine hydroxylase deficiency in Dutch neonates. J Inherit Metab Dis 2001;24:352-8.

ter Heide H, Hendriks HJ, Heijmans H, Menheere PP, Spaapen LJ, Bakker JA, et al. Are children with cystic fibrosis who are treated with a proton-pump inhibitor at risk for vitamin B(12) deficiency? J Pediatr Gastroenterol Nutr 2001;33:342-5.

Dammers R, Rubio-Gozalbo ME, Robben SG, Bakker JA, Spaapen LJ, Forget PP. Nacetyl-glutamate synthetase deficiency or porto-systemic shunt associated encephalopathy? Acta Paediatr 2002;91:729.

Martens DH, Bakker JA, van der Meer SB, Spaapen LJ. Unexplained familial benign methylmalonic aciduria. Eur J Pediatr 2002;161:219-20.

Rubio-Gozalbo ME, Hamming S, van Kroonenburgh MJ, Bakker JA, Vermeer C, Forget PP. Bone mineral density in patients with classic galactosaemia. Arch Dis Child 2002;87:57-60.

Groener J, Maaswinkel-Mooy P, Smit V, van der Hoeven M, Bakker J, Campos Y, et al. New mutations in two Dutch patients with early infantile galactosialidosis. Mol Genet Metab 2003;78:222-8.

Rubio-Gozalbo ME, Vos P, Forget PP, Van Der Meer SB, Wanders RJ, Waterham HR, Bakker JA. Carnitine-acylcarnitine translocase deficiency: case report and review of the literature. Acta Paediatr 2003;92:501-4. 
Bakker J, Gies I, Slavenburg B, Bekers O, Delhaas T, van Dieijen-Visser M. Reference values for $\mathrm{N}$-terminal pro-B-type natriuretic peptide in umbilical cord blood. Clin Chem 2004;50:2465.

Rubio-Gozalbo ME, Bakker JA, Waterham HR, Wanders RJ. Carnitine-acylcarnitine translocase deficiency, clinical, biochemical and genetic aspects. Mol Aspects Med 2004;25:521-32.

Wu X, Steet RA, Bohorov O, Bakker J, Newell J, Krieger M, et al. Mutation of the COG complex subunit gene COG7 causes a lethal congenital disorder. Nat Med 2004;10:51823.

Spaapen LJ, Bakker JA, van der Meer SB, Sijstermans HJ, Steet RA, Wevers RA, et al. Clinical and biochemical presentation of siblings with COG-7 deficiency, a lethal multiple O- and N-glycosylation disorder. J Inherit Metab Dis 2005;28:707-14.

Bierau J, Bakker JA, Lindhout M, van Gennip AH. Determination of ITPase Activity in Erythrocyte Lysates Obtained for Determination of Tpmt Activity. Nucleosides Nucleotides Nucleic Acids 2006;25:1129-32.

Panis B, Bakker JA, Sels JP, Spaapen LJ, van Loon LJ, Rubio-Gozalbo ME. Untreated classical galactosemia patient with mild phenotype. Mol Genet Metab 2006;89:277-9.

van Kimmenade R, van Dielen F, Bakker J, Nijhuis J, Crijns H, Buurman W, et al. Is brain natriuretic peptide production decreased in obese subjects? J Am Coll Cardiol 2006;47:886-7.

van Kimmenade RR, Januzzi JL, Jr., Ellinor PT, Sharma UC, Bakker JA, Low AF, et al. Utility of amino-terminal pro-brain natriuretic Peptide, galectin-3, and apelin for the evaluation of patients with acute heart failure. J Am Coll Cardiol 2006;48:1217-24.

Vlasveld LT, Bos GM, Ermens AA, Bakker JA, Lindemans J. Hyperhomocysteinemia and functional cobalamin deficiency due to granulocytosis-induced alterations in the cobalamin-binding protein. Haematologica 2006;91:394-6.

Bakker JA, Bierau J, Drent M. Therapeutic regimens in interstitial lung disease guided by genetic screening: fact or fiction? Eur Respir J 2007;30:821-2.

Bakker JA, Drent M, Bierau J. Relevance of pharmacogenetic aspects of mercaptopurine metabolism in the treatment of interstitial lung disease. Curr Opin Pulm Med 2007;13:458-63. 
Bierau J, Lindhout $M$, Bakker JA. Pharmacogenetic significance of inosine triphosphatase. Pharmacogenomics 2007;8:1221-8.

Michielsen EC, Bakker JA, Kimmenade RR, Pinto YM, Dieijen-Visser MP. The diagnostic value of serum and urinary NT-proBNP for heart failure. Ann Clin Biochem 2008;45:389-94.

Bakker JA, Lindhout M, Dorland L, Bierau J. A comparative study of inosine triphosphatase activity in fresh erythrocytes and dried blood spots. Clinica chimica acta; international journal of clinical chemistry 2009;405:155.

Bodelier AGL, Masclee AAMM, Bakker JA, Hameeteman WH, Pierik MJ. Azathioprine induced pneumonitis in a patient with ulcerative colitis. Journal of Crohn's and Colitis 2009;3:309-12.

Gubbels CS, Kuppens SM, Bakker JA, Konings CJ, Will Wodzig K, de Sain-van der Velden $M G$, et al. Pregnancy in classic galactosemia despite undetectable anti-Mullerian hormone. Fertility and sterility 2009;91:1293 e13-6.

van Kimmenade RRJ, Januzzi Jr JL, Bakker JA, Houben AJ, Rennenberg R, Kroon AA, et al. Renal Clearance of B-Type Natriuretic Peptide and Amino Terminal Pro-B-Type Natriuretic Peptide: A Mechanistic Study in Hypertensive Subjects. J Am Coll Cardiol 2009;53:884-90.

Bakker JA, Schlesser P, Smeets HJ, Francois B, Bierau J. Biochemical abnormalities in a patient with thymidine phosphorylase deficiency with fatal outcome. J Inherit Metab Dis 2010;33:181.

Lindhout M, Rubio-Gozalbo ME, Bakker JA, Bierau J. Direct non-radioactive assay of galactose-1-phosphate: Uridyltransferase activity using high-performance liquid chromatography. Clinica chimica acta; international journal of clinical chemistry 2010;411:980-3.

Moonen RM, Reyes I, Cavallaro G, Gonzalez-Luis G, Bakker JA, Villamor E. The T1405N Carbamoyl Phosphate Synthetase Polymorphism Does Not Affect Plasma Arginine Concentrations in Preterm Infants. PloS one 2010;5:e10792.

Rubio-Gozalbo ME, Gubbels CS, Bakker JA, Menheere PP, Wodzig WK, Land JA. Gonadal function in male and female patients with classic galactosemia. Human reproduction update 2010;16:177-88. 
Bakker JA, Bierau J, Drent M. Role for ITPA variants in the clinical course of pulmonary Langerhans' cell histiocytosis? Eur Respir J 2010; 36(3), in press

Janssen MJW, Hendrickx BHE, Habets-van der Poel CD, van den Bergh JPW, Haagen AAM, Bakker JA. Accuracy of the Precision ${ }^{\circledR}$ point-of-care ketone test examined by LCMS/MS in the same fingerstick sample. Clin Chem Lab Med 2010, in press 
Dankwoord 


\section{Dankwoord}

Nadat de grootste klus geklaard is en het dan eindelijk zover is dat het manuscript bij de beoordelingscommissie ligt, komt het moment om te beginnen met het schrijven van het dankwoord. Je denkt wel te weten wie je moet bedanken en hoe je dat zou willen doen, maar dan blijken je prozaïsche capaciteiten echter danig beperkt te zijn. Het valt even stil. Dan maar over een andere boeg gegooid, je somt alle mensen op waarvan je (nog) weet dat ze iets hebben bijgedragen en bedankt hun met een paar welgemeende woorden. Nu blijkt echter dat je daardoor snel mensen vergeet, dus dit lijkt ook geen goede manier om een dankwoord te schrijven. Dan maar een nieuwe poging.

Beste Joep, al direct na het afronden van mijn studie Gezondheidswetenschappen hebben we het onderwerp promoveren besproken. Door allerlei omstandigheden heeft het lang geduurd voordat de plannen werkelijk ten uitvoer konden worden gebracht. Ik wil je bedanken voor de mogelijkheden die je mij in de afgelopen jaren geboden hebt om mij verder te ontplooien. Je visie, geduld en vasthoudendheid, maar ook je humor, zijn met name in deze afrondende fase van het promotietraject van grote betekenis voor mij geweest.

Beste Marjolein, een aantal jaren geleden hebben we een keer wat heen en weer gepraat over het onderwerp pharmacogenetica, iets dat je na aan het hart ligt. Wie had toen kunnen denken dat het resultaat zou zijn dat je als promotor in mijn boekje staat. ledere keer als er weer iets in wording was stimuleerde je mij om het maar zo snel mogelijk door te sturen, 'dan kon er je alvast naar kijken'. Dat dit inhield dat het meestal per kerende post, van uitvoerig commentaar voorzien, weer op mijn scherm verscheen, daar had ik geen rekening mee gehouden. Het was wel een stimulans om te proberen je bij te houden. Ik hoop dat onze samenwerking, na nu, nog gewoon doorloopt.

De copromotor is, zoals het woord al zegt, een van de motoren van het geheel. Beste Jörgen, toen we onder leiding van wijlen Albert van Gennip een begin maakten met het traject van mijn promotie hadden we geen idee dat we dat al zo snel zonder Albert onze weg moesten vervolgen. Met verve heb je de rol van copromotor toen op je genomen, maar of je wel goed wist waar je met mij aan begon dat laat ik maar even in het midden. De afgelopen jaren hebben we vaak uitgebreid om de tafel gezeten hoe het nu verder moest, iedere keer vonden we wel een nieuwe (uit)weg. Dat het daarbij ook regelmatig over andere zaken dan het onderwerp van de promotie ging heb ik altijd enorm gewaardeerd en beschouw ik als een verrijking van het geheel. Ondanks onze verschillen was er altijd een vorm van elkaar accepteren zoals je bent, wat geresulteerd heeft in een samenwerking, waarvan dit boekje één van de resultaten is. We hebben nu een basis gelegd waarop we verder kunnen gaan. 
De leden van de beoordelingscommissie, Prof. van Dieijen - Visser, Prof. Balzarini, Prof. Bast, Dr. van Kuilenburg en Prof. Tjan - Heijnen, wil ik danken voor hun bereidheid in de beoordelingscommissie zitting te nemen en de tijd die zij vrij hebben willen maken voor de kritische beoordeling van het manuscript.

Mijn collega stafleden van het laboratorium Erfelijke Metabole Ziekten, Leo, Bert, Irene, Daphna en uiteraard ook Estela, wil ik bedanken voor de steun in de afgelopen jaren, bijv. door het overnemen van diensten. Daarnaast hebben alle medewerkers van het laboratorium de afgelopen jaren op een of andere manier hun steentje bijgedragen, zonder jullie ondersteuning had ik hier niet kunnen staan. Een drietal wil ik graag speciaal op deze plaats noemen. Huub, je kennis van tandem massaspectrometrie was onontbeerlijk voor de meting van de thiopurine metabolieten. Je voorstellen voor verbetering van de analyse waren vaak zeer effectief. Martijn en Dennis, vaak hebben jullie de planning om moeten gooien als ik weer een of ander experiment had gepland dat interfereerde met jullie andere werkzaamheden. Hartelijk dank voor jullie inzet en niet in het minst, geduld en flexibiliteit.

De vele collega's van de afdeling Klinische Genetica wil ik eveneens dank zeggen voor hun steun in de afgelopen periode, niet in het minst door soms alleen al te vragen of er schot in de zaak zat. Met name wil ik in dit verband Aimee en Arthur bedanken voor de hulp bij het moleculaire deel van mijn onderzoek.

De leden van de thiopurine club Zuid-Limburg (en toch ook Eindhoven) wil ik bedanken voor de vruchtbare samenwerking binnen het thiopurine onderzoek. In het bijzonder Wout en Dennis voor hun steun in het verzamelen van onderzoeksmateriaal. Ik wens jullie veel succes bij het afronden van jullie promotietraject.

De jaren dat ik in opleiding was als klinisch chemicus binnen het laboratorium Klinische Chemie zijn voor mij van grote waarde geweest. Marja, Paul, Otto, Wil, Yvonne, Karly en alle andere medewerkers van de laboratoria klinische chemie en hematologie wil ik bedanken voor de geweldige jaren die ik heb gehad op de $5^{\mathrm{e}}$. Beste Snjezana en Jart, betere kamergenoten had ik me die jaren niet kunnen wensen. Onze wegen lopen nu al enige tijd uit elkaar, maar als we elkaar zien is het alsof we gisteren nog de kamer deelden.

Met velen heb ik binnen en buiten Maastricht in de afgelopen 25 jaar samengewerkt, de beschikbare ruimte is te krap om iedereen persoonlijk te bedanken. Toch zijn er drie mensen die niet ongenoemd mogen blijven: Roland, je enthousiasme voor het doen van onderzoek heeft mij duidelijk gemaakt hoe leuk dat kan zijn. De resultaten van onze samenwerking op het gebied van NT-proBNP zijn een stimulans geweest om zelf ook verder te gaan. Nico, een betere verre vriend kon ik me niet wensen, bedankt voor alle gesprekken in de afgelopen jaren. Mathie, vele keren zijn we samen naar 
opleidingsdagen en andere bijeenkomsten gereisd, ik ben je spreekwoordelijke rust steeds meer gaan waarderen. Het doet me deugd dat we nu een weg hebben gevonden om jouw kennis over flowcytometrie te combineren met onze kennis over metabolisme.

Tiny wil ik bedanken voor de efficiënte wijze waarop ze mijn bestanden heeft weten om te zetten in een document dat voor de drukker bruikbaar is. Als er nog drukfouten in het proefschrift staan ligt het in ieder geval niet aan jou. Het vermogen om mijn gedachten om te zetten in een omslag komt geheel voor rekening van Jules, ik ben hem daar zeer erkentelijk voor.

Een mens leeft niet alleen om te werken, met andere woorden, ook buiten het werkveld zijn er vrienden die mij op de been hebben gehouden. Beste Maria \& Winfried, bedankt voor de tijd die we al bomend hebben doorgebracht, naast jullie soms letterlijk praktische hulp. Ik hoop dat onze wekelijkse wandeling, samen met Els, de komende tijd weer meer door kan gaan. Ton \& Herma, Hans \& Atie, Hermien \& Henk, Jiska, Jeroen, Math \& Chrisja, bedankt voor de niet aflatende belangstelling en bemoedigende woorden. Ik besef dat dit slechts een kleine afspiegeling is, maar door deze mensen wil ik ook alle anderen die hebben meegeleefd bedanken.

Mijn familie heeft de afgelopen jaren het aantal keren dat er tijd was om naar Zeeland te komen drastisch zien verminderen. Het was voor jullie misschien niet altijd even duidelijk waarom het nu zo lang moest duren, maar het is dan nu toch eindelijk afgerond en komt die tijd er dan ook weer. Mijn schoonouders, Corrie, Jan en Harm en verdere familieleden wil ik bedanken voor de steun die ze Heleen, Lianne, Marina en mij in de afgelopen jaren hebben gegeven. Mijn moeder, Matty, Ad \& Tannie hebben in de afgelopen jaren misschien wel te vaak gehoord dat 'het druk' was om alles op tijd af te krijgen. Ik dank jullie van harte voor de belangstelling en de steun die jullie ons allen gegeven hebben. Mijn ouders hebben lang geleden mij de mogelijkheid geboden een opleiding te volgen, nu ik dan op dit punt sta doet het pijn dat mijn vader dit niet meer mee mag maken, hij zou trots geweest zijn.

Lianne en Marina, ik ben ongelooflijk trots dat jullie vandaag naast mij willen staan. Vaak lieten jullie mij maar betijen als ik in het weekend weer eens andere zaken dan jullie aandacht gaf, dat was misschien ook wel het beste. $\mathrm{Nu}$ is het dan eindelijk afgerond en kan de focus verlegd worden. Lianne, vaak was je een soort geweten door duidelijk aan te geven dat ik weer eens te veel in mezelf bezig was. Als ergotherapeut ben je gelukkig gewend met onmogelijke mensen om te gaan. Marina, vaak benijd ik je om de wijze waarop jij zaken naast je neer kunt leggen, aan de andere kant weet ik hoe betrokken je bent met mensen. Ik vind het jammer dat het laboratorium je minder kan bekoren dan ik hoopte, maar ik ben er van overtuigd dat je, samen met Jeroen, je weg zult vinden in de biomedische wereld. 
Lieve Heleen, vaak heb ik je de afgelopen jaren tot wanhoop gedreven als ik weer eens iets vergeten was omdat ik alweer met mijn opleiding of promotieonderzoek bezig was. De laatste jaren ging er geen vakantie of weekend voorbij dat jij mij moest delen met mijn studieboeken, laptop of artikelen. Wat ik wel weet is dat ik zonder jou aan mijn zijde het nooit gered zou hebben. Ik ben je daar erg dankbaar voor en hoop dat we vanaf nu meer tijd vrij kunnen maken om samen de dingen te doen die er de laatste jaren bij ingeschoten zijn. 
123

Curriculum Vitae 


\section{Curriculum Vitae}

$\mathrm{Na}$ het afronden van de opleiding tot analytisch chemisch analist aan de Hogeschool West-Brabant te Breda zette Jaap in 1979 de eerste schreden op het metabole pad op het Stofwisselings-laboratorium van het Sophia Kinderziekenhuis te Rotterdam bij ir. W. Blom en dr. J.G.M. Huijmans. In 1985 maakte Jaap de overstap naar het toen onder leiding van dr. L.J.M. Spaapen opgestarte Laboratorium Erfelijke Metabole Ziekten te Maastricht. Vanaf 1987 werd een begin gemaakt met de studie Gezondheidswetenschappen aan de toenmalige Rijksuniversiteit Limburg. Na het afronden van de studie eind 1994, volgde in 1995 een aanstelling als staflid bij het genoemde laboratorium. In 2002 werd de erkenning als klinisch biochemisch geneticus verworven. In november 2002 werd gestart met de opleiding tot klinisch chemicus binnen het klinisch chemisch laboratorium van het Academisch Ziekenhuis Maastricht, opleiders: prof. dr. M.P. van Dieijen - Visser en dr. P.P.C.A. Menheere. Na het succesvol afronden van deze opleiding in 2007 en het verkrijgen van de aantekening metabole ziekten in 2008, werd het reeds eerder gestarte promotieonderzoek in de jaren daarna afgerond. Jaap is nog steeds als staflid verbonden aan het laboratorium Erfelijke Metabole Ziekten van de afdeling Klinische Genetica van het Maastrichts Universitair Medisch Centrum.

Jaap is getrouwd met Heleen en de trotse vader van Lianne en Marina. 